\begin{tabular}{c|c|c|}
\hline & $\begin{array}{c}\text { Journal of Advances in Science and Engineering } \\
\text { (JASE) }\end{array}$ & \\
\hline
\end{tabular}

\title{
ANALYSIS OF LINE OUTAGE DETECTION IN NIGERIA 330KV TRANSMISSION LINES USING PHASOR MEASUREMENT UNITS
}

\section{THESIS}

SUBMITTED IN PARTIAL FULFILMENT OF THE REQUIREMENTS FOR

THE AWARD OF THE DEGREE OF

\section{MASTER OF ENGINEERING} IN

POWER AND MACHINES ENGINEERING

BY

OBODOAGWU, NKEM FRANCIS

(PG/ENG1410534)

Email: nkem.obodoagwu@eng.uniben.edu

Under the Supervision of

Engr. Prof. Emmanuel A. Ogujor Professor of Electrical Power Systems

DEPARTMENT OF ELECTRICAL/ELECTRONIC ENGINEERING FACULTY OF ENGINEERING UNIVERSITY OF BENIN, BENIN CITY, NIGERIA

JUNE 2017 


\section{CERTIFICATION}

This is to certify that this project "Analysis of Line Outage Detection in Nigeria 330kV Transmission Lines using Phasor Measurement Units" was carried out by Obodoagwu Nkem Francis (PG/ENG1410534) and submitted to the Department of Electrical/Electronic Engineering, Faculty of Engineering, University of Benin, Benin city, Nigeria and is approved for its contribution to knowledge and literary presentation.

Engr. Prof. Emmanuel A. Ogujor

Date:

Supervisor

Engr. Prof. S. A. Ike

Date:

Head of Department 
DOI: https://doi.org/10.37121/jase.v2i3.68

\section{DEDICATION}

This project is dedicated to God Almighty who has been my source of strength and impetus. 


\section{ACKNOWLEGEMENT}

Bless the Lord oh my soul and forget not His benefits. Thanks to God the giver of strength and in whom all wisdom dwells.

My deepest appreciation goes to my Parent Mr and Mrs R. O. Obodoagwu and siblings for their support, advice, love to ensure that I get to this stage of my life. I would like to thank so immensely my Supervisor, Prof. E. A. Ogujor for painstakingly reading this work between lines and effecting all the necessary corrections on it and for his useful advice and patience during the cause of the research. I am also deeply indebted to Engr. Dr. M. S. Okundamiya (Ambrose Alli University), Engr. M. Ekwuno, Engr. P. Oriaifo, Engr M. Onwah, Engr. N. Njoku and Engr. D. Daberechi for their contributions and ever-ready willingness to assist and motivate, and more importantly their critical review of the work and useful suggestion to making this work a huge success.

Special thanks to the Department PG Coordinator, Prof. F. O. Edeko, Prof. S. O. Igbinovia and other lecturers whose impact will forever remain a memorial. I am grateful to Engr. C. Nnajide of TCN Osogbo, for given me access to outage data and useful guide on how to collate the data for this research work. Without mincing words; I am blessed and surrounded by amazing friends in the likes; David Olaye, Arinze Adibe, Samuel Iduh, Toju Leko, Daniel Oyagha, Lawrence Osaigbovo, Benjamin and all my course mates (M.Eng. 2014/2015) and others too numerous to mention; thanks for tolerating my excesses and your useful impact.

God bless you all. 


\begin{abstract}
In this work, an analysis of line outage detection in Nigeria 330kV transmission lines using Phasor Measurement Units was presented. This requires collection and analysis of the data obtained from Transmission Company of Nigeria with the aid of PSAT 2.10.1 / MATLAB SIMULINK using Newton-Raphson power flow algorithm and also to determine the effectiveness of PMU when introduced in our power system network. 12 buses and 3 Generators system were considered for the studied.

This was achieved by collecting relevant transmission parameters for $330 \mathrm{kV}$ line and was simulated on PSAT 2.10.1 and MATLAB 2015a using Newton-Raphson power flow algorithm. The work involved an offline and online analysis. For the offline analysis the admittance / impedance matrix for $Y$-bus and bus voltage for pre-outage was obtained via the power flow analysis and change in impedance for the lines were calculated. These values were further normalised in order to reduce the value to a row echelon form. Then for the online analysis; the change in phase angle from the Phasor Measurement Unit (PMU) online simulation for pre-outage and also post-outage was calculated and a normalised column matrix was gotten. Finally, the effectiveness of the line outage detection was graphically represented using MATLAB software to plot the values of the normalised values of the offline and online analysis; i.e., by comparing the normalised form of the offline and online values. These results clearly show that PMUs gives an accurate monitoring and total observability when introduced in Nigeria power system.
\end{abstract}




\section{CONTENTS}

CERTIFICATION

DEDICATION III

ACKNOWLEGEMENT IV

ABSTRACT V V

CONTENTS VI

LIST OF SYMBOLS AND ABBREVIATION VII

LIST OF FIGURES $\quad$ IX

LIST OF TABLES $\quad X$

CHAPTER ONE: INTRODUCTION 1

1.1 Background to the Study 1

1.2 Statement of Problem 4

1.3 Aim of the Study 5

1.4 Objectives of the Study 5

1.5 Research Methodology 5

1.6 Motivation of the Study 6

1.7 Scope of the Study 6

CHAPTER TWO: LITERATURE REVIEW

2.1 Phasor Measurement Unit 7

2.1.1 Basic Definition of Phasor Measurement Unit 7

2.1.2 Important of PMU in Line Outage Identification 8

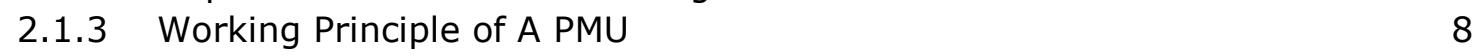

2.2 Definition of Terms 10

2.2.1 Current and Potential Transformer 10

$\begin{array}{ll}2.2 .2 & \text { Anti-Aliasing Filter (AAF) }\end{array}$

$\begin{array}{ll}2.2 .3 \text { Global Positioning System (GPS) } & 10\end{array}$

2.2.4 Phase Locked Oscillator (PLO) 10

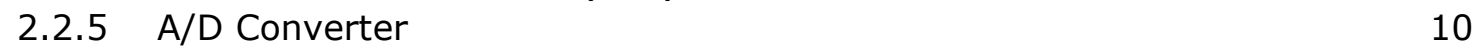

2.2.6 Phasor Microprocessor 10

2.2.7 Optimal PMU Placement 11

2.2.8 Power System Analysis Toolbox (PSAT) 11

2.2.9 Power Outage 11

2.3 PMU Utilisation in Power System 11

2.4 Related Works $\quad 12$

CHAPTER THREE: RESEARCH METHODOLOGY 28

3.1 Research Data 28

3.2 Data Preparation 28

3.3 Method of Data Analysis 28

3.4 Equation of Power Flow and Line Outage Detection 32

CHAPTER FOUR: DATA ANALYSIS AND DISCUSSION

4.1 Simulation $\quad 39$

4.2 Discussion 46

CHAPTER FIVE: CONCLUSION AND RECOMMENDATIONS 49

$\begin{array}{llr}5.1 & \text { Conclusion } & 49\end{array}$

$\begin{array}{llr}5.2 & \text { Recommendations } & 49\end{array}$

5.3 Further Studies $\quad 50$

5.4 Conflict of Interests 50

REFERENCES

APPENDIX

vil Page ISSN: 2636-607X 


\section{LIST OF SYMBOLS AND ABBREVIATION}

\begin{tabular}{|c|c|}
\hline$A / D$ & Analogue to Digital \\
\hline AAF & Anti- Aliasing Filter \\
\hline ADC & Analogue / Digital Converter \\
\hline ADMM & Alternating Direction Method of Multi-Phasors \\
\hline AI & Artificial Intelligence \\
\hline AIS & Artificial Immunity system \\
\hline BIP & Binary Integer Programming \\
\hline DCS & Distributed Control Systems \\
\hline DFR & Disturbance Fault Recorder \\
\hline DFT & Discrete Fourier Transform \\
\hline GPS & Global Positioning System \\
\hline GS & Generation Station \\
\hline ILP & Integer Linear Programming \\
\hline KF & Kalman Filter \\
\hline LSE & Linear State Estimation \\
\hline NIPP & Nigeria Independent Power Project \\
\hline NLP & Non-Linear Programming \\
\hline OPP & Optimal Placement Problem \\
\hline PLO & Phase Locked Oscillator \\
\hline PMU & Phasor Measurement Unit \\
\hline PSAT & Power System Analysis Toolbox \\
\hline PSCAD & Power System Computer Aided Design \\
\hline QIEA & Quantum Inspired Evolutionary Algorithm \\
\hline
\end{tabular}


RBF Radial Basis Function

RTU Remote Terminal Unit

SCADA Supervisory Control and Data Acquisition

SPC System Protection Centre

SQP Sequential Quadratic Programming

SVM Support Vector Machine

TCN Transmission Company of Nigeria

TS Transmission Station

WAMPAC Wide Area Measurement Protection and Control

WAMS Wide Area Measurement System

WLS Weighted Least Square 


\section{LIST OF FIGURES}

Figure 1.1. Transmission Grid in Nigeria (Updated on $30^{\text {th }}$ June, 2016) 2

Figure 2.1. (a) Sinusoidal waveform (b) Phasor Representation 8

Figure 2.2. Block diagram of a PMU 9

Figure 2.3. Potential and Current Instrumentation Channel 9

$\begin{array}{lll}\text { Figure 2.4. } & \text { PMU Utilisation } & 12\end{array}$

Figure 3.1. 330kV Transmission National Grid of Nigeria drawn on PSAT/MATLAB SIMULINK

Figure 3.2. A session of the $330 \mathrm{kV}$ Transmission Grid Representing the South West Region of Nigeria 30

Figure 4.1. PMU reading for Pre-Outage 39

Figure 4.2. PMU reading for Ikeja-Osogbo Outage line 40

Figure 4.3. PMU reading for Ayede-Olorunsogo Outage line 41

Figure 4.4. PMU reading for Sakete-Ikeja Outage line 43

Figure 4.5. Plot of E-Normalised (Change in Impedance) and Normalised Theta (change in angle) against Matrix index representing Ikeja West - Osogbo line

Figure 4.6. Plot of E-Normalised (Change in Impedance) and Normalised Theta (change in angle) against Matrix index representing Ayede-Olorunsogo line

Figure 4.7. Plot of E-Normalised (Change in Impedance) and Normalised Theta (change in angle) against Matrix index representing Sakete-Ikeja West line 


\section{LIST OF TABLES}

Table 1.1. Operating Power plants in Nigeria and their rated capacities

Table 1.2. National Independent Power Projects and their Installed Capacity 3

Table 4.1. Change in Angle reading for Ikeja -Osogbo 40

Table 4.2. Change in Angle reading for Ayede -Olorunsogo 42

Table 4.3. Change in Angle reading for Sakete-Ikeja 44

Table 4.4. MALTAB Simulation Result 45 


\section{CHAPTER ONE}

\section{INTRODUCTION}

\subsection{Background to the Study}

The Nigerian power system network (Figure 1.1), like other network elsewhere, is made up of a large interconnected network that is spread across the country nationwide. This grid presently consists of seventeen generating stations, which comprises thermal, gas and hydro plant with an installed capacity of 9065MW (Ogbuefi \& Madueme, 2015), while the transmission lines is currently made up of $9,454.8 \mathrm{~km}$ of $330 \mathrm{kV}$ lines, $8,985.28 \mathrm{~km}$ of $132 \mathrm{kV}$ lines, $23 \mathrm{~km}$ of $330 / 132 \mathrm{kV}$ substations and $-91 \mathrm{~km}$ of $132 / 33 \mathrm{kV}$ substations (Omorogiuwa \& Ogujor, 2012). Table 1.1 represents the complete power generating and existed power stations that is currently in used with their available installed capacities, while Table 1.2 represents the generating stations with their suppose installed capacities.

Table 1.1. Operating Power plants in Nigeria and their rated capacities

\begin{tabular}{|c|c|c|c|c|c|}
\hline S/N & Station & State & Turbine & $\begin{array}{c}\text { Installed } \\
\text { Capacity } \\
(\mathbf{M W})\end{array}$ & $\begin{array}{c}\text { Available } \\
\text { Capacity } \\
\text { (MW) }\end{array}$ \\
\hline 1 & Jebba & Niger & Hydro & 504 & 352 \\
\hline 2 & Kainji & Niger & Hydro & 760 & 259 \\
\hline 3 & Shiroro & Niger & Hydro & 600 & 402 \\
\hline 4 & Egbin & Lagos & Steam & 1320 & 900 \\
\hline 5 & A.E.S (Egbin) & Lagos & Gas & 250 & 211.8 \\
\hline 6 & Afam I-V & Rivers & Gas & 726 & 60 \\
\hline 7 & Afam VI (Shell) & Rivers & Gas & 650 & 520 \\
\hline 8 & Delta (Ughelli) & Delta & Gas & 912 & 281 \\
\hline 9 & Gerugu & Kogi & Gas & 414 & 120 \\
\hline 10 & Ibom & Akwa-Ibom & Gas & 155 & 25.3 \\
\hline 11 & Okpai (Agip) & Delta & Gas & 900 & 221 \\
\hline 12 & Olorunshogo phase I & Ogun & Gas & 100 & 54.3 \\
\hline 13 & Olorunshogo phase II & Ogun & Gas & 200 & 105.5 \\
\hline 14 & Omoku & Rivers & Gas & 150 & 53 \\
\hline 15 & Omotosho & Ondo & Gas & 304 & 88.3 \\
\hline 16 & Sapele & Delta & Gas & 1020 & 170 \\
\hline 17 & Trans-Amadi & Rivers & Gas & 100 & 57.3 \\
\hline & & & $\mathbf{9 , 0 6 5}$ & $\mathbf{3 , 8 8 0 . 5}$ \\
\hline
\end{tabular}

Source: Omorogiuwa \& Ogujor (2012) 


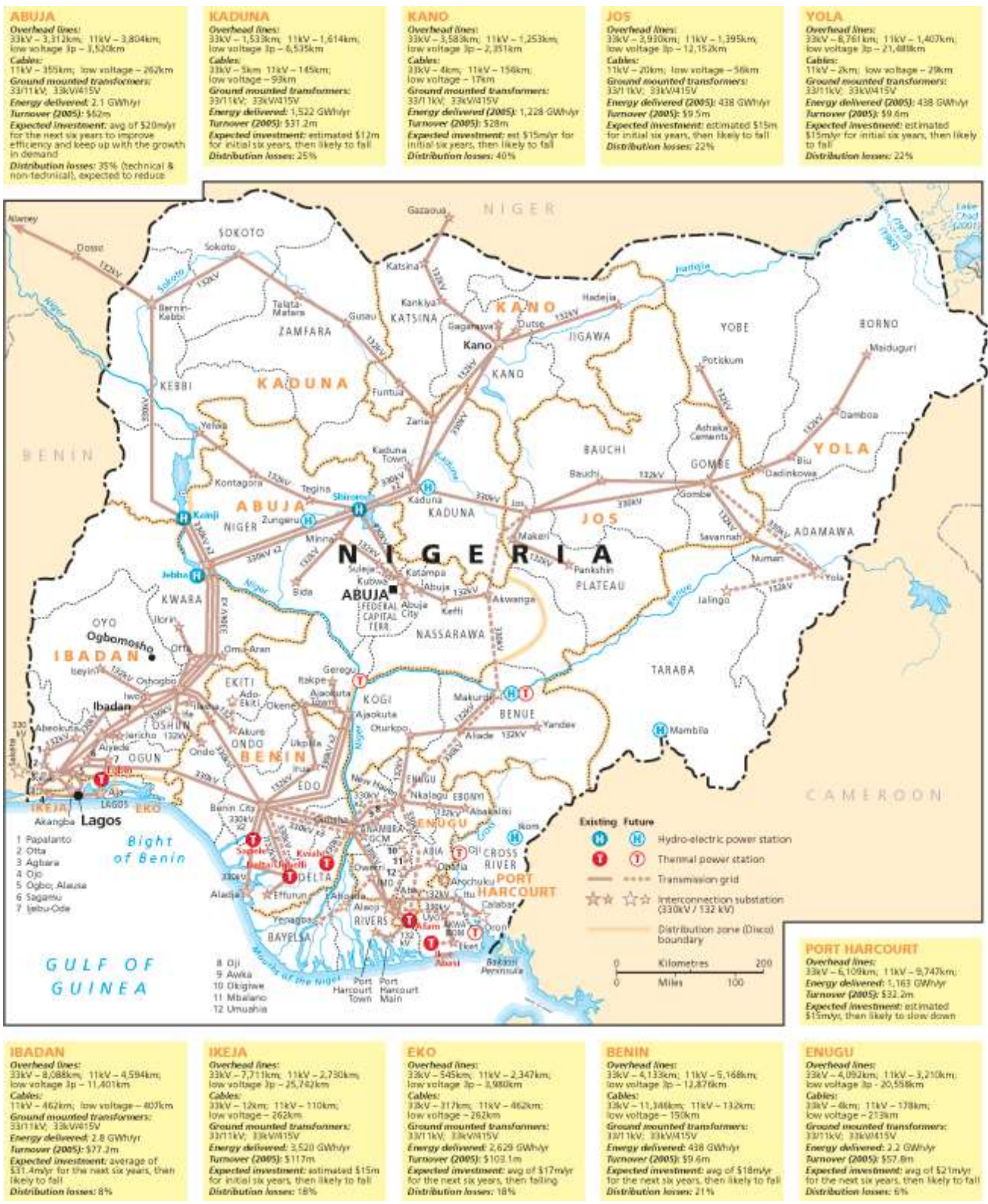

Figure 1.1. Transmission Grid in Nigeria (Updated on 30th June, 2016)

Source: Global Energy Network Institute (2016) 
Table 1.2. National Independent Power Projects and their Installed Capacity

\begin{tabular}{|c|c|c|c|c|}
\hline S/N & Station & State & Turbine & $\begin{array}{c}\text { Installed Capacity } \\
\text { (MW) }\end{array}$ \\
\hline 1 & Alaoji & Abia & Hydro & 961 \\
\hline 2 & Calabar & Cross River & Gas & 563 \\
\hline 3 & Egbema & Imo & Gas & 338 \\
\hline 4 & Gbaran & Bayelsa & Gas & 225 \\
\hline 5 & Ihorvbor & Edo & Gas & 451 \\
\hline 6 & Olorunsogo II & Ogun & Gas & 675 \\
\hline 7 & Omoku & Rivers & Gas & 252 \\
\hline 8 & Omotosho II & Ondo & Gas & 450 \\
\hline 9 & Sapele & Delta & Gas & 451 \\
\hline & Total Power & & & $\mathbf{4 , 3 6 6}$ \\
\hline
\end{tabular}

Source: Omorogiuwa \& Ogujor (2012)

This Electrical power is generated at specific location far from load centres before it is delivered to consumers through our transmission and distribution systems. The purpose is to generate and supply real and reactive power to consumers economically and reliably (Arabali et al., 2016).

Transmission lines are subjected to an unfriendly condition through thick forest from generation to control room and from control room for effective monitoring. On this lines fault cannot be neglected (Arabali et al., 2016). Location of faults on this line has been a studied for a long decade. Accuracy in locating of fault has a great impact for the economic operation of our power systems in Nigeria electricity markets. This has provided quick response to the repairs of our systems and availability over time, and has help in saving time, performance and effort to corrective maintenance. Hence, the reliability of the system is increased (Abdelaziz et al., 2011).

The lack of situation awareness is one of the major reasons for blackout in Nigeria power system as at today, because most of our systems are not remote base from my recent findings, and even Nigeria Independent Power Project (NIPP), there is no complete observability of the whole systems.

Modern power system has introduced a large number of Phasor measurement units to the grids to perform numerous tasks, such as protection, monitoring and controlling of the power system. A single or multiple line outage transmission lines

$$
\text { IS S : 2636-607X 3|Page }
$$


disturbs the flow of the power system and changes the phase angles measured at the various buses where the PMUs are positioned (Awais et al., 2016).

Due to the growing trend of remodelling of power system network for quality and uninterrupted power; the Phasor Measurement Unit can be brought into play for effective monitoring (Kumar et al., 2015). The phasor measurement units have the potential to revolutionize the way electric power system are monitored and controlled (Kumar et al., 2015). This has significantly improved the methods to monitor and analyse power system dynamics (Abdelaziz et al., 2011; Arabali et al., 2016). Phasor measurement unit (PMU) is used to obtain magnitude and phasor values of voltage, current, power and their angles accurately. This has helped to estimate the system conditions (Srikumar et al., 2015).

Phasor measurement units monitor power systems by providing near real time measurements of voltage magnitude and angles (Arabali et al., 2016). The knowledge of the voltage magnitude and phase angle at each bus enables the performance of various crucial tasks, such as event detection, optimising power flows, maintaining system stability and reliability etc. PMU are very appropriate for online monitoring of angles thereby helping the operators during system restoration i.e., in determining when the system is over stressed up and putting some control measure in place (Srikumar et al., 2015).

PMU report phasor measurement with high frequency, and changes in voltage due to topology changes of the power grid tend to be larger than the variation of voltage phasor during normal operation for example fluctuation during demand (Srikumar et al., 2015). Accuracy and prompt identification of these line outages is mandatory and plays an important role in the system reliability and give a secure operation of our power grid.

\subsection{Statement of Problem}

It is a known fact that Electricity Power System in Nigeria is faced with so many challenges like, line overloading, epileptic power supply, losses on transmission and distribution lines, indiscriminate outages, system collapse, inadequate generation, and poor localise equipment which are no longer invoke; and cannot be integrated with most of our recently completed Independent Power Project stations. Therefore, there is the need to incorporate more intelligent system to aid
4 I Page
I S S N : $2636-607 X$ 
in power profile analysis (real time measurement of voltage magnitudes and angles) for effective monitoring of power system dynamics using (PMUs), and a complete situation awareness of our entire grid which could been seen as improved method from the deficiencies from other monitoring devices like EMS/SCADA.

\subsection{Aim of the Study}

The aim of this study is to detect and analyse line outage in Nigeria $330 \mathrm{kV}$ transmission lines, using Phasor Measurement Units.

\subsection{Objectives of the Study}

The objectives of the study are to:

(a) collect and analyse data obtained from Transmission Company of Nigeria with the aid of PSAT 2.10.1/MATLAB SIMULINK using Newton-Raphson power flow algorithm;

(b) carry out load flow analysis on Nigeria Transmission line maintained at $330 \mathrm{kV}$, considering 12 buses and 3 Generators system; and

(c) analyse the data obtained using PSAT / MATLAB software for pre-outage and post-outage considering the proposed network.

\subsection{Research Methodology}

The methodology to be adopted for this work would involve:

(a) Collection of relevant transmission parameters such as GeneratorsTransformer data, Generator ratings, number of $330 \mathrm{kV}$ buses, line impedance values from Transmission Company of Nigeria, Osogbo Osun State, Nigeria.

(b) Modelling of $330 \mathrm{kV}$ Nigeria transmission network, consisting of 12 buses and 3 generators on PSAT 2.10.1 and MATLAB 2015a using NewtonRaphson power flow algorithm.

(c) The admittance matrix for Y-bus and bus voltage for pre-outage via the power flow analysis and elimination of the row and column associated with slack bus and primary bus from the Generator were obtained.

(d) Converting the Admittance Y-Bus to Impedance value. 
(e) Selection of a one single line representing a possible outage.

(f) Calculation of the change in impedance $\Delta Z$ for the lines.

(g) Performing rank for the change in impedance matrix for step ( $f$ ).

(h) Normalizing the first row of the matrix of the reduced row echelon form.

(i) Step (c) to (h) to be repeated for other possible single lines representing outages.

(j) Obtain the Phase Angle from online simulation from the PMU for Pre-Outage and also Post Outage for all the lines listed in (i).

(k) Calculation of change in voltage phase angle between Pre-Outage and Post Outages at all buses under consideration.

(I) Normalising the column matrix from the output of step (k).

(m) The normalised column matrix of change in voltage phase angle i.e., step (I) is compared with each normalized basic vector of transmission line outages (h) and (i).

(n) Finding the closest Vector to the Angle to determine the line outage.

(o) Plotting of the result of $(n)$ on a graph using MATLAB software

\subsection{Motivation of the Study}

Due to recent advancement in technology globally in power system, failure rate of electrical component poses a challenge. Continuous and efficient supply of power is a hallmark of a developed economy, therefore any Nation whose energy need is epileptic in supply imperils its economic development (Obiaya, 2013). Therefore making our system smarter, reliable and more efficient should be our ultimate goal. PMU should be adopted to avert this menace in identifying potential risks and failure before a total system collapse will occurs. This is a way of combating this problem.

\subsection{Scope of the Study}

This study will be limited to a session of the Nigeria $330 \mathrm{kV}$ transmission network by identifying possible lines under outage within the south western region using PSAT/MATLAB Simulink software. Each line to be put under outage represents a typical outage lines when it occurs.
6 I Page
I S S N : $2636-607 x$ 


\section{CHAPTER TWO \\ LITERATURE REVIEW}

\subsection{Phasor Measurement Unit}

Phasor Measurement Units (PMUs) or Synchronised Phasor was first invented in 1988 by Dr. Arun G. Phadke and Dr. James S. Thorp at Virgina tech (www.wikipedia.org). These instruments work with Global Positioning System (GPS) to synchronised measurements of positive sequence voltage phasors at various buses within the network and positive sequence current phasors in the lines connected to those buses. The positive sequence voltages at all network buses constitute the state vector of a power system.

\subsubsection{Basic Definition of Phasor Measurement Unit}

PMU is a device, which measures the electrical waves on an electricity grid, using a common time source for synchronisation. In a very clear term, PMU are devices used in measurement to measure the phasor angle between voltage and current and displays these results for analysis of power system.

The mathematical description of waveforms for an alternating current is a pure sinusoidal waveform can be represented by a unique complex number known as a phasor. Consider a sinusoidal signal

$$
\mathrm{x}(\mathrm{t})=\mathrm{x}_{\mathrm{m}} \cos (\mathrm{wt}+\theta)
$$

The phasor representation of this sinusoid is given by

$$
X=\frac{X_{m}}{\sqrt{2}} e^{j \theta}=X_{m}(\cos \theta+\sin \theta)
$$

The magnitude of the phasor is the rms value of the sinusoid shown in (2.3) and its phase angle $w$ is the frequency. Figure 2.1 shows a typical signal waveform and the phasor representation.

$\frac{\mathrm{x}_{\mathrm{m}}}{\sqrt{2}}$

The positive phase angles (Figure 2.1) are measured in counter clockwise direction from the real axis. Phasor representation implies that the signal remains stationary at all times, leading to a constant phasor representation i.e., a constant phasor implies a stationary waveform. This PMU uses a frequency tracking step and thus estimates the period of the fundamental frequency component before the phasor

$$
\text { ISSN: } 2636-607 X \quad 7 \text { |Page }
$$


is estimated. The task of the phasor is to separate the fundamental frequency $50 \mathrm{~Hz}$ component and find its phasor representation.

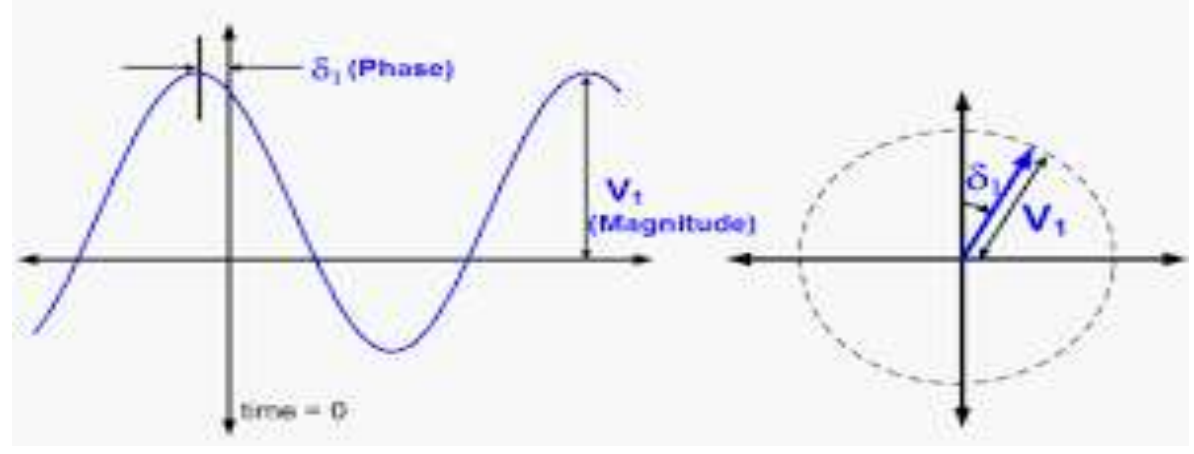

(a)

(b)

Figure 2.1. (a) Sinusoidal waveform (b) Phasor Representation

\subsubsection{Important of PMU in Line Outage Identification}

The importance of PMU in line outage identification are, it:

(a) improves situation awareness using real-time synchro-phasor measurement;

(b) provides GPS-synchronised, more accurate and dense measurements of phasor voltage and phasor current;

(c) has the ability to provide geographical dispersed accurate synchronised measurements over the entire power grid (Srikumar et al., 2015);

(d) gives a smaller error variances compared to other measurements; and

(e) gives an identification of line outages in power grids spread over vast geographical location (Awais et al., 2016).

\subsubsection{Working Principle of A PMU}

Figure 2.2 represents the block diagram of working principle of a PMU, i.e., describing various functions that makes up the PMU while Figure 2.3 represents potential and current transformer channel serving as inputs to the PMU. 


\section{- A phasor measurement unit}

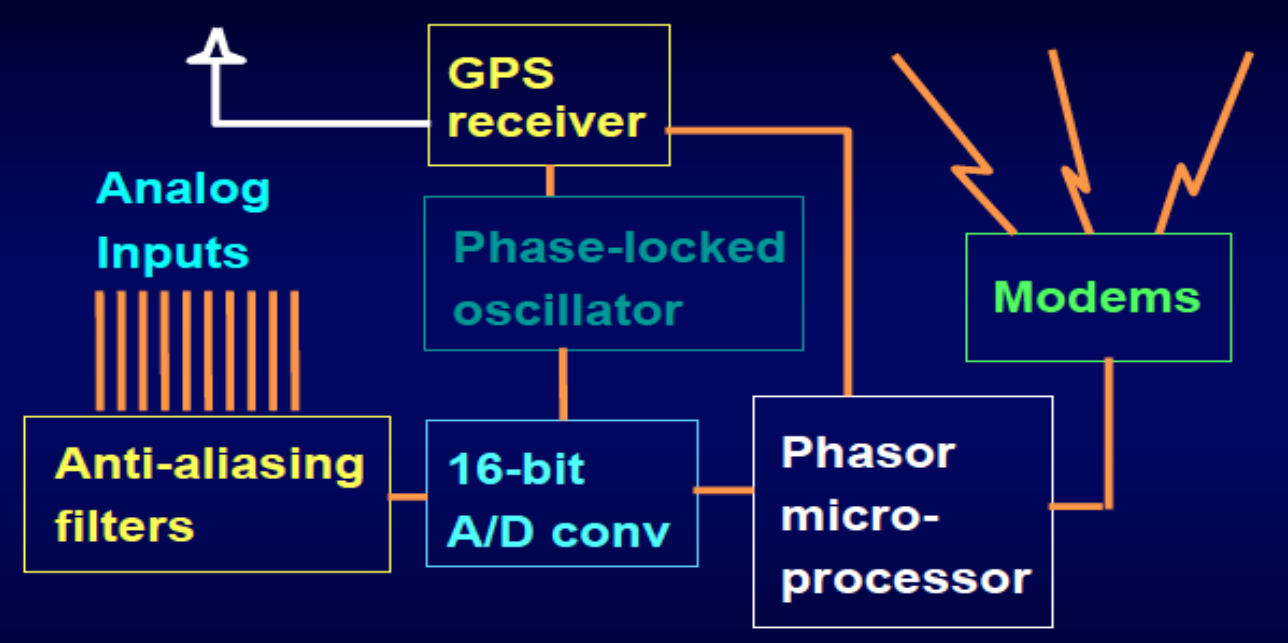

Except for synchronization, the hardware is the same as that of a digital fault recorder or a digital relay.

Figure 2.2. Block diagram of a PMU

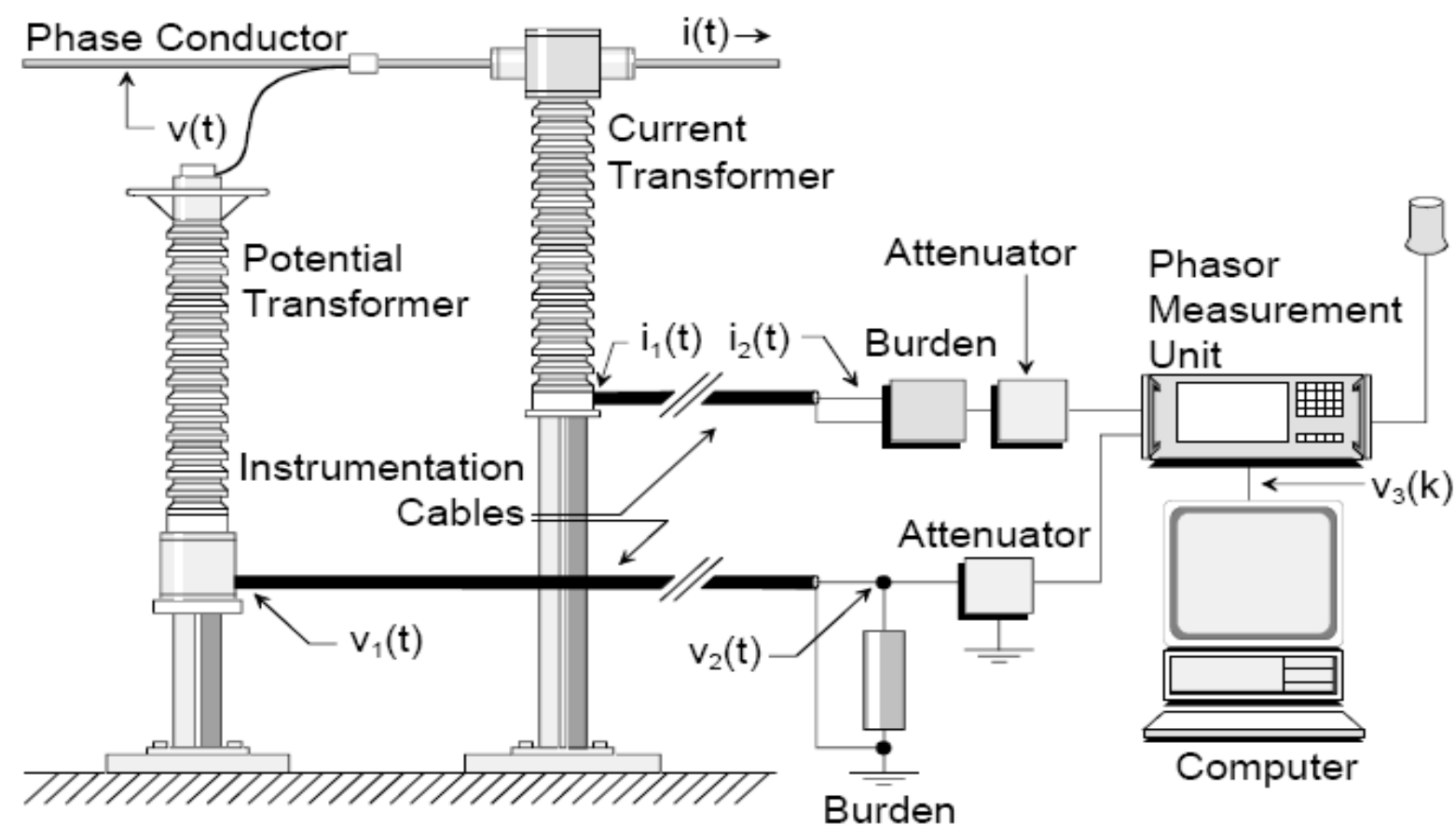

Figure 2.3. Potential and Current Instrumentation Channel 


\subsection{Definition of Terms}

\subsubsection{Current and Potential Transformer}

These help to connect the PMU to the grid as shown on Figure 2.3. They are connected through an electronic device called attenuator. The attenuator serves as the input to the PMU and helps to reduce the amplitude or power of the signal without appreciably distorting its waveform.

\subsubsection{Anti-Aliasing Filter (AAF)}

It receives the analogue voltages and current signals from the Secondary side of the current and potential transformers and also used to restrict the bandwidth of the signal also produces a delay which depends on the characteristics of the filter. This delay is a function of the signal frequency.

\subsubsection{Global Positioning System (GPS)}

This is a satellite based navigation system that gives accurate information about actual location and time irrespective of weather conditions. It consists of a network of 24 satellites orbiting in 6 geo-synchronous orbits such that at any given instant 4 satellites are visible from any point on the earth surface. It is capable of giving one pulse per seconds.

\subsubsection{Phase Locked Oscillator (PLO)}

This help to divide the pulse as received from the GPS into required number of pulses per second for sampling.

\subsubsection{A/D Converter}

This converts the analogue to digital (A/D) signals from $A A F$, at a sampling instants rate designed by the sampling time signals from the PLO. These digitized samples are then fed to the phasor microprocessor.

\subsubsection{Phasor Microprocessor}

This is programmed to calculate the positive sequence components at a timed rate, from the digitised sampled data by Discrete Fourier Transform algorithm. This measured data are transmitted to the remote location by using modems. 


\subsubsection{Optimal PMU Placement}

This is defined as the finding the installation location of PMUs required for the complete observability of the power system such that the total investment cost is minimised.

\subsubsection{Power System Analysis Toolbox (PSAT)}

PSAT is a MATLAB tool box for electric power system analysis and control. This is used for power flow, continuation power flow, optimal power flow, small signal stability and time domain simulation. The core area is in power flow which also takes care of state variable initialization such as optimal PMU placement.

\subsubsection{Power Outage}

This is the condition of a component or power system when it is not available to properly perform its intended function. An outage may be scheduled or forced outages. Scheduled outage results when a component is consciously taken out of service at a selected time usually for purposes of maintenance and repairs. Forced outages may be temporary or permanent outages. Permanent forced outages require repairs or replacements before restoration of service continuity. Temporal (transient) outages imply no permanent damage and no need for repairs/replacement. The forced and momentary outages in transmission and distribution systems can be due to a number of reasons such as lightning, falling trees as a result of heavy wind, bird, vehicle accidents, over loading of the supply feeder leading to frequent breakdown of the feeder, earth fault, over current fault, system collapse at the source, poor generation of electricity leading to load shedding at the supply source etc.

\subsection{PMU Utilisation in Power System}

The phasor measurement units installed at various buses in the power system network provides with stored values of time-tagged phasor measurement data at various nodes in the network.

These data are gathered by the device called phasor data concentrator, which synchronises the measurement taken every time independent of when the data are fed to the advanced application software for the analysis of the power system as shown in Figure 2.4. Based on this analysis, system control, protection and 
various functions are well managed within the system (Mauryan \& Ramkumar, 2014).

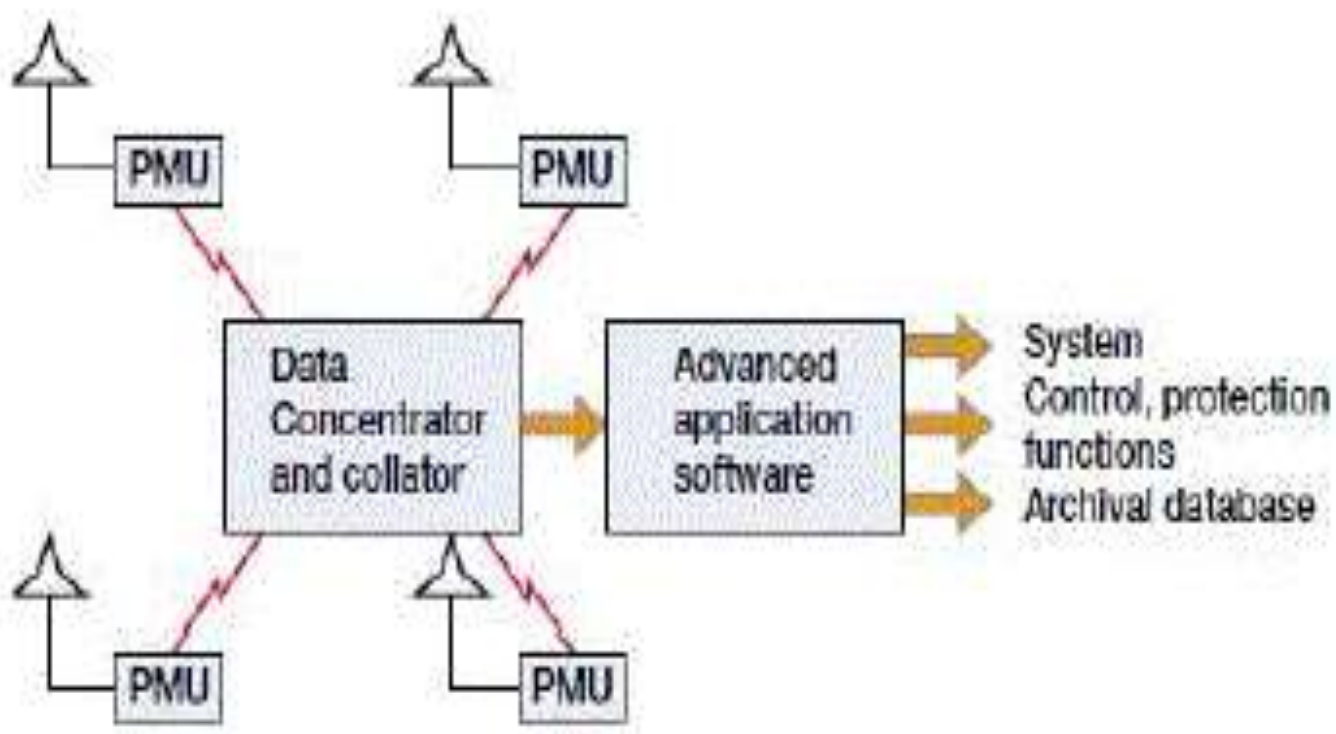

Figure 2.4. PMU Utilisation

\subsection{Related Works}

A proper methodology is required to analyse single line outage detection using Phasor Measurement Units. This chapter reviews the research work and studies that have been done in the area of Line outage detection, Applications and Optimal placement. The following are the list of researchers who have worked considering Phasor Measurement Units device.

Oduntan et al. (2016) proposed a method based on network connectivity information for the optimal placement of Phasor Measurement Unit (PMU), which minimize the cost of installation and provide the entire power system observability. The technique was based on hybridising the particle swarm optimisation and tabu-search (PSO-TS) algorithm. The lists from the tabu were used within the PSO algorithm which was tested in IEEE 14-Bus and IEEE 30-bus systems. There were two PSO algorithms; one was aims to differentiate the best solutions obtained by particles while the second prevent local optimal solutions without respect to the constraints. The scope of the work was limited to the optimal location of PMUs in power system and use of PMUs for state estimation.

Bindeshwar et al. (2011) proposed a review on different application of PMUs in electrical power system networks incorporated with FACTS controllers for 
advanced power system monitoring, protection, and control. It note the maximum research work carried out for optimal placement of PMUs in power system networks point of view in all the three decades. The paper addressed a survey on optimal placement of Phasor Measurement Units (PMUs) in power system for enhancement of power system stability such as rotor angle stability, frequency stability, voltage stability, power system oscillations, and voltage stability by using different FACTS controllers such as TCSC, SVC, SSSC, STATCOM, UPFC and IPFC in an integrated power system networks. The paper also discussed the current states of the research and development in the field of applications in PMUs in power system stability.

Awais et al. (2016) proposed a computational efficient technique based on Quantum Inspired Evolutionary Algorithm (QIEA) for the identification of multiple power line outages in smart power grids. A customised version of QIEA was also proposed, and it effectiveness was validated against various IEEE bus systems with multiple line outages used as an example. The simulation results gotten demonstrated the validity and accuracy of the proposed solution. In this work, $A$ novel approach based on quantum inspired evolutionary algorithm (QIEA) to solve multiple line outage identification problem which is categorised as a probabilistic evolutionary algorithm. The proposed solution was capable to identify an (arbitrary) number of line outages with any possible combination and also avoid local optima. This solution is the first solution that falls into the category of variable MLOI solutions. The simulations was performed for various IEE reference bus system, it demonstrate that the proposed QIEA individual solution is more accurate as compared to various other met-heuristic approaches. In this work linear DC power flow model was defined, which assumes the conservation of power flow i.e., the power injected into bus " $n$ " must be equal to power flowing out of it mathematically.

Huang et al. (2008) briefly summarised two documents: PMU testing guide and synchrophasor accuracy characterisation and also present methods for evaluating phasor performance in both steady-state and dynamic situations as well from PMU hardware to instrumentation channels. It was concluded that performing those procedures on PMUs to be deployed will help users to assure consistent PMU system performance and support interoperability of PMUs from various vendors. 
Mekhamer et al. (2012) introduces an important application of PMUs in power system protection which is the detection of single line outage. It main focus was on line outage problem and proposes an artificial intelligence based technique for outage detection. This was achieved base on the variations of phase angles measured at the system buses where the PMUs are located. A protection scheme against over loading leading to system collapse called support vector machine (SVM) classification tool was proposed. The effectiveness of the proposed approach was tested using offline simulation for both the IEEE 14-bus and the IEEE 30-bus systems and also in order to ensure the superiority of the SVM classification tool in the field of line outage detection. Several study cases was studied and noted including the complete observability principle. This was done by using SVM classification tool using either of polynomial kernel or radial basis function (RBF) kernel. The task of SVM is to utilize the output information from the PMUs to determine a status for each line if it is out of service or not. A mathematical model was applied to calculate the phasor angles. The above proposed approach uses the Rockfeller and Udren algorithm, which depends on successive three samples to calculate the power voltage magnitude and angle. Also the paper show the superiority of the RBF kernel compared with the polynomial kernel in the process of classification related to the line outage problem.

Rebiee et al. (2013) discussed some valuable experiences and view point associated with the practical aspects of PMU installation, among the points consider are: the required substation infrastructure and facilities, installation requirements, communication system preparation, and monitoring centre establishment and lessons learnt from the project implementation. It also stresses the practical aspects of a typical Wide Area Measurement System (WAMS) implementation project. This consist of generic specification of the project, substations defects and their associated solutions, and monitoring centre capabilities, amongst are the lack of CVTs in some substation bus-bars, missing communication active equipment in some cases, lack of connection to the optical fibre network associated with some substations, particular condition of distributed control system (DCS) substations, logic of line connectivity to bus-bars, determination of PMU to bus-bars, and determination of PMU locations in 
substations. The reviewed on this paper gave a convincing reason to initiate the WAMs development project.

Kumar et al. (2013) did a formulation of measurement by using WLS state estimation and PMU were incorporated with use of traditional technique. This was done by launching of PMUs on specific buses and their effect on accuracy to test cases of several parameters in different cases. Also the impact of PMU on bus voltage, bus current and real power flows were illustrated. The parameter assessment obtained on IEEE 6 bus system and IEEE 9 bus system was discussed. The problem of finding optimal placement of PMU devices a state estimation of power system was also investigated. This paper reproduces the accuracy of measurement with or without using PMU on state estimation parameters. For examinations of the system accuracy with or without PMU on system variables, some cases were tested with the aid of MATLAB simulated software. This was achieved by first testing the traditional method parameters without PMU and their performance was also tested in comparison with the PMU. From the comparison, the result shows that for effective installation of PMUs; it reduces the chances of error in measurement of estimated variables. In summary the study was carried out to ascertain the correlation between traditional technique and full weighted least square state estimation technique with the PMU.

Kumar et al. (2015) aimed to build a laboratory prototype of PMU that would estimate the phasor updating process of a commercial PMU at the benefit of improved measurement accuracy, reduced manufacturing cost and increased timely information. It also provides an experimentation regarding the behaviour of phasor updation in PMUs. This was done with the aid of MATLAB/Simulink program which was used to implement the idea of recursive and non-recursive algorithm. Simulation model for PMUs was developed for recursive and nonrecursive algorithm. The phasor estimation algorithms are simulated and verified in MATLAB/Simulink. It was observed from the work that on application point of view for WAMS, recursive algorithm will prove to be a better method than nonrecursive algorithm. The comparison of phase angle in between the different remote locations is easier and accurate because of constant phase angle differences. 
Bilik et al. (2015) developed system for PMU testing for the purpose of obtaining sample PMU test results. This article deals with procedure of tests for testing of static and dynamic properties of units for measurement of synchronous phasor (PMUs). The tests are performed by means of the use of a tester working on the basis of virtual working on the basis of virtual instrumentation. This paper also carried out some tests which were performed in the developed testing system. The PMU type SEL-351A was subjected to the tests and time synchronisation of the tested PMU was done using the IRIG-B protocol distributed from the central source of precise time information.

Sarri et al. (2016) assessed the performance of linear state estimation (LSE) processes of power systems relying on synchrophasor measurements. The performance assessment was conducted with respect to two different families of SE algorithms, i.e., static represented by weighted least square (WLS) and recursive represented by Kalman filter $(\mathrm{KF})$. From the comparison of the performance of two different families of LSE processes, based on WLS (LWLS-SE) and KF (DKF-SE), that uses synchrophasor measurements. The theory predicts that DKF-SE provides a better accuracy as long as its process model is correct.

Goklani et al. (2014) presents various aspects of optimal phasor measurement unit placement problem in smart grid. In this work the cost of installation of PMUs was taken as the installation of PMUs, which was taken as the objective function to be minimised and the constraint being the observability of the power systems. The observability was defined using matrix containing ones and zeros.

For the TORA software, integer linear programming (ILP) was used for optional placement of the PMUs. The several methods of optional placement of PMU were compared using simulation Power System Analysis Toolbox (PSAT) and TORA software. The analysis of their merits and demerits was also carried out. This method was required to determine the minimum number of PMUs required making a power system observable.

Liang \& Wen-Zhan (2014) proposes a distributed framework based on WAMS, the proposed approach allows multiple line outage identification using limited PMU measurements. A numerical tests was carried out which demonstrated the merits of the proposed schemes in coordinating the discovery of multiple line outages in a power grid. This was carried out in-network information processing and only
16 | Page
I S S N : $2636-607 x$ 
shares estimates on boundaries with the neighbouring control areas. The novel framework was relied on the convex-relaxed formulation of the line outage detection problem and leverages the alternating direction method of multi-phasors (ADMM) for its distributed solution. The framework invokes a low computational complexity, requiring only linear and simple matrix-vector operations. The work was also extended to incorporate the sparse property of the measurement matrix and employ the LSQ R-algorithm to enable a warm start, which further accelerates the algorithms. An analysis and simulation test was done to validate the correctness and effectiveness of the proposed approach. The proposed algorithm was assumed to work in transmission networks. Due to the present challenge of unavailability of infrastructure of smart sensor network it was recommended that they can be applied for distribution networks theoretically.

Schwiil \& Dobsan (2012) detect the location of line outages inside a specific area of the power system from synchrophasor measurement at the border of the area and inside the area. DC power flow model of the area was proposed in processing the area synchrophasor measurements. The method used extends the previous methods (Tate \& Overbye's) that locate line trips in an entire network so that they work in a particular area and a case of islanding was dealt with. In this paper, an assumption was made; that a change in synchrophasor angles were made available using the detection and filtering methods and it also shown how to adapt line outage location method to an area within the interconnection with synchrophasor measurements inside the area and around border of the area. This work also confirms whether the line outage occurred inside the monitored area or not, giving useful discrimination of the source of changes in the power system. This work also converts a way to model the effect of line outages that island the area and also discriminate these islanding line outages with synchrophasor measurements.

Abdelaziz et al. (2013) present a modification on an existing algorithm, which presents a study for power oscillations with a laboratory model comprising a strong network, a transmission line and a generator, an algorithm tested for a three phase short circuit fault for a single machine infinite bus system: an approach to design power system transient stability assessment using direct methods for a multi-machine system that uses measured values of the currents and voltages of 
the three phases of two buses (equivalent to PMU data) was presented. The measured data was transformed from time domain into phasor domain using discrete Fourier Transform (DFT) to predict whether the swing is a stable or an unstable one. The performance of the method was tested on a simulated multi machine system using PSCAD and MATLAB software. The proposed scheme can be used for the detection of out of step condition using an extension of the equal - area criterion. This proved that it is an efficient method for determining the transient stability of a power system and detecting the out of step condition for muilt-machine system as one machine against infinite bus or two machine systems.

Mousavian \& Feizollahi (2015) proposed a new investment decision model to determine the optimal placement of PMUs that guarantees the full observability of the power grid. The new model utilises network observability rules and determines the optimal investment decision for the placement of PMUs in the power grid. Since genetic algorithm is well-known to have superior performance on solving discretebinary optimisation problem - specific genetic algorithm was developed to solve the proposed model. Furthermore, a two phase PMU placement plan was also proposed which provides utility companies with flexibility of whether to install all PMUs in one or two phases and avoids unnecessary investment costs. In the first phase, PMUs were installed to make the power grid fully observable and postpone the $\mathrm{N}-1$ observability placement to the second phase. The performance of the proposed algorithm was tested in several IEEE test systems. The experimental results were compared with the heuristic, meta-heuristic and integer linear programming based methods. Furthermore, the alternative optimal solutions provided by our GA were utilised to determine the optimal two phase investment. This gives flexibility to investors on where to install PMUs, which is advantageous to find the optimal-two phase investment plan as well that makes the power grid fully observable and resilient against single contingencies it two phases. The main disadvantage of this approach is that the optimality of the solution is not guaranteed, which is the common short coming of all heuristic and meta-heuristic methods compared to the ILP based methods. The analysis shows that the proposed approach is promising and verifies it efficacy. 
Vignesh et al. (2015) present methodologies for modelling the loads under large as well as small disturbances using the measurements from phasor measurement units optimisation. A computationally efficient algorithm was developed to estimate the parameters under small disturbances and was presented using linearized model for the loads and eigen value sensitivity. A result was obtained from the simulation carried out on a small test system as well as on a practical larger power system. In this paper, a variable projection method which reduces the overall parameter space and ensures better convergence as compared to the existing algorithms, such as Gauss- Newton and levenberg-Marquardt and also proposes methodologies to determine the load models using PMU measurements under both large and small disturbances in a power system. The proposed load modelling can be implemented in practice to update the model parameters almost in real-time. A sensitivity analysis was performed to identify the most significant parameters of the load model. An efficient optimisation algorithm was then used to estimate only the significant model parameters i.e., for small disturbances, while for large disturbances, the accuracy and the speed of execution of the load modelling function are enhanced by using a variable projection based efficient optimisation algorithm to determine the model parameters.

Wen-Tai et al. (2015) developed a frame work for identifying multiple power line outages based on the PMUs measurements in the presence of bad data caused by communication errors or system malfunctions. This was done by designing an algorithm to identify locations of line outage and recover the faulty measurements simultaneously. The proposed algorithm does not require any prior information on the number of line outages and the noise variance. Some studies were carried out on test system of different sizes to validate the effectiveness and efficiency of the proposed approach. A computer simulation was used to demonstrate the effectiveness and efficiency of the proposed line outage identification algorithm.

Zhou et al. (2006) proposed an alternative approach, which leaves the traditional state estimation software in place, and discusses a novel method of incorporating the phasor measurement and the results of the traditional state estimator in a post processing linear estimator. The paper presents the basic theory and provides verification through simulations of the two alternative strategies. It was shown that the new technique provide non-linear state estimator and does not require 
modification of the existing EMS software. The approach proposed in this paper is such that it should be possible to continue with all other application functions exactly as before. The output of the traditional state estimator was processed by the proposed algorithm to incorporate PMU data and was put back in the same format as that produced by the traditional state estimator. In summary, the paper considered alternative techniques for using synchronised phasor measurements as additional data in traditional state estimator software in modern EMS and simply shows that by increasing the number of phasor measurements on a power system, the quality of the estimated state is progressively improved.

Darvishi \& Dobson (2015) demonstrated how to combine synchrophasor measurements around the border of an area to quickly monitor the severity of multiple outages inside the area. In order to achieve this, voltage angles around the border of an area of the power system was combine into a bulk angle across the area. The area angle concept is a generalisation of the angle across a cut set area concept developed and proposed for stress monitoring. DC load flow model was used for the analysis and it was observed that synchrophasor measurements around the border of an area can be advantageous for other applications such as combining $\mathrm{AC}$ voltage measurements in a transmission corridor to monitor voltage collapse or locating line outages in the area.

Kesherwani et al. (2012) present the assessment methodology for voltage stability using PMU with complete system observability. The data obtained by PMU's were used for voltage stability assessment with the help of L-index. In this paper a similar formulation of optimal PMU placement problem was also done by integer linear programming with and without conventional power flow and power injection measurement i.e., the OPP problem was formulated using topology based algorithm and solved using integer linear programming on MATLAB.

Pinte et al. (2014) describes the steps, challenges and reasoning involved in building a single-phase, distribution - level PMU using National instruments products.

Theodorakatos et al. (2014) formulated Optimal Placement (OPP) problem by using a non-linear programming (NLP) problem and a sequential quadratic programming (SQP) method. Simulations were carried out on IEEE standard test systems, using MATLAB. The numerical results were compared to those obtained 
by a binary integer programming (BIP) model, also implemented in MATLAB. The comparative study shows that the proposed formulation yields the same number of PMUs as the BIP model. This was done by minimising the quadratic objective function which was subject to equality non-linear bus constraints, where the decision variables are defined on the bounded set. The quadratic function represents the total PMU installation cost, whereas the non-linear constraints express the network observability conditions. The main contribution of this paper lies in investigating the feasibility of using NLP for the OPP problem, despite the fact that this problem is discrete in nature. Hence, Binary integer programming model was developed, which guarantees convergence to the optimum solution using existing optimisation software. The BIP model was used as a comparative reference to demonstrate the efficiency and accuracy of the proposed model.

Pereira et al. (2006) present a technique for fault location on overhead distribution feeders using measurements of pre - and during fault voltage and current phasors at the sending node of a substation along with during - fault voltage measurement at the nodes along the feeder and a data base containing electrical, operational and topological parameters of the distribution networks, and fault simulation. The proposed technique was tested on an overhead line feeder and the results show that the technique is robust and efficient for carrying out fault location in a fast and accurate way.

Srikumar et al. (2015) discussed on algorithm to detect line outages on the transmission system using the bus voltage phasor measurement available from PMUs in conjunction with change in the system topology arising due to line outage. The algorithm also suggests the minimum number of PMUs required for effective line outage detection for a given system. This was simulated in Mi Power TM software to obtain the bus voltage angle and the algorithm to detect effective line outage was programmed using MATLAB. The problem addressed in this paper is the detection of single line outage using only the data provided by the PMU and system topology information. The problem is formulated on the basis that " $n$ " bus system is connected by single lines and only " $n$ " single transmission line outage occurs. It is based upon the voltage phasor angles measured by the PMUs for the buses. These angles are obtained by simulating the " $n$ " system and carrying out load flow studies on it. Later, the algorithm to detect line outage is implemented 
on IEEE power systems using MATLAB. The systems were simulated and analysed using Mi Power ${ }^{\mathrm{TM}}$ software package. The paper also discusses the important role of PMU in line outage detection and show cases a methodology to detect single line outages with available date from PMU in conjunction with system topology information.

Arabali et al. (2016) proposed a new state estimation methodology based on the concepts of sparse vector recovery and line outage modelling i.e., it introduces a new line outage model based on voltage angle measurements that determines the changes in network topology after contingencies using sparse vector recovery since reporting rates of PMUs are faster than those of conventional PQ meters. This proposed method uses the estimated transmission line flows, PMU data and new network topology to provide system estimates until the conventional PQ measurement become available. The method make use of the PMU data, PQ measurements and new network topology to provide state estimates for post contingency networks. The proposed state estimation method overcomes the post - contingencies issues of change in topology and loss of measurements and the optimisation problem in convex. The performance and accuracy of the proposed methods were evaluated for the various IEEE bus systems. The simulation results show that the method provides good results for the three networks.

Abdelaziz et al. (2011) generate a method using only voltage measurements and also proposed a new algorithm using both voltage and current measurement with higher degree of accuracy. A comparison between the two algorithms in terms of accuracy and reliability was carried out to show the validity of the new algorithm over others. The two methods were tested using results of an off-line simulation program PSCAD (Power System Computer Aided Design) and the mathematical analysis with the aid of MATLAB. Comparison between the proposed PMU based fault location algorithms and some other conventional and new techniques was also presented. The method also considers the transmission line parameters such as surge impedance and propagation constant; which is also dependent on the primitive parameters of the transmission line (the line resistance, inductance and capacitance per unit length). The work on this paper also clarifies that, the algorithm based only on the voltages measurements has an advantage and that it is free from the CTs errors and it doesn't require current measurements. The 
second proposed method has more advantages because; it has more accurate results as it deals with more details about the system (Voltages and Currents).

Dotta et al. (2014) discuss the design and usage of a Simulink-based PMU simulator package. This can be used for teaching and research to explore the algorithms involved in the phasor measurement process. It replicates the device architecture and other conventional algorithms.

Satyendra \& Singh (2014): in this paper, integer programming based methodology was presented for the optimal placement of PMU in order to minimise the cost of installation and provides the entire system observability. The concepts of zero injection buses were used in this paper for further reduction in number of PMUs. A criterion was also proposed to select the appropriate location of PMU and to deal with problem of having multiple results which might create confusion. The proposed algorithm was tested on IEEE 14-bus, IEEE 24-bus and IEEEE 30-bus systems. In addition, multiple choices of locations were eliminated by selecting the combination of buses having maximum redundancy. Simulation results on the following IEEE buses 14-, 24-, and 30- test systems indicate that the proposed placement method satisfactorily and provides full observable system measurements with minimum number of PMUs.

Abood \& Sreeram (2014) present the main categories for PMUs placement strategies according to the objective of PMUs employment. The paper focuses on the objectives because PMUs can be installed for many objectives and optimal PMUs placement problem is a multi-dimensional and multi-functional problem.

Liang et al. (2016) developed a hybrid filter algorithm to deal with the state estimation (SE) problem for power systems by taking into account the impact from the PMUs. The proposed algorithm was applied to give an estimate of the states of the power systems with both traditional and PMU parameters in the presence of probabilistic data missing phenomenon. An extensive simulation was carried out on the 14 bus standard IEE test system and it was shown that the proposed algorithm gives much improved estimation performances over the traditional extended Kalman filter algorithm method.

Martin et al. (2006) describes a set of test used to determine PMU measurement characteristics under steady and dynamic conditions. The methodology was based 
on the use of test signals that are mathematically generated from a signal model and played into the PMU with precise GPS synchronisation.

Mauryan \& Ramkumar (2014) present a brief review on the phasor measurement unit and its application in the power system such as state estimation, power system protection, and power system control.

Anil kumar \& Lakshmi (2014) present the fault detection and classification in power system using PMU. The proposed technique is based mainly on two components to identify the faults on the transmission lines. The first component is the voltage reduction due to fault occurrence. The second component is the power flow detection after fault occurrence. The phase angle was used to determine the direction of fault current with respect to a reference quantity. In summary it presents a new protection technique for transmission grids using Phasor Synchronised measuring techniques in a wide area system.

Tate \& Overbye (2007) proposed an algorithm which uses known system topology information together with PMU phasor angle measurements, to detect system line outages. The algorithm also provides an estimate of the pre-outage flow on the outage line. This was done by using simulated and real PMU data from two systems: a 37-bus study case and TVA control area. The problem addressed was the detection of system events using only PMU data, transmission line and transformer parameter data, and system topology information.

Garcia et al. (2016), a statistical classifier that localises line outages using time series PMU data that is sampled during the transient response of the system. The classifier is a linear multinomial regression model that is trained by solving a maximum likelihood problem. 57 bus systems were used to compare the results to existing quasi - steady state and to illustrate the ability of the classifier to quickly identify line outages before a steady state is reached.

Ali et al. (2014) proposed a neural network based voltage instability detector which utilising wide area monitoring system and measured angle of the installed PMUs. The detector depends on the bus voltage angle which is measured by the installed PMUs. Furthermore, the effect of different loading conditions was applied to the simulation system to get their corresponding bus angles values. The work done on this paper was developed through three stages. The first stage was the 
simulation of the power system using MATLAB to get the system load flow results. The second stage was the normalisation of the output of the first stage. The third stage was the design and training of a feed-forward neural network which utilise thirty percent of the studied cases. The network was programmed to give the voltage stability status of the power system buses based on bus voltage angles. The newly developed ANN based voltage detector was designed to study the voltage stability status of the whole system buses as one unit. The smart developed method was applied to IEEE 14-bus standard system. The system was later simulated and about one thousand studied cases were obtained i.e., Four hundred studied cases of them were used for training of the ANN and the rest were used for testing stage. It was found that the accuracy of ANN was about $90 \%$.

Oshevire et al. (2013) examined the prospects and possible application of Smart Grid Technology (SGT) to the Nigeria power system. The study shows that the smart grid system will make the present network more efficient and reliable by connecting different sources of distributed generators into the existing grid. Basic requirements necessary for the application of SGT using the Nigeria power system as a case study were discussed. The paper proposed a method of supply reliability evaluation for micro grids, including renewable energy sources, installation of electric energy storage systems etc.

Nafeena \& Seralathan (2014) present a novel approach to optimal placement of PMUs for state estimation. This was done by determining the optimal measurement set in order to achieve full network observability using heuristic approach during normal conditions. Artificial Bee Colony algorithm was used as the tool for optimisation to obtain the minimal number of PMUs and their corresponding locations while satisfying the associated constraint. The integer based artificial bee colony optimisation method was tested on various standards of IEEE bus system such as 14-bus, 30-bus, 57-bus and 118-bus. The proposed two stage algorithm on the paper determines the minimum number of strategic bus locations where PMU must be placed for complete observability. The first stage of the algorithm determines the important bus locations for allocating PMUs. The second stage is pruning stage which is checks the possible ways to further reduce any PMUs minimum number of strategic bus locations where PMU must be placed

$$
\text { I SSN : } 2636-607 X \quad 25 \text { | Page }
$$


for complete observability. Measurement redundancy was also checked. Simulation results for different networks show the effectiveness of the proposed method in obtaining the minimum number of PMU required for complete observability of power systems. A drawback was noted for heuristic method which is the time to execute and it was mitigated using Artificial Bee Colony Approach.

Marwa \& Noha (2013), a new approach for Artificial Immunity system (AIS) based voltage instability detection during transient period was developed. The AIS technique was developed to predict the system behaviour and determine voltage instability occurrence. The voltage instability was analysed and studied using the concept of Wide Area Measurement Protection and Control (WAMPAC). The newly developed voltage instability detector was applied to the IEEE 14 bus system. This gave an acceptable result in the expected system behaviour. The work was progressed through three main stages. First stage is simulating power system using PSAF. Second stage is handling and processing data, before using it by the AIS technique. Third stage is the use of the developed AIS technique to detect system stability, and inform system protection centre (SPC) in case of voltage instability.

Ganga et al. (2012), deals with a study to determine the optimal locations of PMUs for a given power system. This paper focuses on the use of PMU measurements in state estimators. The principle objective was the investigation of various methods of determining optimal locations for PMUs so that the entire power system is observable. The recently developed artificial intelligence (AI) techniques, like Genetic Algorithm and artificial bee colony techniques were applied to find out the optimal placement of PMUs for various systems. The artificial bee colony approval for solving a binary mode of optimization gives the desired optimised results successfully. The ABC approach guarantees a global or near global solution with a properly chosen colony parameters like maximum number of iterations, population size, on looker bees, employed bees and threshold limit.

Gunjker et al. (2015) present an extensive simulation studies on fault location carried out using MATLAB. A brand-new adaptive PMU based protection scheme for both transposed and un-transposed parallel transmission lines was also presented. The development of the scheme was based on the distributed line model and the synchronised phasor measurement at both ends of line by means
26 | Page
I S S N : $2636-607 X$ 
of eigen value/eigen vector theory to decouple the mutual coupling effects between the parallel lines, the fault detection and location indices. The extensive simulation studies show that the performance of the proposed algorithm is very excellent and the average error of fault location was well less than $1 \%$ under various system operations with a consideration on fault factors. The simulation results also demonstrate the feasibility and effectiveness of the proposed fault location technique for multi-terminal transmission lines with arbitrary configurations. The proposed fault location technique was an accurate method and its performance is almost unaffected by system operation conditions and fault events.

Chakrapani \& Dushmanta (2015) gave an insight of the importance and application of Phasor Measurement unit in power system. It also presents the modelling of phasor measurement unit in MATLAB as well as realization of Phasor data considering only a two bus system as against my work, which intend to consider 16 bus systems on Nigeria Transmission line. The work on the paper was done with the aid of Simulink model of 2-bus system comprising of PMU block in MATLAB. The real data were obtained to understand the dynamic behaviour or change in the system irrespective of the state. 


\section{CHAPTER THREE RESEARCH METHODOLOGY}

\subsection{Research Data}

Data collection is the process of gathering and measuring information on targeted variables such as lines and Generators parameters in an established systematic fashion, which then enables one to perform analysis and evaluate outcomes. The various data (Generator Data, Generator-Transformer Data, Transmission Line Data, and Load Data) that was used for the network proposed in this research are tabulated on Appendix A A typical Generator Data as collected, Appendix B - A typical Generator Transformer Data, Appendix C - Transmission line parameter, Appendix D - A typical Load Data as collected and Appendix E - Data for Generating stations from January to April, 2017.

\subsection{Data Preparation}

The data to be used are summarised by taking the average of the power on the load bus and the generators data within a period of four months; alongside the transmission lines parameters and the Generators-Transformers data were also considered. These were managed in Microsoft Excel format and were entered as input to the 330kV transmission network drawn on PSAT/MATLAB Simulink 2015a (Figure 3.1), with the aid of the prototype received from Transmission Company of Nigeria (TCN).

The network to be considered represents the South - West region (Figure 3.2). It has twelve (12) buses maintained at $330 \mathrm{kV}$, three (3) Generators and six (6) numbers of PMU as determined from PSAT optimal placement. Ikeja-West to Osogbo, Ikeja-West to Sakete, and Ayede to Olorunsogo lines representing a single circuit network were considered as the lines under outage and were analysed following the algorithm on session (3.3).

\subsection{Method of Data Analysis}

The methodology used for this work involved collection of relevant transmission parameters such as Generators-Transformer data, Generator ratings, number of 330kV buses, and line impedance values from Transmission Company of Nigeria, Osogbo, Osun state, Nigeria. The entire $330 \mathrm{kV}$ transmission line diagram was modelled and simulated on PSAT 2.10.1 and MATLAB 2015a as shown on Figure 3.1. The south western region was then considered for this work due to the complexity involved considering the entire network during power flow analysis. 


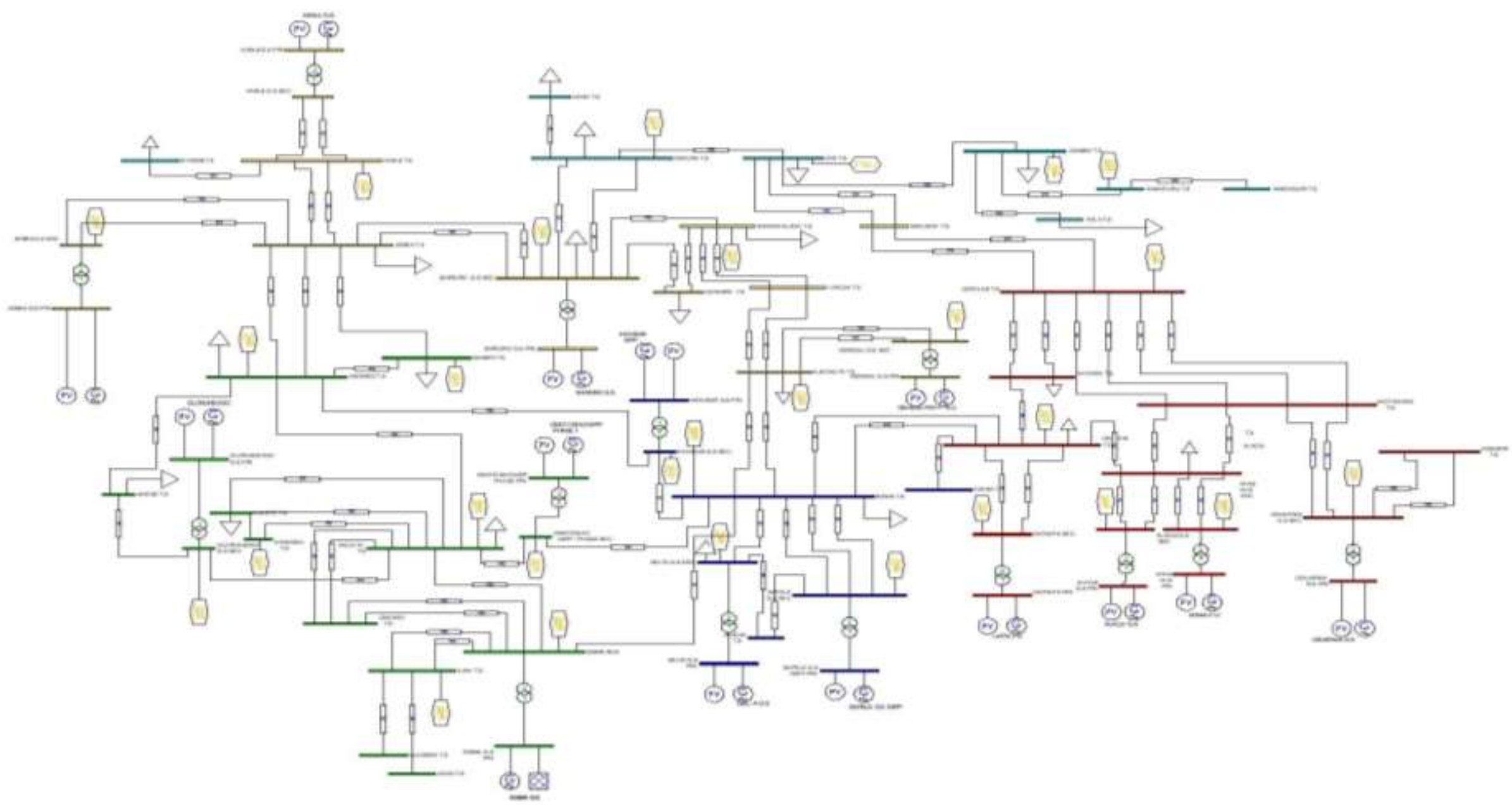

Figure 3.1. $330 \mathrm{kV}$ Transmission National Grid of Nigeria drawn on PSAT/MATLAB Simulink 


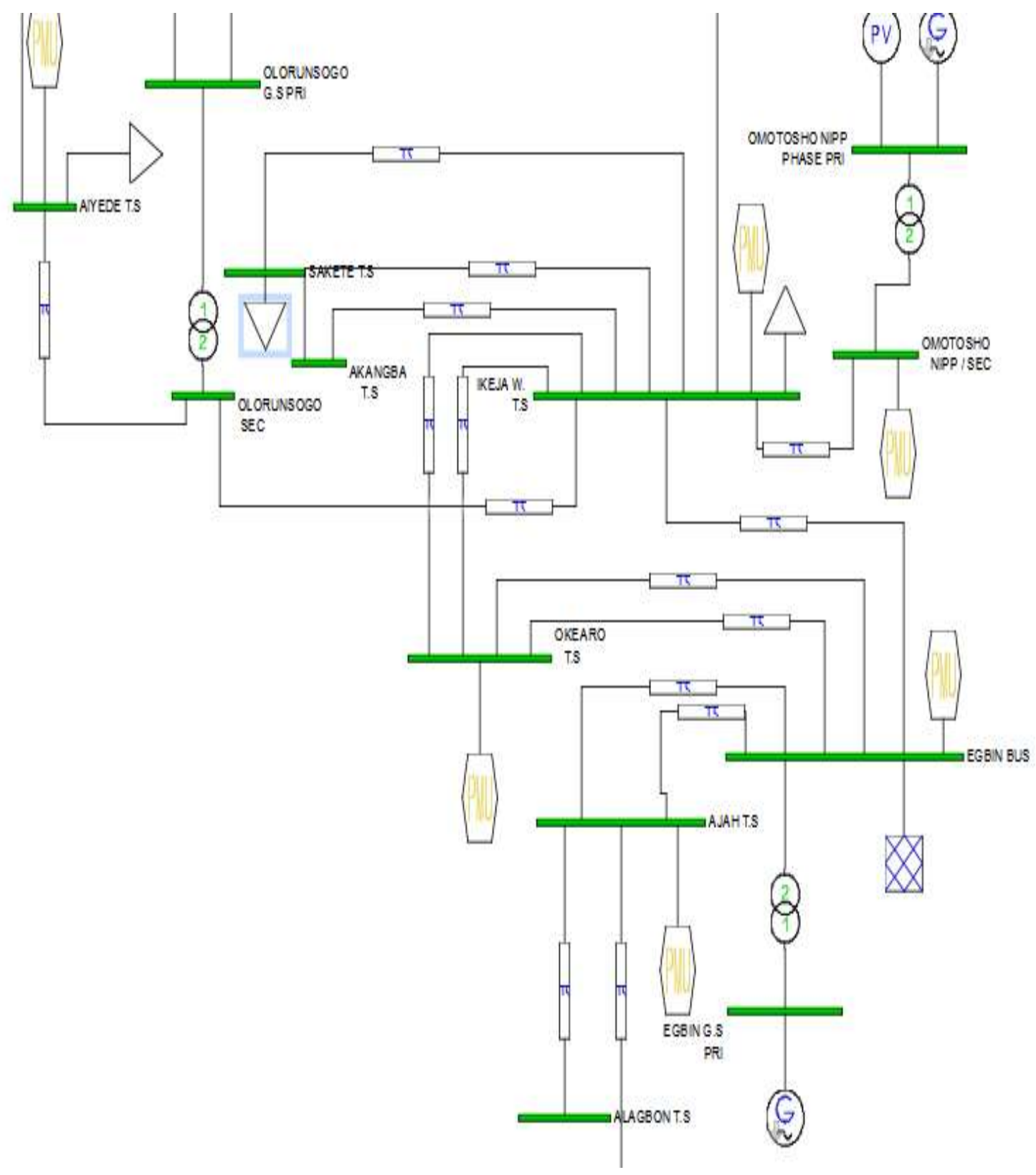

Figure 3.2. A session of the $330 \mathrm{kV}$ Transmission Grid Representing the South West Region of Nigeria

The network for this study consists of 12 buses at $330 \mathrm{kV}$, with 3 generators and 6 PMUs device. Egbin power station was used as the slack bus among other power generating stations; this is as a result of having the largest generating power and would be suitable as the slack bus in the system. In order to determine the following: Voltage magnitudes, Phase angles, active and reactive power etc., throughout the network, buses were maintained at $330 \mathrm{kV}$. The method was then divided into offline analysis and online analysis. For the offline analysis, the following steps were carried out to achieve the normalised values of change in admittance: 
(a) the admittance matrix for Y-bus and bus voltage for pre-outage was obtained via the power flow analysis;

(b) then the row and column of the primary bus bar of Generator and the row and column associated with slack bus was eliminated i.e., since the angle change at slack bus is always zero;

(c) converting the Admittance Y-Bus to Impedance values;

(d) selection of a single line linking Ikeja to Osogbo representing a possible outage;

(e) calculation of the change in impedance $\Delta Z$ for line (Ikeja-West to Osogbo);

(f) performing rank for the change in impedance matrix for step g (i.e.) finding a single vector. This was done by performing reduced row echelon form (rref) on the transpose of the change in impedance;

(g) normalising the first row of the matrix of the reduced row echelon form;

(h) step (c) to (g) was repeated for other single lines such as Sakete to Ikeja-West, and Olorunsogo to Ayede to obtain the normalised values of change in impedance; and

(i) recursive $\mathrm{N}-1$ method on PSAT for optimal placement of PMU was used to obtain the number of PMU for total observability of the system and the Phasor voltage and angle at all the buses.

While for the online analysis, the following steps were carried out to achieve the normalised values of change in angle.

(i) The Phase Angle from online simulation for the Pre-Outage and also Post Outage was obtained for all the lines listed in $(h)$

(ii) Calculation of change in voltage phase angle between Pre-Outage and Post Outages at buses.

(iii) Normalising the column matrix from the output of step (ii).

(iv) The normalised column matrix of change in voltage phase angle (iii) is compared with each normalised basic vector of transmission line outages $(g)$ and $(h)$.

(v) Finding the closest Vector to the Angle to determine the line outage.

(vi) Plotting of the result of (iv) on a graph using MATLAB software. 


\subsection{Equation of Power Flow and Line Outage Detection}

In general, the flow of power in a power system is governed by basic electric circuit theory. A power flow study is performed in order to determine where and to what degree the active and reactive powers flow (Mahoney, 2011). Beginning from Ohm's law and the definition of complex electric power, the following power flow equations are derived:

$$
\begin{aligned}
& \mathrm{P}_{\mathrm{i}}=\sum_{n=1}^{N}\left(\left|\mathrm{Y}_{\mathrm{i}}\left\|\mathrm{V}_{\mathrm{i}}\right\| \mathrm{V}_{\mathrm{n}}\right| \cos \left(\delta_{\mathrm{in}}+\theta_{\mathrm{n}}-\theta_{\mathrm{i}}\right)\right) \\
& \mathrm{Q}_{\mathrm{i}}=\sum_{n=1}^{N}-\left(\left|\mathrm{Y}_{\mathrm{i}}\left\|\mathrm{V}_{\mathrm{i}}\right\| \mathrm{V}_{\mathrm{n}}\right| \sin \left(\delta_{\text {in }}+\theta_{\mathrm{n}}-\theta_{\mathrm{i}}\right)\right)
\end{aligned}
$$

Where $N$ is the number of buses, $i$ is the Bus identity, $P_{\mathrm{i}}$ is the real power and $Q_{i}$ is the reactive power injected.

The admittance of a branch element in the power system $i$ defined as:

$$
\left|Y_{\text {in }}\right|<\delta_{\text {in }}
$$

And the bus voltage and magnitude at bus $\mathrm{i}$

$$
\left|V_{\text {in }}\right| \angle \theta_{\text {in }}
$$

The power flow solution is a process of solving the power flow equations such that the active power generated equals the active power loss plus the real powers of the loads. Similarly, the reactive power generated must equal the reactive powers of the connected loads. Since the power flow problem is non-linear in nature, most solution methods use an iterative approach to arrive at a solution. In an attempt to provide a faster, though less accurate solution, the DC power-flow was created. A DC power flow represents an entirely linear set of equations which do not require iteration. Some assumptions are made to arrive at the DC power flow solution.

First, many large systems have branch impedances whose real part is in significant compared to the imaginary part:

$$
z=r+j x
$$

Where $\mathrm{r} \ll \mathrm{x} \Rightarrow \mathrm{z} \approx \mathrm{jx}$ 
It is important to note that since the impedance is approximately equal to the reactance, the $j$ can be dropped as long as it is known that all calculations are performed on the imaginary components only. Also, in general, if an angle is represented in radians, the sine of that angle is approximately equal to the angle itself (Mahoney, 2011):

$$
\operatorname{Sin}(\theta) \approx \theta
$$

Lastly, when expressed using the per-unit system, the voltages at every bus are approximately equal to 1 . With only the real part of the impedance remaining and since the angle $\delta_{\mathrm{ij}}$ of each impedance is $90^{\circ}$. Thus, the power flow equations become:

$$
\begin{aligned}
\mathrm{P}_{\mathrm{i}} & \left.=\sum_{n=1}^{N}\left(\mid \mathrm{Y}_{\mathrm{in}}\right]\left(\theta_{\mathrm{n}}-\theta_{\mathrm{i}}\right)\right) \\
\mathrm{Q}_{\mathrm{i}} & =0
\end{aligned}
$$

Additionally, the power flowing through a single branch from bus I to bus $\mathrm{j}$ can then be approximated as:

$$
P_{i j} \cong \frac{\left|V_{i}\right|\left|V_{j}\right|}{\left|X_{i j}\right|} \sin \left(\theta_{i j}\right)
$$

The real power injected at any bus can then be expressed as a sum of the incident branch flows which consist of admittances and bus voltage angles. Therefore, a relation between bus power injections and bus voltage angles can be written in matrix form:

$$
\mathrm{P}=\mathrm{Y}^{\theta}
$$

More often, the quantity of interest is the bus voltage angle, since it can be used to determine the line flows as in (3.10). For this reason, the DC power flow equations can be expressed in terms of an admittance matrix, $\mathbf{Y}$, or an impedance matrix $\mathbf{X}$ :

$$
\begin{aligned}
& \theta=\mathrm{Y}^{-1} \mathrm{P} \\
& \theta=\mathrm{XP}
\end{aligned}
$$


Due to their linear nature, the DC power flow (3.11) and (3.12) are useful in many applications. One particularly important application is in the area of contingency analysis. During normal operation, it is often unrealistic to solve a full power flow in the case of some system contingency. Instead, a set of so-called linear distribution factors is used to quickly calculate the change in line flows or bus voltage angles when system contingencies occur. Using the DC power flow assumption as stated earlier, it is possible to view the system impedance matrix $\mathbf{X}$ as a linear transformation. Since $\mathbf{X}$ is a mapping from vectors in the space of injected powers to the space of bus voltage angles, it can be viewed as the matrix representation of a linear transformation between two finite dimensional vector spaces. Thus, in order to detect line outages, there must be some way to characterise the vectors in the range of $\mathbf{X}$ as belonging to a specific subset.

Each subset represents the possible bus voltage angles which may occur due to an individual line outage. Before a line outage occurs, it is assumed that the linear transformation matrix $\mathbf{X}$ has been calculated. During and after the outage itself, it is also assumed that a certain number of bus voltage angles are measurable via PMUs. The only unknown quantities then are the injected real powers at each bus. Since bus voltage magnitudes have been shown to provide the most telling information about power system events, it can be reasoned that their difference before an event and after an event describes the true character of said event. The model of a power system before an outage:

$$
\theta_{\mathrm{pre}}=\mathrm{XP}
$$

and the same system after a line outage is as follows:

$$
\theta_{\text {post }}=[\mathrm{X}+\Delta \mathrm{X}] \mathrm{P}
$$

Due to the line outage, the impedance matrix is modified. The character of this modification is well known, but may be easier to visualise in terms of admittance. Recall that $Y=X^{-1}$. Therefore

$$
\mathrm{Y}=\mathrm{X}^{-1} \Rightarrow[\mathrm{X}+\Delta \mathrm{X}]=[\mathrm{Y}+\Delta \mathrm{Y}]^{-1}
$$


The line between bus $i$ and bus $j$ whose admittance is $y_{i j}$ can be removed from the original admittance matrix $\mathbf{Y}$ to yield the new admittance matrix $\hat{\mathbf{Y}}$ as follows:

$$
\begin{aligned}
& \text { (i) (j) }
\end{aligned}
$$

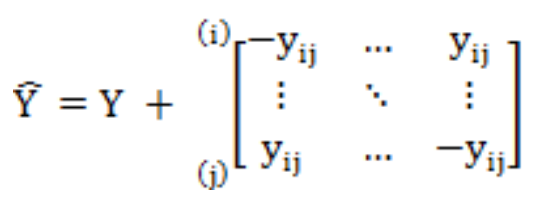

Typically, this same operation can be modelled with impedances by adding another artificial line of negative impedance equal to the original in parallel with the original line. To remove the effect of the artificial line Kron Reduction is then performed (Mahoney, 2011). In (3.15), the negative of the admittance is on the main diagonal, but the actual admittances are in row $i$, column $j$ and row $j$, column $i$. For a 3 × 3 admittance matrix, when removing a line between bus 1 and bus 3 , the above equation could be written as:

$$
\mathrm{Y}=\left[\begin{array}{lll}
\mathrm{y}_{11} & \mathrm{y}_{12} & \mathrm{y}_{13} \\
\mathrm{y}_{21} & \mathrm{y}_{22} & \mathrm{y}_{23} \\
\mathrm{y}_{31} & \mathrm{y}_{32} & \mathrm{y}_{33}
\end{array}\right]+\left[\begin{array}{ccc}
-\mathrm{y}_{13} & 0 & \mathrm{y}_{13} \\
0 & 0 & 0 \\
\mathrm{y}_{13} & 0 & -\mathrm{y}_{13}
\end{array}\right]
$$

Using the Sherman-Morrison-Woodbury (SMW) matrix identity, it is possible to determine the impedance matrix form of this equivalent admittance matrix form. The SMW matrix identity is simply a method for finding the inverse of a matrix when the matrix is updated with a rank $k$ update:

$$
(A+U C V)^{-1}=A^{-1}-A^{-1} U\left(C^{-1}+V A^{-1} U\right)^{-1} V^{-1}
$$

Rewriting the (3.17), it is possible to arrive at a form similar to the Woodbury identity. Again, assuming a three bus system:

$$
\begin{aligned}
\widehat{Y} & =\left[\begin{array}{lll}
y_{11} & y_{12} & y_{13} \\
y_{21} & y_{22} & y_{23} \\
y_{31} & y_{32} & y_{33}
\end{array}\right]+\left[\begin{array}{ccc}
-y_{13} & 0 & y_{13} \\
0 & 0 & 0 \\
y_{13} & 0 & -y_{13}
\end{array}\right] \\
& =Y+\left[\begin{array}{c}
1 \\
0 \\
-1
\end{array}\right]\left[\begin{array}{lll}
-y_{13} & 0 & y_{13}
\end{array}\right] \\
& =Y-\left[\begin{array}{c}
1 \\
0 \\
-1
\end{array}\right]\left[\begin{array}{ll}
-y_{13}
\end{array}\right]\left[\begin{array}{lll}
1 & 0 & -1
\end{array}\right]
\end{aligned}
$$

Now, (3.19) can be inverted using the SMW identity as follow 


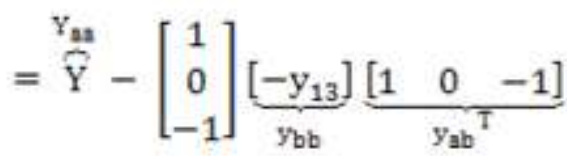

The expression above is made up of four separate pieces which can be rewritten as follows:

$$
\begin{aligned}
\left(y_{a a}-y_{a b} y_{b b}\right. & \left.y_{a b}{ }^{T}\right)^{-1} \\
& =y_{a a}{ }^{-1} \\
& -y_{a a}{ }^{-1} y_{a b}\left(y_{b b}{ }^{-1}+y_{a b} y_{a a}{ }^{-1} y_{a b}{ }^{T}\right)^{-1} y_{a a}{ }^{-1} y_{a b}{ }^{\top}
\end{aligned}
$$

Equivalently, the original admittance matrix is simply the inverse of the original impedance matrix:

$$
\begin{aligned}
& \left(y_{a a}-y_{a b} y_{b b} y_{a b}{ }^{T}\right)^{-1}
\end{aligned}
$$

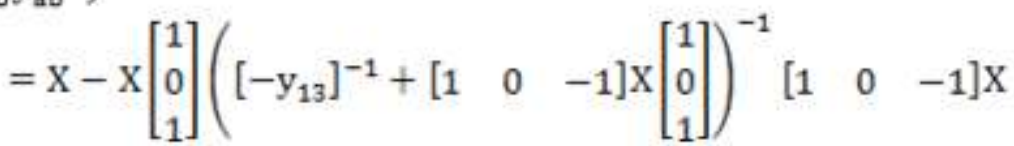

The second term which is subtracted from the original impedance matrix is made up of three separate pieces. The first piece on the left can be rewritten as follows:

$$
X=\left[\begin{array}{c}
1 \\
0 \\
-1
\end{array}\right]=\left[\begin{array}{ll}
X_{11} & -X_{13} \\
X_{21} & -X_{23} \\
X_{31} & -X_{33}
\end{array}\right]=\left[\operatorname{Col}_{1}-\operatorname{Col}_{j}\right]
$$

The right most piece is simply the transpose of the leftmost piece and can be rewritten similarly:

$$
\left[\begin{array}{lll}
1 & 0 & -1
\end{array}\right] \mathrm{X}=\left[\begin{array}{lll}
\mathrm{X}_{11}-\mathrm{X}_{31} & \mathrm{X}_{12}-\mathrm{X}_{32} & \mathrm{X}_{13}-\mathrm{X}_{33}
\end{array}\right]=\left[\begin{array}{l}
\text { Row }_{\mathrm{i}}-\text { Row }_{\mathrm{j}}
\end{array}\right]
$$

and

$$
\left[-\mathrm{y}_{13}\right]^{-1}+\left[\begin{array}{lll}
1 & 0 & -1
\end{array}\right] \mathrm{x}\left[\begin{array}{c}
1 \\
0 \\
-1
\end{array}\right]
$$

When line impedance is removed from the system the equation becomes:

$$
\begin{aligned}
& {\left[-\mathrm{y}_{13}\right]^{-1}+\left[\begin{array}{lll}
\mathrm{x}_{11}-\mathrm{x}_{31} & \mathrm{x}_{12}-\mathrm{x}_{32} & \mathrm{x}_{13}-\mathrm{x}_{33}
\end{array}\right]\left[\begin{array}{c}
1 \\
0 \\
-1
\end{array}\right]} \\
& {\left[-\mathrm{y}_{13}\right]^{-1}+\left[\mathrm{x}_{11}-\mathrm{x}_{31}-\left(\mathrm{x}_{13}-\mathrm{x}_{33}\right)\right] \leftarrow \mathrm{x}_{13}=\mathrm{x}_{31}} \\
& =X_{13}+\mathrm{x}_{11}+\mathrm{x}_{33}-2\left(\mathrm{x}_{13}\right)
\end{aligned}
$$


Taking the inverse of the result above simply yields a scalar in the case of a single line removal:

$$
\begin{aligned}
\left(x_{13}+x_{11}+\right. & \left.x_{33}-2\left(x_{13}\right)\right)^{-1} \\
& =\frac{1}{x_{13}+x_{11}+x_{33}-2\left(x_{13}\right)}
\end{aligned}
$$

With each of the rewritten pieces, it is easy to see how line impedance is removed from a system impedance matrix:

$$
\begin{aligned}
{\left[\operatorname{Col}_{\mathrm{i}}-\mathrm{Col}_{\mathrm{j}}\right]\left[\frac{1}{\mathrm{Z}_{\mathrm{ii}}+\mathrm{Z}_{\mathrm{ij}}-2 \mathrm{Z}_{\mathrm{ij}}+\mathrm{Z}_{13}}\right]\left[\operatorname{Row}_{\mathrm{i}}-\text { Row }_{\mathrm{j}}\right]=} \\
=\mathrm{X}\left[\begin{array}{c}
1 \\
0 \\
-1
\end{array}\right]\left(\left(\left[-\mathrm{y}_{13}\right]^{-1}\right)+\left[\begin{array}{lll}
1 & 0 & -1
\end{array}\right] \mathrm{X}\left[\begin{array}{c}
1 \\
0 \\
-1
\end{array}\right]\right)^{-1}\left[\begin{array}{lll}
1 & 0 & -1
\end{array}\right] \mathrm{X}
\end{aligned}
$$

Thus, the Kron Reduction which is typically used to add a new loop element to an impedance matrix is nothing more than an application of the SMW matrix identity. The typical form of Kron Reduction $\mathrm{K}$ is:

$$
\mathrm{K}=\mathrm{X}-\Delta \mathrm{X}
$$

Now, with the ability to model the change in the power system due to a line removal, it is possible to determine analytically the effect of a line outage on bus voltage angles. In the equation above, the term $\Delta \mathbf{X}$ is the representation of the line removal. The question however, is how to isolate this portion so that, when PMU measurements are used, only the change in the impedance matrix is characterised. To accomplish this, the difference in pre and post outage angles must be used. In order to examine the difference in pre and post outage angles, the power system can be modelled using the DC power flow assumptions. As shown above the models before and after an outage is:

$$
\begin{aligned}
& \theta_{\text {pre }}=\mathrm{XP} \\
& \theta_{\text {post }}=[\mathrm{X}+\Delta \mathrm{X}] \mathrm{P}
\end{aligned}
$$

However, as was shown above, the model after the outage can also be written as (3.30). To characterise their difference (the impedance change), the post outage angles are subtracted from their pre outages angles: 


$$
\theta_{\text {pre }}-\theta_{\text {post }}=\Delta \theta=[\Delta \mathrm{X}] \mathrm{P}
$$

The vector $\boldsymbol{\Delta} \boldsymbol{\theta}$ is the image of the line outage in terms of bus voltage angles. Here, as before, the assumption is that an angle measurement is available at every bus. Also, as before, this assumption can be relaxed without loss of generality. The vector $\boldsymbol{\Delta} \boldsymbol{\theta}$ can be found off-line, for every line outage since the matrix $\boldsymbol{\Delta} \mathbf{X}$ can be calculated from the topology and the list of branch impedances. The impedance change can be shown to be a rank one matrix. Normalising a vector:

$$
\Delta \theta_{\text {norm }}=\frac{\Delta \theta}{|\Delta \theta|}
$$

With these equations above, when the measured $\boldsymbol{\Delta} \boldsymbol{\theta}$ vector is also normalised to rank one, the vectors will be identical, i.e., using DC power flow assumptions. 


\section{CHAPTER FOUR \\ DATA ANALYSIS AND DISCUSSION}

\subsection{Simulation}

The data used in this study was based on what was collected from TCN, Control Centre Osogbo and the equation used in achieving these have been presented in chapters 3; i.e., (3.23) to (3.32). Figure 4.1 shows the estimated voltage in Per Units and the estimated angles in radian using Recursive $\mathrm{N}-1$ spanning method for selection of the best suitable location that will give a total system observability using PMU at the stipulated position within the network; without leaving any bus un-observed. This figure represents when the system is in a stable state.

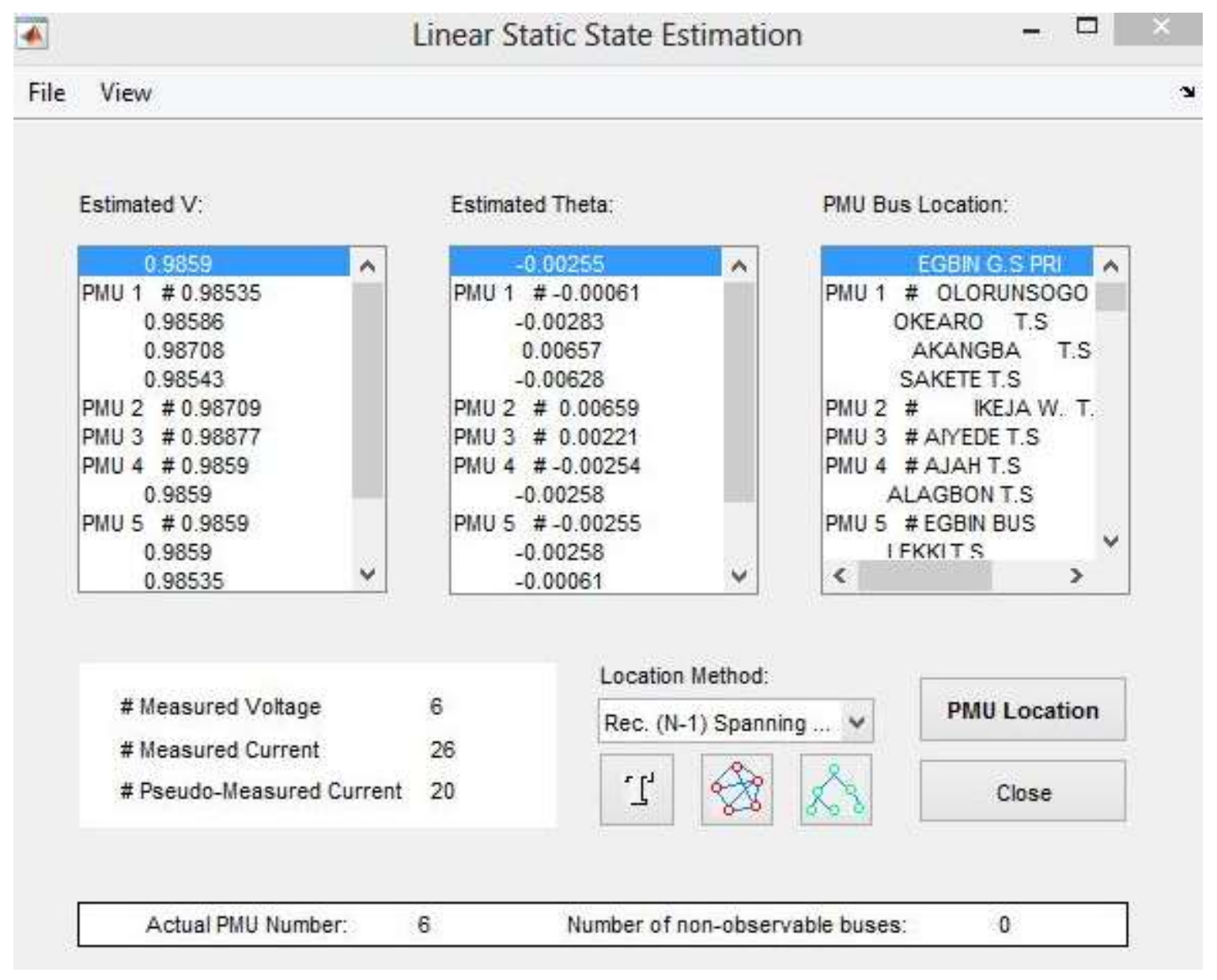

Figure 4.1. PMU reading for Pre-Outage

Figure 4.2 shows the estimated voltage in per units and the estimated angles in radian using recursive $\mathrm{N}-1$ spanning method for selection of the best suitable location that will give a total system observability using PMU at the stipulated position within the network; without leaving any bus un-observed. This figure represent when the system is in an unstable state and the values gotten from the simulation; i.e., when Ikeja-Osogbo line 
is taking out of the system before running simulation on PSAT. While Table 4.1 represents the various angles at each bus and their changes in degree.

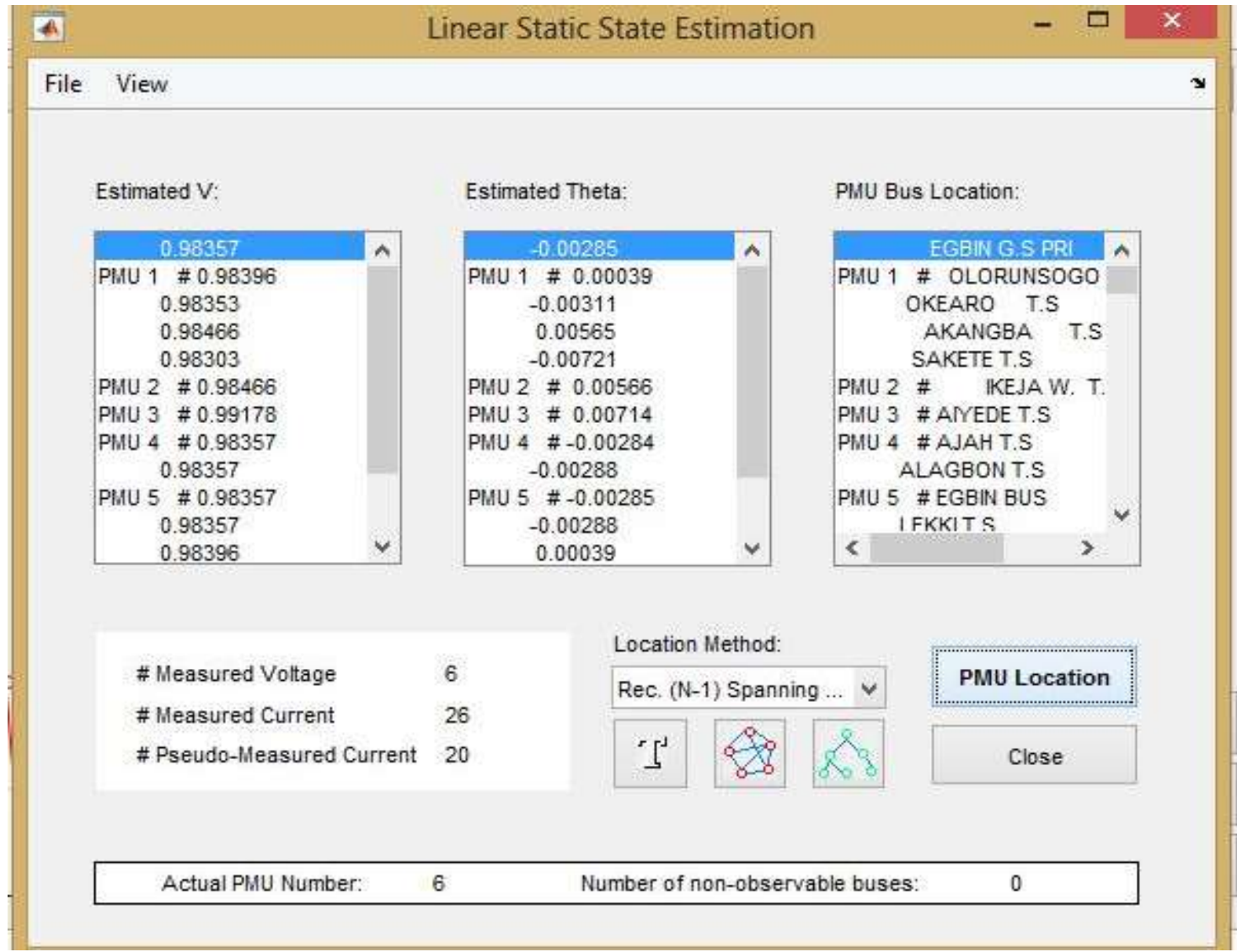

Figure 4.2. PMU reading for Ikeja-Osogbo Outage line

Table 4.1. Change in Angle reading for Ikeja -Osogbo

\begin{tabular}{|c|c|c|c|}
\hline Bus & Pre-Outage & Post-Outage & $\Delta \boldsymbol{\theta}$ in Degree \\
\hline Egbin GS Pri & 0.984586561 & -0.163271801 & 1.147858362 \\
\hline Olorunsogo Sec & -3.281955203 & 0.022342457 & -3.30429766 \\
\hline Okearo TS & 0.918947457 & -0.178166773 & 1.097114229 \\
\hline Akangba TS & 3.019398786 & 0.323679185 & 2.695719601 \\
\hline Sakete TS & 3.052218338 & -0.413049013 & 3.465267352 \\
\hline Ikeja West TS & 3.052218338 & 0.324252069 & 2.72796627 \\
\hline Aiyede TS & -16.18003915 & 0.409038829 & -16.58907798 \\
\hline Ajah TS & 0.984586561 & -0.162698918 & 1.147285479 \\
\hline Alagbon TS & 0.984586561 & -0.164990452 & 1.149577013 \\
\hline Egbin BuS & 0.984586561 & -0.163271801 & 1.147858362 \\
\hline Lekki TS & 0.984586561 & -0.164990452 & 1.149577013 \\
\hline Olorunsogo GS Pri & -3.281955203 & 0.022342457 & -3.30429766 \\
\hline Omotosho NIPP / Sec & 3.183496546 & 0.889115213 & 2.294381333 \\
\hline Omotosho NIPP Phase Pri & 3.183496546 & 0.889115213 & 2.294381333 \\
\hline Osogbo TS & -19.36353569 & 0.409038829 & -19.77257452 \\
\hline
\end{tabular}

GS: Generation Station; TS: Transmission Station 
Figure 4.3 simply shows the estimated Voltage in Per Units and the estimated angles in radian using recursive $\mathrm{N}-1$ spanning method for selection of the best suitable location that will give a total system observability using PMU at the stipulated position within the network; without leaving any bus un-observed. This figure represent when the system is in an unstable state and the values gotten from the simulation; i.e., when AyedeOlorunsogo line is taking out of the system before running simulation on PSAT. Table 4.2 represents the various angles at each bus and their changes in degree.

\begin{tabular}{lll}
\hline L Linear Static State Estimation & - & $\mathrm{x}$ \\
File View & $\square$ & $\mathbf{x}$
\end{tabular}

Estimated V:

\begin{tabular}{|c|c|}
\hline 0.98257 & $\hat{A}$ \\
PMU $1 \quad \# 0.98259$ & \\
0.98252 \\
0.98389 \\
0.98221 \\
PMU $2 \# 0.98389$ \\
PMU $3 \# 0.98152$ \\
PMU $4 \quad \# 0.98257$ \\
0.98256 \\
PMU $5 \quad \# 0.98257$ \\
0.98256 \\
0.98259 \\
\hline
\end{tabular}

Estimated Theta:

\begin{tabular}{|c|c|}
\hline-0.00152 & A \\
\hline PMU $1 \#-0.00126$ & \\
\hline-0.00183 & \\
\hline 0.00861 & \\
\hline-0.00432 & \\
\hline PMU 2 2 \# 0.00863 & \\
\hline PMU $3 \#-0.01175$ & \\
\hline PMU 4 \# -0.00151 & \\
\hline-0.00155 & \\
\hline PMU $5 \#-0.00152$ & \\
\hline-0.00155 & \\
\hline$-0: 00126$ & $\checkmark$ \\
\hline
\end{tabular}

PMU Bus Location:



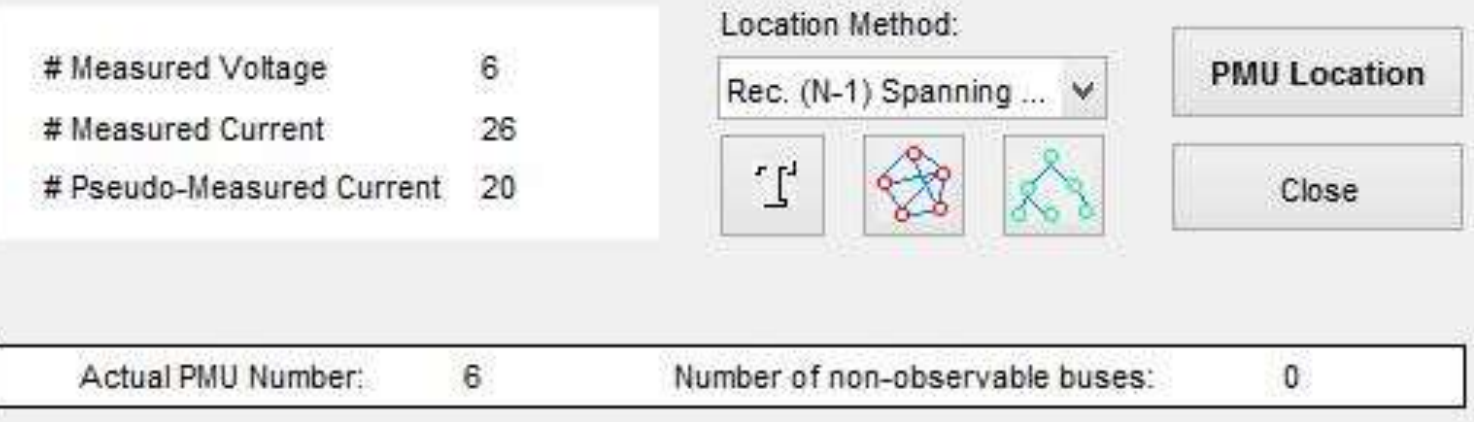

Figure 4.3. PMU reading for Ayede-Olorunsogo Outage line 
Table 4.2. Change in Angle reading for Ayede -Olorunsogo

\begin{tabular}{|c|c|c|c|}
\hline Bus & Pre-Outage & Post-Outage & $\boldsymbol{\Delta} \boldsymbol{\theta}$ in Degree \\
\hline Egbin GS Pri & 0.984586561 & -0.087078294 & 1.071664855 \\
\hline Olorunsogo Sec & -3.281955203 & -0.072183323 & -3.20977188 \\
\hline Okearo TS & 0.918947457 & -0.104837683 & 1.02378514 \\
\hline Akangba TS & 3.019398786 & 0.493252705 & 2.526146081 \\
\hline Sakete TS & 3.052218338 & -0.247485678 & 3.299704016 \\
\hline Ikeja West TS & 3.052218338 & 0.494398472 & 2.557819866 \\
\hline Aiyede TS & -16.18003915 & -0.673138129 & -15.50690102 \\
\hline Ajah TS & 0.984586561 & -0.086505411 & 1.071091971 \\
\hline Alagbon TS & 0.984586561 & -0.088796945 & 1.073383505 \\
\hline Egbin Bus & 0.984586561 & -0.087078294 & 1.071664855 \\
\hline Lekki TS & 0.984586561 & -0.088796945 & 1.073383505 \\
\hline Olorunsogo GS Pri & -3.281955203 & -0.072183323 & -3.20977188 \\
\hline Omotosho NIPP / Sec & 3.183496546 & 1.071292171 & 2.112204376 \\
\hline Omotosho NIPP Phase Pri & 3.183496546 & 1.071292171 & 2.112204376 \\
\hline Osogbo TS & -19.36353569 & -0.673138129 & -18.69039757 \\
\hline
\end{tabular}

GS: Generation Station; TS: Transmission Station

Figure 4.4 simply shows the estimated Voltage in PU and the estimated angles in radian using recursive $\mathrm{N}-1$ spanning method for selection of the best suitable location that will give a total observability using PMU at the stipulated position within the network; without leaving any bus un-observed. 


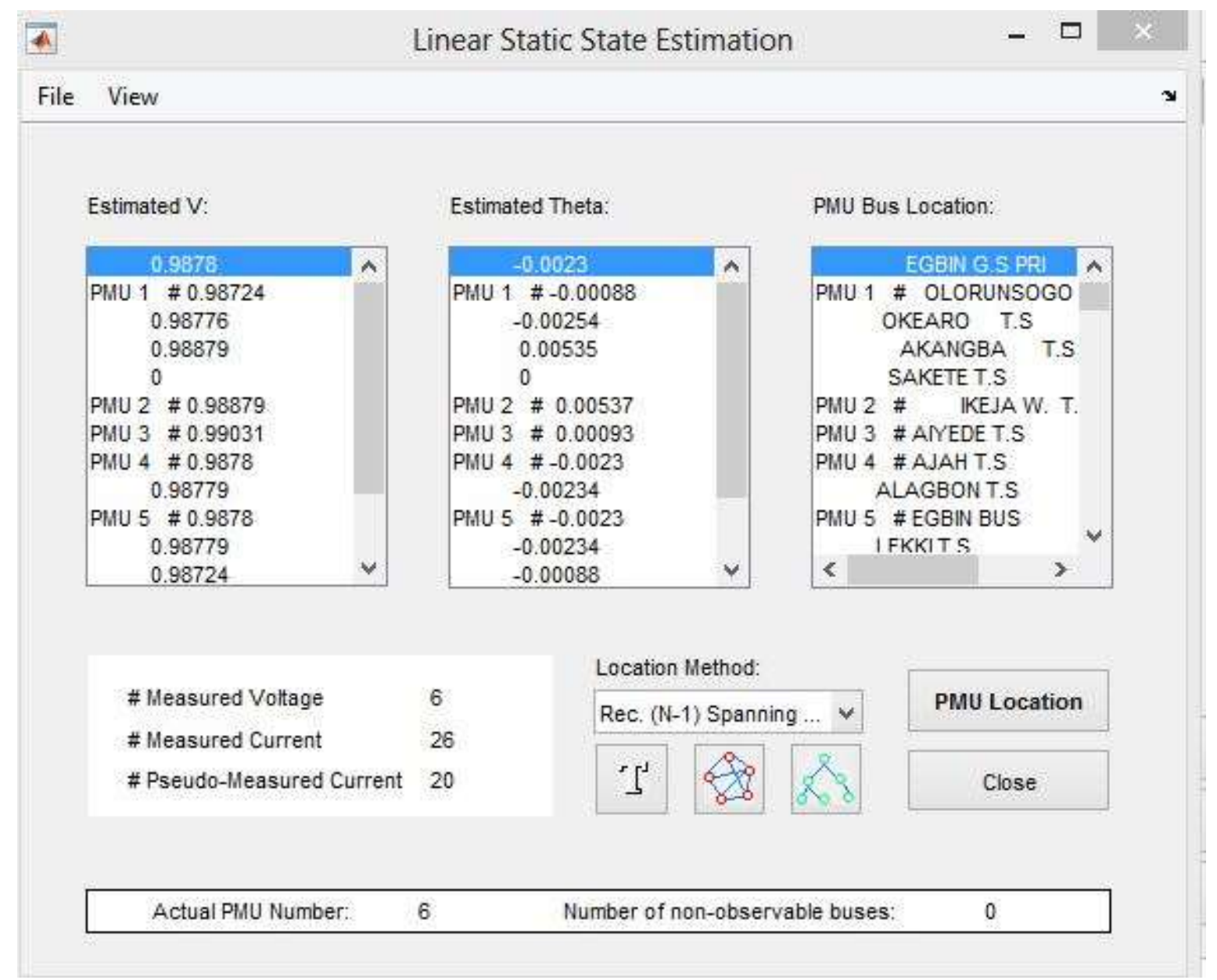

Figure 4.4. PMU reading for Sakete-Ikeja Outage line

This figure represent when the system is in an unstable state and the values gotten from the simulation; i.e., when Sakete-Ikeja line is taking out of the system before running simulation on PSAT. 
Table 4.3. Change in Angle reading for Sakete-Ikeja

\begin{tabular}{|c|c|c|c|}
\hline Bus & Pre-Outage & Post-Outage & $\boldsymbol{\Delta} \boldsymbol{\theta}$ in Degree \\
\hline Egbin GS Pri & 0.984586561 & -0.163271801 & 1.147858362 \\
\hline Olorunsogo Sec & -3.281955203 & 0.022342457 & -3.30429766 \\
\hline Okearo TS & 0.918947457 & -0.178166773 & 1.097114229 \\
\hline Akangba TS & 3.019398786 & 0.323679185 & 2.695719601 \\
\hline Sakete TS & 3.052218338 & -0.413049013 & 3.465267352 \\
\hline Ikeja West TS & 3.052218338 & 0.324252069 & 2.72796627 \\
\hline Aiyede TS & -16.18003915 & 0.409038829 & -16.58907798 \\
\hline Ajah TS & 0.984586561 & -0.162698918 & 1.147285479 \\
\hline Alagbon TS & 0.984586561 & -0.164990452 & 1.149577013 \\
\hline Egbin Bus & 0.984586561 & -0.163271801 & 1.147858362 \\
\hline Lekki TS & 0.984586561 & -0.164990452 & 1.149577013 \\
\hline Olorunsogo GS Pri & -3.281955203 & 0.022342457 & -3.30429766 \\
\hline Omotosho NIPP / Sec & 3.183496546 & 0.889115213 & 2.294381333 \\
\hline Omotosho NIPP Phase Pri & 3.183496546 & 0.889115213 & 2.294381333 \\
\hline Osogbo TS & -19.36353569 & 0.409038829 & -19.77257452 \\
\hline
\end{tabular}

GS: Generation Station; TS: Transmission Station

Table 4.3 represents the various angles at each bus and their changes in degree. Table 4.4 presents the summary of the results gotten from PSAT/MATLAB simulation considering five numbers of line outages which shows abrupt change in angles. Appendix F represents Matlab script used in achieving the results. Enorm represent the normalised echeleon reduce ranking form of change in impedance value, while Theta represent the normalised angles in degrees. Figures 4.5 to 4.7 show the graphical representation of results for effective line outage detection in south west region of Nigeria $330 \mathrm{kV}$ transmission lines. Appendixes $\mathrm{G}$ and $\mathrm{H}$ show the load flow result and signal profiles when the system was stable while Appendix I shows the graphical representation of the network considered for optimal placement of PMU. 
Table 4.4. MALTAB Simulation Result

\begin{tabular}{|c|c|c|c|c|c|c|c|c|c|c|c|}
\hline \multicolumn{12}{|l|}{ Ikeja-Osogbo } \\
\hline Echeleon Normalised & 0.0746 & 0.0562 & 0.1522 & 0.1522 & 0.1522 & 0.7515 & 0.0424 & 0.0424 & 0.0424 & 0.0827 & 0.6051 \\
\hline Theta & 0.1251 & 0.035 & 0.1151 & 0.1164 & 0.1164 & 0.6169 & 0.0375 & 0.0375 & 0.0375 & 0.1214 & 0.737 \\
\hline \multicolumn{12}{|l|}{ Olorunsogo-Ayede } \\
\hline Echeleon Normalised & 0.0445 & 0.4297 & 0.0445 & 0.0445 & 0.0445 & 0.0445 & 0.695 & 0.0445 & 0.0445 & 0.0445 & 0.4297 \\
\hline Theta & 0.0366 & 0.128 & 0.0347 & 0.0933 & 0.1222 & 0.0945 & $0 . \overline{6} 211$ & 0.0365 & 0.0366 & 0.0366 & 0.128 \\
\hline Echeleon Normalised & 0.0558 & 0.0399 & 0.1079 & 0.7579 & 0.1079 & 0.5689 & 0.0301 & 0.0301 & 0.0301 & 0.0587 & 0.2603 \\
\hline Theta & 0.0367 & 0.0394 & 0.1659 & 0.854 & 0.1659 & 0.1741 & 0.0326 & 0.0326 & 0.0326 & 0.3671 & 0.2108 \\
\hline
\end{tabular}




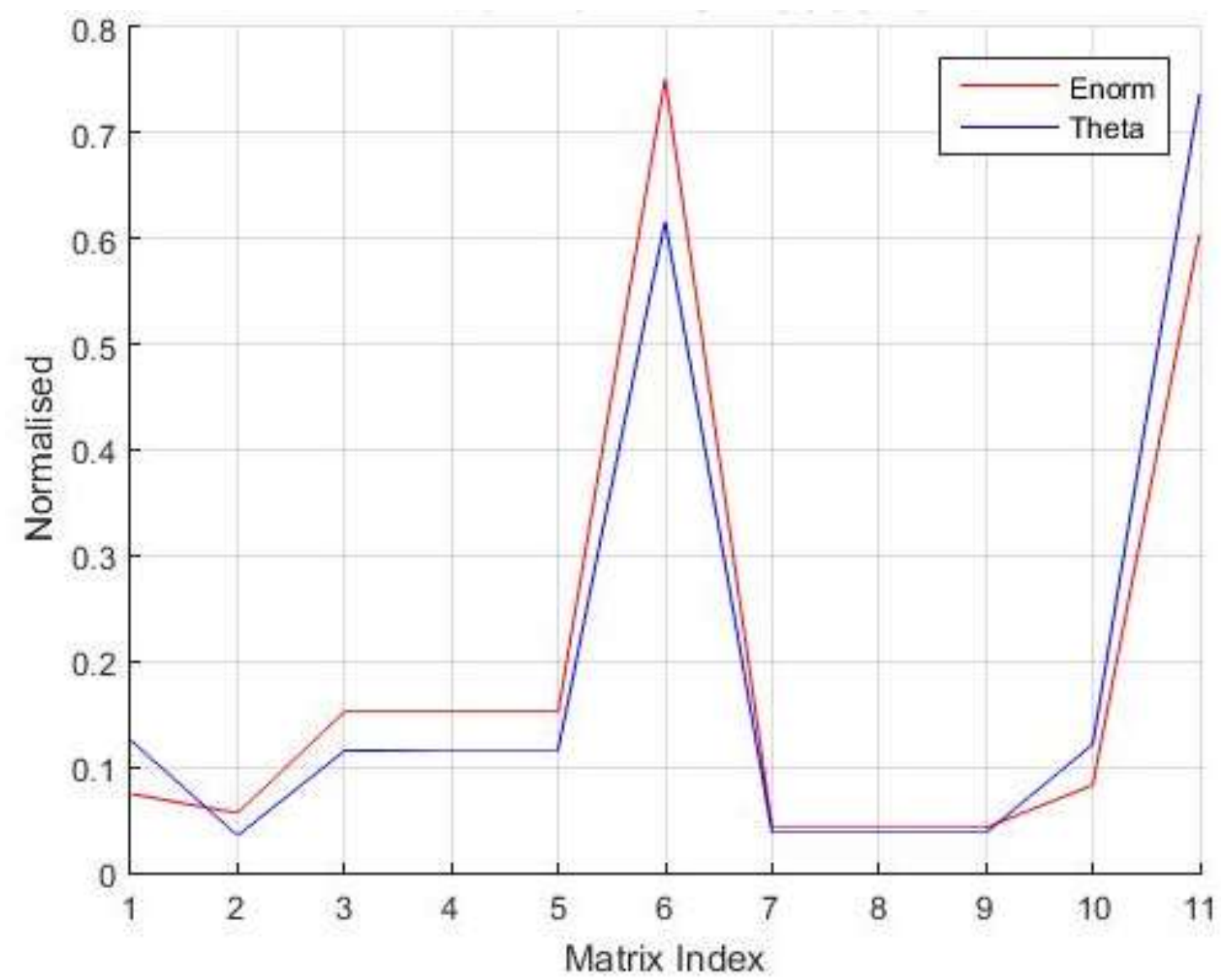

Figure 4.5. Plot of E-Normalised (Change in Impedance) and Normalised Theta (change in angle) against Matrix index representing Ikeja West - Osogbo line

\subsection{Discussion}

Based on the plot of various lines outages considered for this study, the blue graph gotten from the online analysis almost matches closely with the echeleon normalised red graph (i.e., off line analysis), which shows the effective line outage detection when PMU is placed at various buses within the south west region.

Figure 4.5 represents the modelled line outage for Ikeja-Osogbo. The red line almost matches closely with the blue lines. At buses 7, 8, and 9 the line experience the closes match. This signifies that PMU has the ability to identify the change in line flows or bus voltage angles when there is a disturbance or contingencies in the system. 


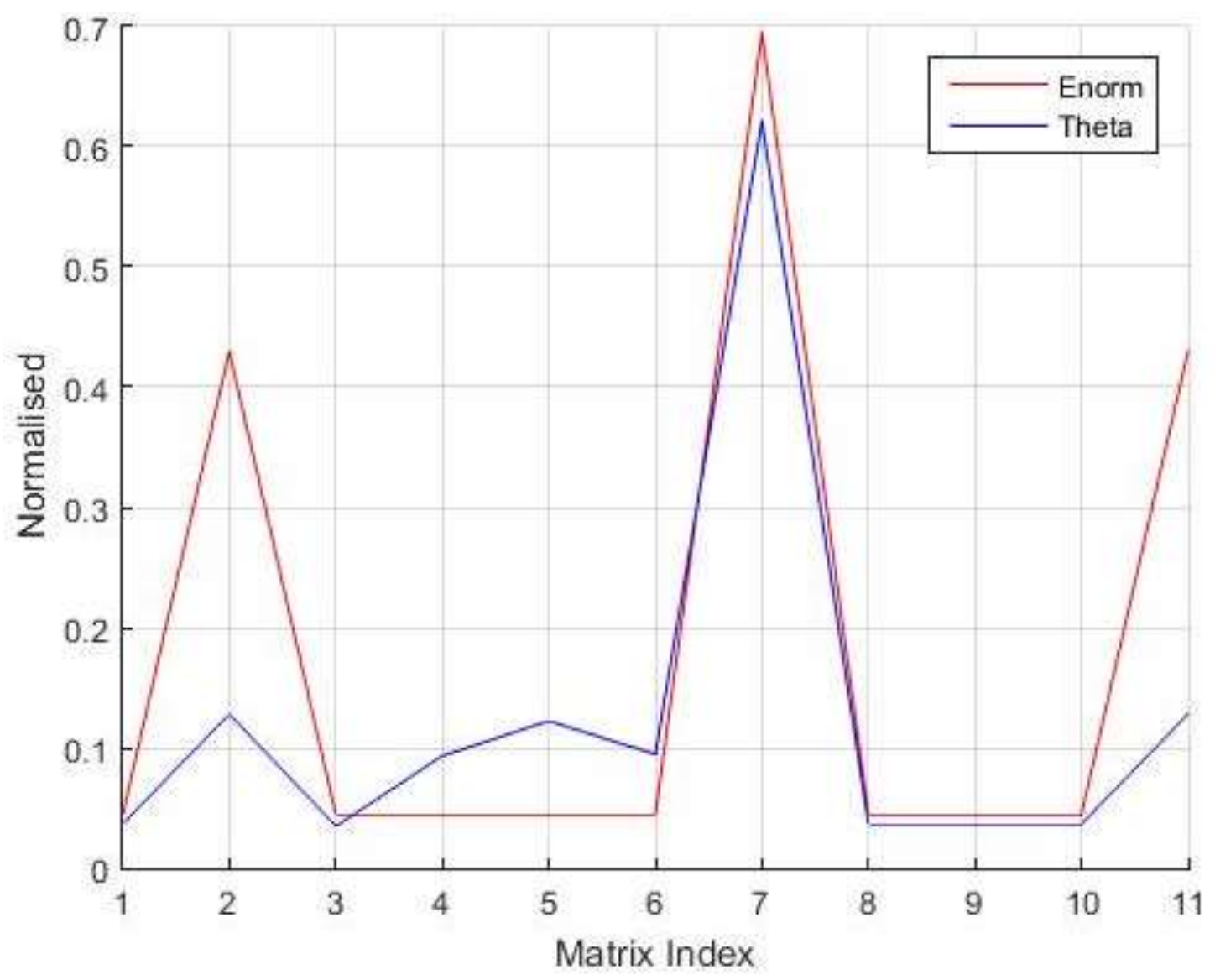

Figure 4.6. Plot of E-Normalised (Change in Impedance) and Normalised Theta (change in angle) against Matrix index representing AyedeOlorunsogo line

Figure 4.6 represent the modelled line outage for Ayede to Olorunsogo. The red line also follows the same pattern with the blue line and has the greatest match at bus $1,8,9$ and 10 .

Figure 4.7 representing Ikeja to Sakete line has a close match at bus 2, 7, 8, and 9. From analysis the various lines that were on outage can be observed by more than one bus having PMU, this also proved that there is a complete observabilty when a line is on outage. Other lines like Akangba to Ikeja been a double circuit did not converge due to zero change in angle. 


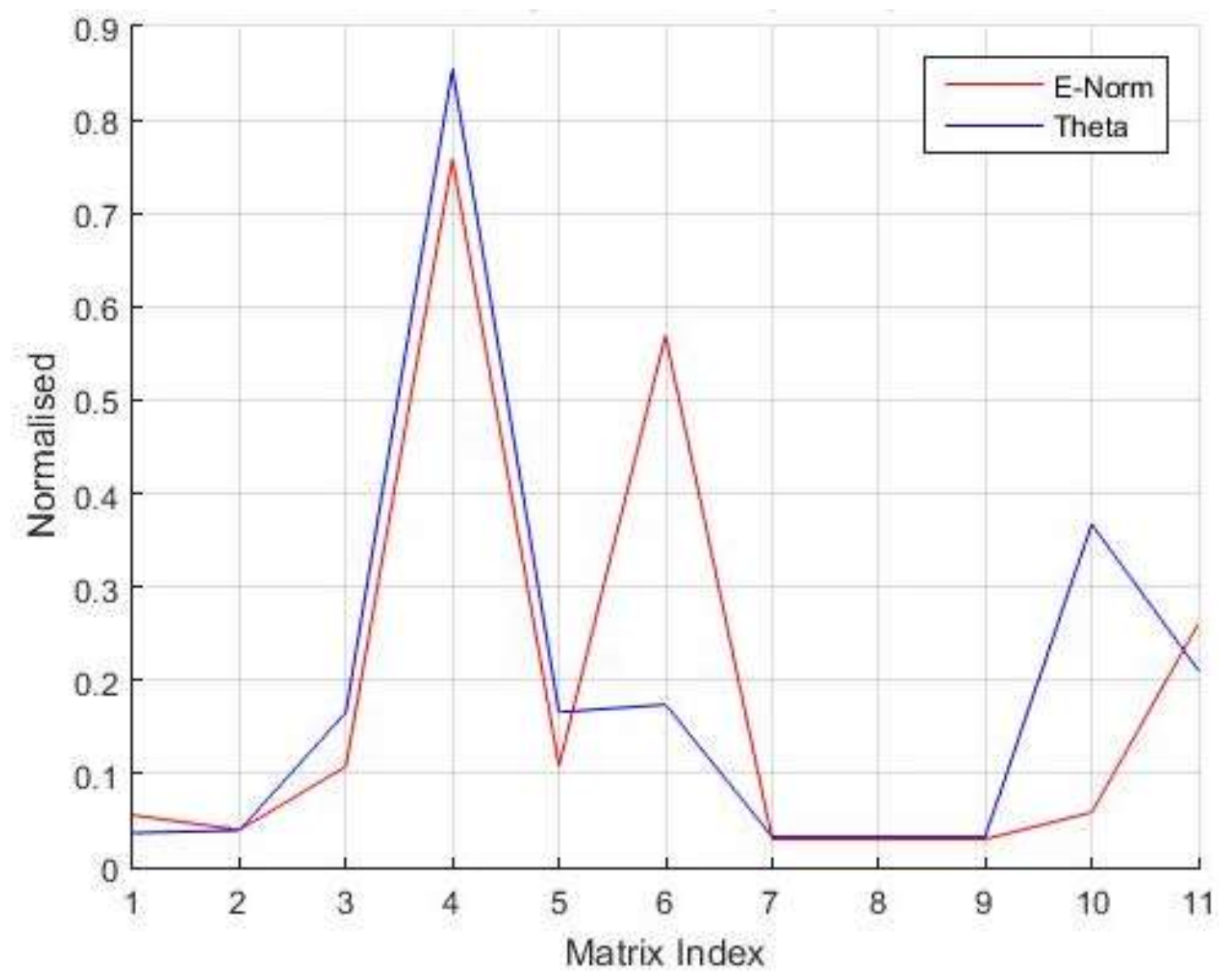

Figure 4.7. Plot of E-Normalised (Change in Impedance) and Normalised Theta (change in angle) against Matrix index representing Sakete-Ikeja West line

The theta-norm is simply the normalised vector of change in bus voltage angles obtained from PMUs installed in the system and e-norm is the normalised vector of change in impedance matrix. The X-axis of the graph represents the normalised values of vectors corresponding to offline and online analysis and $\mathrm{Y}$-axis represents the index value of these vectors 


\section{CHAPTER FIVE \\ CONCLUSION AND RECOMMENDATIONS}

\subsection{Conclusion}

This thesis discusses the analysis of single line outages using PMU data's considering south west region of Nigeria as a case study. With the analysis done so far it can been seen that PMU has the ability to identify single line outages when introduced in our National Grid. Figures 4.5, 4.6 and 4.7 represent the various line outage model; the red lines almost lapped with the blue lines in the entire sample carried out. They all followed repeated pattern i.e., the red and the blue line for their respective model. This clearly shows that PMU has the ability to identify the change in line flows or bus voltage angles when there is a disturbance or contingencies in the system. This work has also presented the important role of PMU in line outage detection compared to other existing systems such like SCADA which does not provide complete situational awareness such as detection of line outage. But with deployment of PMUs in the system, even with incomplete observability, applications using PMU data can be created to detect the line outage.

In order to identify a line outage correctly, a simulation of loading and generation condition must have already been simulated to correlate the line outage with peculiar changes i.e. difference in bus voltage angle and change in impedance matrix. The methodology discussed did not consider transmission line power flow due to the complexity involved in calculation but requires only the bus voltage angle and system topology for single line outage detection.

To this end, it can be said that the objectives and aim of this study have been achieved. For a better, improved reliability and efficiency, introducing PMU into the national grid will reduce the number of outages to minimal and mean time to failure, because with the known.

\subsection{Recommendations}

Based on the deductions from the analysis of data collected from TCN, Osogbo over the period of this study, the following recommendations are made.

(a) The present data recording system should be improved from manual to automated form. An improvement needs to be made in this area, because a wrong data will surely give a deviation from the expected result. 
(b) More research work needs to be done in this area, because it seems (Nigerian's) are lagging behind from the numbers of literature reviewed on in this study.

\subsection{Further Studies}

As it is well known in many research works especially a new area such as this that every aspect cannot be fully covered, there are still more that can be done hence the future work could include:

(a) multiple lines outages on Nigeria $330 \mathrm{kV}$ lines and also on our Distribution Network which are very prone to unplanned outages;

(b) modernising Nigerian Transmission Grid using PMU; and

(c) two or more sophisticated software such as MATPOWER and POWER WORLD should be used to compare and verify results from the lead software in the near future.

\subsection{Conflict of Interests}

The author declares that there is no conflict of interests regarding the publication of this paper. 


\section{REFERENCES}

Abdelaziz, A. Y., Ibrahim, A. M., \& Hasan, Z. G. (2013). Phasor measurement units for out-of step detection of a multi-machine system using system reduction. Journal of Science and Engineering, 1(2): 121-132.

Abdelaziz, A. Y., Mekhamer, S. F., Ezzat, M., \& El-Saadany, E. F. (2011). Fault location techniques for transmission lines using phasor measurement Units: A new contribution. 2011 Power Engineering Society IEEE General Meeting, Detroit, Michigan, USA.

Abood, H. G., \& Sreeram, V. (2014). A review on phasor measurement units placement for state estimation studies. In 2014 Australasian Universities Power Engineering Conference, Proceedings of IEEE, Institute of Electrical and Electronics Engineers: 1 6. https://doi.org/10.1109/AUPEC.2014.6966493

Ali, A. K., El-Amary, N. H., Ibrahim, A. M., \& Mekhamer, S. F. (2014). Intelligent voltage instability detector based on phasor measurement units. International Journal of Scientific \& Engineering Research, 5(4): 1302-1307.

Anil Kumar, C., \& Lakshmi, K. (2014). Monitoring and detection of fault using phasor measurement units. International Journal of Electrical, Electronics and Mechanical Controls, 3(2): 1-10.

Arabali, A., Majidi, M., Fadali, M. S., \& Etezadi-Amoli, M. (2016). Line outage identificationbased state estimation in a power system with multiple line outages. Electric Power System Research, 133, 79-86. https://doi.org/10.1016/j.epsr.2015.12.013

Awais, M., Ahmed, A., Naeem, M., Iqbal, M., Qadri, N., \& Anpalagan, A. (2016). Multiple line outages identification: A customized quantum inspired approach. Electric Power System Research, 134, 47-55. https://doi.org/10.1016/j.epsr.2015.12.001

Bilik, P., Horinek, M., Martinek, R., \& Vanus, J. (2015). Results of multiple PMU testing procedures, $1-4 . \quad$ Retrieved on $30^{\text {th }}$ June, 2016 from https://www.researchgate.net/profile/Radek_Martinek2/publication/283877667_Resu Its_of_Multiple_Phasor_Measurement_Units_Testing_Procedures/links/56d4014e08ae 059e37622343/Results-of-Multiple-Phasor-Measurement-Units-TestingProcedures.pdf

Bindeshwar, S., Sharma, N. K., Tiwari, A. N., Verma, K. S., \& Singh, S. N. (2011). Applications of phasor measurement units in electrical power system incorporated with FACTS controllers. International Journal of Engineering, Science and Technology, 3(3): 64-82.

Chakrapani, M., \& Dushmanta, K. M. (2015). Modelling of phasor measurement unit and phasor data realisation with 2 bus system. International Journal of Engineering Science and Advance Research, 1(2): 3-8.

Darvishi, A., \& Dobson, I. (2015). Area angle can monitor cascading outages with synchrophasors. IEEE Power \& Energy Society Innovative Smart Grid Technologies Conference, 18-20 February, Washington, DC, USA. https://doi.org/10.1109/ISGT.2015.7131778 
Dotta, D., Chow, J. H., \& Bertagnolli, B. (2014). A teaching tool for phasor measurement estimation. 2015 IEEE Power \& Energy Society General Meeting, 26-30 July, Denver, CO, USA. https://doi.org/10.1109/PESGM.2015.7285853

Ganga, R. T., Sridhar, S., \& Varun, K. V. (2012). Optimal placement of phasor measurement units for state estimation using artificial intelligence techniques. International Journal of Scientific \& Engineering Research, 3(2): 1-5.

Garcia, M., Catanach, T., Wiel S. V., Bent, R., \& Lawrence, E. (2016). Line outage localization using phasor measurement data in transient state. IEEE Transactions on Power Systems, 31(4): 3019 - 3027. https://doi.org/10.1109/TPWRS.2015.2461461

Global Energy Network Institute (2016). Map of Nigerian electricity grid. Retrieved from https://www.geni.org/globalenergy/library/national_energy_grid/nigeria/nigeriannati onalelectricitygrid.shtml on $30^{\text {th }}$ June, 2016.

Goklani, H. H., Chauhan, N. A., \& Prajapati, M. B. (2014). Optimal placement of phasor measurement unit in smartgrid. International Conference on Advance Trends in Engineering and Technology, Jaipur, Rajsthan https://doi.org/10.13140/2.1.5000.3207

Gunjker, R. R., Wadkar, V. S., \& Uddin, M. (2015). Analysis of fault location for transmission lines. International Journal of Scientific \& Engineering Research, 6(3): 1315-1324.

Huang, Z., Kasztenny, B., Madani, V., Martin, K., Meliopoulos, S., Novosel, D., \& Stenbakken, J., (2008). Performance evaluation of phasor measurement systems. IEEE Power Engineering Society General Meeting, Pittsburgh, PA.

Kesherwani, S., Singh, S. P., \& Singh, S. P. (2012). Voltage stability assessment using phasor measurement units in power network with full system observability. 2nd International Conference on Power, Control and Embedded Systems, 17-19 December, Allahabad, India. https://doi.org/10.1109/ICPCES.2012.6508139

Kumar, D., Ghosh, D., \& Mohanta, D. K. (2015). Simulation of phasor measurement unit in MATLAB. International Conference on Signal Processing and Communication Engineering Systems, 2-3 January, Guntur, India: 15-18. https://doi.org/10.1109/SPACES.2015.7058244

Kumar, J., Rai, J. N., Vipin, \&Sharma, K. (2013). Power system state estimation by use of WLS with phasor measurement unit. International Journal of Engineering Research \& Technology, 2(2): 1 - 7.

Liang, H., Zidong, W., Izaz, R., \& Xiaohui, L. (2016). A constrained optimization approach to dynamic state estimation for power systems including PMU and missing measurements. IEEE Transactions on Control Systems Technology, 24(2): 703 - 710. https://doi.org/10.1109/TCST.2015.2445852

Liang, Z., \& Wen-Zhan, S. (2014). Distributed power-line outage detection based on wide area measurement system. Sensors, 14(7): 13114 - 13133. https://doi.org/10.3390/s140713114 
Mahoney, N. J. (2011). Improved Line Outage Detection Using Synchro-phasor Measurements. M.Sc. thesis, Department of Electrical Engineering, Clemso University, South Carolina. https://tigerprints.clemson.edu/all_theses/1142

Martin, K. E., Faris, A. J., \& Hauer, J. F. (2006). Standardized testing of phasor measurement units. Proceedings of the 9th Annual Georgia Tech Fault and Disturbance Analysis Conference, 1-2 May, Atlanta, Georgia: 1-19.

Marwa, A. A., \& Noha, H. E. (2013). Voltage instability prediction using artificial immunity system. International Journal of Scientific \& Engineering Research, 4(11): 559-563.

Mauryan, K. S., \& Ramkumar, V. (2014). Phasor measurement units in power system networks- a review. International Journal of Advanced Information and Communication Technology, 1(1): 120-125.

Mekhamer, S. F., Abdelaziz, A.Y., \& Ezzat, M. (2012). Detection of line outage in transmission networks using phasor measurement units aided by support vector machine algorithms. Proceedings of the $15^{\text {th }}$ International Middle East Power Systems Conference, 23 - 25 December, Alexandria University, Egypt: 1-10.

Mousavian, S., \& Feizollahi, M. (2015). An investment decision model for the optimal allocation of phasor measurement units. Expert Systems with Applications, 42(21): 7276-7284. https://doi.org/10.1016/j.eswa.2015.05.041

Nafeena, R., \& Seralathan, C. M. (2014). A heuristric based artificial bee colony algorithm for Optimum placement of PMU for complete observability of power system. International Journal of Scientific \& Engineering Research, 5(3): 112-117.

Obiaya, A. (2013). Conquering the power monster: how the deal was done. Journal of the Bureau of Public Enterprises, 44

Oduntan, B., Ariyo, F., Akintade, S. (2016). Optimal placement of phasor measurement unit on electrical grid using a hybrid technique. American Scientific Research Journal for Engineering, Technology, and Science, 1(1): 112-121

Ogbuefi, U. C., \& Madueme, T. C. (2015). A power flow analysis of the Nigerian 330kV electric power system. IOSR Journal of Electrical and Electronics Engineering, 10(1): $44-57$.

Omorogiuwa, E., \& Ogujor, E. A. (2012). Determination of bus voltages, power losses and flows in the Nigeria $330 \mathrm{kV}$ integrated power system. International Journal of Advances in Engineering \& Technology, 4(1): 94-106.

Oshevire, P., Oladimeji, T., \& Onohaebi, S. (2013). Smart grid technology and its possible applications to the Nigeria $330 \mathrm{kV}$ power system. Smart Grid and Renewable Energy, 4(5): 391-397. https://doi.org/10.4236/sgre.2013.45045

Pereira, R. A. F., da Silva, L. G. W., Kezunovic, M., \& Mantovani, J. R. S. (2006). Location of single-line-to-ground faults on distribution feeders using voltage measurements. Presented at the Latin America Transmission and Distribution Conference Exposition, 15-18 August, Caracas, Venezuela.

Pinte, B., Quinlan, M., Yoon, A., Reinhard, K., \& Sauer, P. W. (2014). A one-phase, distribution-level phasor measurement unit for post-event analysis. Paper presented at 2014 IEEE Power and Energy Conference at Illinois, 28 February - 1 March, Champaign, IL, United States. https://doi.org/10.1109/PECI.2014.6804575

$$
\text { IS N : } 2636-607 X \quad 53 \text { | Pag e }
$$


Rabiee, S., Ayoubzadeh, H., Farrokhzad, D., \& Aminifar, F. (2013). Practical aspects of phasor measurement unit installation in power grids, Smart Grid Conference, $17-18$ December, Tehran, Iran: 20-25.

Sarri, S., Zanni, L., Popovic, M., Boudec, J. L., \& Paolone, M. (2016). Performance assessment of linear state estimators using synchrophasor measurements. IEEE Transactions on Instrumentation and Measurement, 65, 535-548.

Satyendra, P. S., \& Singh, S. P. (2014). Optimal pmu placement in power system considering the measurement redundancy. Advance in Electronic and Electric Engineering, 4(6): 593-598.

Schwill, H. \& Dobsan, I. (2012). Locating line outage in a specific area of a power system with synchrophasors. North American Power Symposium, University of Illinois UrbanaChampaign: 1-6

Srikumar, M. S., Ananthapadmanbha, T., Faraz Zafar Khan, Girish, V. (2015). Line outage detection using phasor measurement units. Procedia Technology, 21, 88 - 95. https://doi.org/10.1016/j.protcy.2015.10.014

Tate, J. E., \& Overbye, T. J. (2007). Line outage detection using phasor angle measurements. IEEE Transactions on Power Systems, 23(4): 1644 - 1652. https://doi.org/10.1109/TPWRS.2008.2004826

Theodorakatos, N. P., Manousakis, N. M., \& Korres, G. N. (2014). Optimal pmu placement using nonlinear programming. An International Conference on Engineering and Applied Sciences Optimization, 4-6 June, Kos Island, Greece: 240 - 258.

Vignesh, V., Chakrabarti, S., \& Srivastava, S. C. (2015). Power system load modelling under large and small disturbances using phasor measurement units data. IET Generation, Transmission \& Distribution, 9(12): 1316-1323.

Wen-Tai, L., Chao-Kai, W., Jung-Chieh, C., Kai-Kit, W., \& Jen-Hao, T. Y. (2015). Location identification of power line outages using pmu measurements with bad data. IEEE Transactions on Power Systems, 31(5): $3624 \quad$ - 3635. https://doi.org/10.1109/TPWRS.2015.2495214

Zhou, M., Centeno, V. A., Thorp, J. S., \& Phadke, A. G. (2006). An alternative for including phasor measurements in state estimators. IEEE Transactions on Power Systems, 21(4): 1930 - 1937. https://doi.org/10.1109/TPWRS.2006.881112 


\section{APPENDIX}

Appendix A. A Typical Generator Data as Collected `

\begin{tabular}{|c|c|c|c|c|c|}
\hline Station & Nomenclature & Type & $\begin{array}{l}\text { Rating } \\
\text { (MVA) }\end{array}$ & $\begin{array}{c}\text { Terminal Voltage } \\
(\mathrm{kV})\end{array}$ & $\begin{array}{l}\text { Rated PF } \\
\text { (PU) }\end{array}$ \\
\hline \multirow{3}{*}{ Okpai } & GT1 & Gas & 210 & $15.75+/-5 \%$ & 0.85 \\
\hline & GT2 & Gas & 210 & $15.75+/-5 \%$ & 0.85 \\
\hline & ST1 & Steam & 210 & $15.75+/-5 \%$ & 0.85 \\
\hline \multirow{2}{*}{ Delta I } & GT1 & Gas & 45 & & \\
\hline & GT2 & Gas & 45 & & \\
\hline \multirow{6}{*}{ Delta II } & GT3 & Gas & 29.725 & $11.5+/-5 \%$ & 0.8 \\
\hline & GT4 & Gas & 29.725 & $11.5+/-5 \%$ & 0.8 \\
\hline & GT5 & Gas & 29.725 & $11.5+/-5 \%$ & 0.8 \\
\hline & GT6 & Gas & 29.725 & $11.5+/-5 \%$ & 0.8 \\
\hline & GT7 & Gas & 29.725 & $11.5+/-5 \%$ & 0.8 \\
\hline & GT78 & Gas & 29.725 & $11.5+/-5 \%$ & 0.8 \\
\hline \multirow{6}{*}{ Delta III } & GT9 & Gas & 29.725 & $11.5+/-5 \%$ & 0.8 \\
\hline & GT10 & Gas & 29.725 & $11.5+/-5 \%$ & 0.8 \\
\hline & GT11 & Gas & 29.725 & $11.5+/-5 \%$ & 0.8 \\
\hline & GT12 & Gas & 29.725 & $11.5+/-5 \%$ & 0.8 \\
\hline & GT13 & Gas & 29.725 & $11.5+/-5 \%$ & 0.8 \\
\hline & GT14 & Gas & 29.725 & $11.5+/-5 \%$ & 0.8 \\
\hline \multirow{6}{*}{ Delta IV } & GT15 & Gas & 133.75 & $11.5+/-5 \%$ & 0.85 \\
\hline & GT16 & Gas & 133.75 & $11.5+/-5 \%$ & 0.85 \\
\hline & GT17 & Gas & 133.75 & $11.5+/-5 \%$ & 0.85 \\
\hline & GT18 & Gas & 133.75 & $11.5+/-5 \%$ & 0.85 \\
\hline & GT19 & Gas & 133.75 & $11.5+/-5 \%$ & 0.85 \\
\hline & GT20 & Gas & 133.75 & $11.5+/-5 \%$ & 0.85 \\
\hline \multirow{10}{*}{ Sapele } & ST1 & Steam & 133.97 & $15.75+/-5 \%$ & 0.9 \\
\hline & ST2 & Steam & 133.97 & $15.75+/-5 \%$ & 0.9 \\
\hline & ST3 & Steam & 133.97 & $15.75+/-5 \%$ & 0.9 \\
\hline & ST4 & Steam & 133.97 & $15.75+/-5 \%$ & 0.9 \\
\hline & ST5 & Steam & 133.97 & $15.75+/-5 \%$ & 0.9 \\
\hline & ST6 & Steam & 133.97 & $15.75+/-5 \%$ & 0.9 \\
\hline & GT1 & Gas & 110 & $10.5+/-7.5 \%$ & 0.8 \\
\hline & GT2 & Gas & 110 & $10.5+/-7.5 \%$ & 0.8 \\
\hline & GT3 & Gas & 110 & $10.5+/-7.5 \%$ & 0.8 \\
\hline & GT4 & Gas & 110 & $10.5+/-7.5 \%$ & 0.8 \\
\hline \multirow{6}{*}{ Egbin } & ST1 & Steam & 245.8 & 16 & 0.9 \\
\hline & ST2 & Steam & 245.8 & 16 & 0.9 \\
\hline & ST3 & Steam & 245.8 & 16 & 0.9 \\
\hline & ST4 & Steam & 245.8 & 16 & 0.9 \\
\hline & ST5 & Steam & 245.8 & 16 & 0.9 \\
\hline & ST6 & Steam & 245.8 & 16 & 0.9 \\
\hline
\end{tabular}


Appendix A. A Typical Generator Data as Collected (Continuation)

\begin{tabular}{|c|c|c|c|c|c|}
\hline Station & Nomenclature & Type & $\begin{array}{l}\text { Rating } \\
\text { (MVA) }\end{array}$ & $\begin{array}{c}\text { Terminal Voltage } \\
\text { (kV) }\end{array}$ & $\begin{array}{l}\text { Rated PF } \\
\text { (PU) }\end{array}$ \\
\hline \multirow{9}{*}{ Aes } & GT 1 & Gas & 38.6 & 10.5 & 0.8 \\
\hline & GT 2 & Gas & 38.6 & 10.5 & 0.8 \\
\hline & GT 3 & Gas & 38.6 & 10.5 & 0.8 \\
\hline & GT 4 & Gas & 39.54 & 10.5 & 0.8 \\
\hline & GT 5 & Gas & 39.54 & 10.5 & 0.8 \\
\hline & GT 6 & Gas & 39.54 & 10.5 & 0.8 \\
\hline & GT 7 & Gas & 40.5 & 10.5 & 0.9 \\
\hline & GT 8 & Gas & 40.5 & 10.5 & 0.9 \\
\hline & GT 9 & Gas & 40.5 & 10.5 & 0.9 \\
\hline \multirow{6}{*}{ Jebba } & $2 \mathrm{G} 1$ & Hydro & 119 & 16 & 0.85 \\
\hline & $2 \mathrm{G} 2$ & Hydro & 119 & 16 & 0.85 \\
\hline & $2 \mathrm{G3}$ & Hydro & 119 & 16 & 0.85 \\
\hline & $2 \mathrm{G} 4$ & Hydro & 119 & 16 & 0.85 \\
\hline & $2 \mathrm{G} 5$ & Hydro & 119 & 16 & 0.85 \\
\hline & $2 \mathrm{G} 6$ & Hydro & 119 & 16 & 0.85 \\
\hline \multirow{8}{*}{ Kainji } & $1 \mathrm{G5}$ & Hydro & 126 & 16 & 0.95 \\
\hline & $1 \mathrm{G} 6$ & Hydro & 126 & 16 & 0.95 \\
\hline & $1 \mathrm{G7}$ & Hydro & 85 & 16 & 0.95 \\
\hline & $1 \mathrm{G} 8$ & Hydro & 85 & 16 & 0.95 \\
\hline & $1 \mathrm{G9}$ & Hydro & 85 & 16 & 0.95 \\
\hline & $1 \mathrm{G} 10$ & Hydro & 85 & 16 & 0.95 \\
\hline & $1 \mathrm{G} 11$ & Hydro & 115 & 16 & 0.95 \\
\hline & $1 \mathrm{G} 12$ & Hydro & 115 & 16 & 0.95 \\
\hline \multirow{4}{*}{ Shiroro } & UNIT1 & Hydro & 176.5 & 15.65 & 0.85 \\
\hline & UNIT2 & Hydro & 176.5 & 15.65 & 0.85 \\
\hline & UNIT3 & Hydro & 176.5 & 15.65 & 0.85 \\
\hline & UNIT4 & Hydro & 176.5 & 15.65 & 0.85 \\
\hline \multirow{4}{*}{ Afam I } & GT1 & Gas & 16 & $10.5 \pm 7.5$ & 0.8 \\
\hline & GT2 & Gas & 16 & $10.5 \pm 7.5$ & 0.8 \\
\hline & GT3 & Gas & 25 & $10.5 \pm 7.5$ & 0.8 \\
\hline & GT4 & Gas & 25 & $10.5 \pm 7.5$ & 0.8 \\
\hline \multirow{4}{*}{ Afam II } & GT5 & Gas & 30 & $10.5 \pm 7.5$ & 0.8 \\
\hline & GT6 & Gas & 30 & $10.5 \pm 7.5$ & 0.8 \\
\hline & GT7 & Gas & 30 & $10.5 \pm 7.5$ & 0.8 \\
\hline & GT8 & Gas & 30 & $10.5 \pm 7.5$ & 0.8 \\
\hline \multirow{4}{*}{ Afam III } & GT9 & Gas & 34 & $10.5 \pm 7.5$ & 0.8 \\
\hline & GT10 & Gas & 34 & $10.5 \pm 7.5$ & 0.8 \\
\hline & GT11 & Gas & 34 & $10.5 \pm 7.5$ & 0.8 \\
\hline & GT12 & Gas & 34 & $10.5 \pm 7.5$ & 0.8 \\
\hline
\end{tabular}


Appendix A. A Typical Generator Data as Collected (Continuation)

\begin{tabular}{|c|c|c|c|c|c|}
\hline Station & Nomenclature & Type & $\begin{array}{l}\text { Rating } \\
\text { (MVA) }\end{array}$ & $\begin{array}{c}\text { Terminal Voltage } \\
(\mathrm{kV})\end{array}$ & $\begin{array}{l}\text { Rated PF } \\
\text { (PU) }\end{array}$ \\
\hline \multirow{6}{*}{ Afam IV } & GT13 & Gas & 110 & $10.5 \pm 7.5$ & 0.8 \\
\hline & GT14 & Gas & 110 & $10.5 \pm 7.5$ & 0.8 \\
\hline & GT15 & Gas & 110 & $11.5 \pm 5$ & 0.8 \\
\hline & GT16 & Gas & 110 & $11.5 \pm 5$ & 0.8 \\
\hline & GT17 & Gas & 110 & $11.5 \pm 5$ & 0.8 \\
\hline & GT18 & Gas & 110 & $11.5 \pm 5$ & 0.8 \\
\hline \multirow{2}{*}{ Afam V } & GT19 & Gas & 162.69 & $15.75 \pm 5$ & 0.85 \\
\hline & GT20 & Gas & 162.69 & $15.75 \pm 5$ & 0.85 \\
\hline \multirow{8}{*}{ Papalanto } & GT1 & Gas & 48 & 10.5 & 0.8 \\
\hline & GT2 & Gas & 48 & 10.5 & 0.8 \\
\hline & GT3 & Gas & 48 & 10.5 & 0.8 \\
\hline & GT4 & Gas & 48 & 10.5 & 0.8 \\
\hline & GT5 & Gas & 48 & 10.5 & 0.8 \\
\hline & GT6 & Gas & 48 & 10.5 & 0.8 \\
\hline & GT7 & Gas & 48 & 10.5 & 0.8 \\
\hline & GT8 & Gas & 48 & 10.5 & 0.8 \\
\hline \multirow{8}{*}{ Omotoso } & GT1 & Gas & 47.5 & $10.5+/-5 \%$ & 0.8 \\
\hline & GT2 & Gas & 47.5 & $10.5+/-5 \%$ & 0.8 \\
\hline & GT3 & Gas & 47.5 & $10.5+/-5 \%$ & 0.8 \\
\hline & GT4 & Gas & 47.5 & $10.5+/-5 \%$ & 0.8 \\
\hline & GT5 & Gas & 47.5 & $10.5+/-5 \%$ & 0.8 \\
\hline & GT6 & Gas & 47.5 & $10.5+/-5 \%$ & 0.8 \\
\hline & GT7 & Gas & 47.5 & $10.5+/-5 \%$ & 0.8 \\
\hline & GT8 & Gas & 47.5 & $10.5+/-5 \%$ & 0.8 \\
\hline \multirow{3}{*}{ Geregu } & GT1 & Gas & 174 & $15.75+/-5 \%$ & 0.85 \\
\hline & GT2 & Gas & 174 & $15.75+/-5 \%$ & 0.85 \\
\hline & GT3 & Gas & 174 & $15.75+/-5 \%$ & 0.85 \\
\hline \multirow{3}{*}{ Alaoji } & GT1 & Gas & 141.25 & 15 & 0.85 \\
\hline & GT2 & Gas & 141.25 & 15 & 0.85 \\
\hline & GT3 & Gas & 141.25 & 15 & 0.8 \\
\hline \multirow{5}{*}{ Calabar } & Unit1 & Gas & 141.25 & 15 & 0.8 \\
\hline & Unit2 & Gas & 141.25 & 15 & 0.8 \\
\hline & Unit3 & Gas & 141.25 & 15 & 0.8 \\
\hline & Unit4 & Gas & 141.25 & 15 & 0.8 \\
\hline & Unit5 & Gas & 141.25 & 15 & 0.8 \\
\hline \multirow{3}{*}{ Egbema } & Unit1 & Gas & 141.25 & 15 & 0.8 \\
\hline & Unit2 & Gas & 141.25 & 15 & 0.8 \\
\hline & Unit3 & Gas & 141.25 & 15 & 0.8 \\
\hline
\end{tabular}


Appendix A. A Typical Generator Data as Collected (Continuation)

\begin{tabular}{|c|c|c|c|c|c|}
\hline Station & Nomenclature & Type & $\begin{array}{l}\text { Rating } \\
\text { (MVA) }\end{array}$ & $\begin{array}{c}\text { Terminal Voltage } \\
(\mathrm{kV})\end{array}$ & $\begin{array}{l}\text { Rated PF } \\
\text { (PU) }\end{array}$ \\
\hline \multirow{4}{*}{ Eyaen } & Unit1 & Gas & 141.25 & 15 & 0.8 \\
\hline & Unit2 & Gas & 141.25 & 15 & 0.8 \\
\hline & Unit3 & Gas & 141.25 & 15 & 0.8 \\
\hline & Unit4 & Gas & 141.25 & 15 & 0.8 \\
\hline \multirow{2}{*}{ Gbaran } & Unit1 & Gas & 141.25 & 15 & 0.8 \\
\hline & Unit2 & Gas & 141.25 & 15 & 0.8 \\
\hline \multirow{3}{*}{ Ikot Abasi } & Unit1 & Gas & 141.25 & 15 & 0.8 \\
\hline & Unit2 & Gas & 141.25 & 15 & 0.8 \\
\hline & Unit3 & Gas & 141.25 & 15 & 0.8 \\
\hline \multirow{4}{*}{ Sapele } & Unit1 & Gas & 141.25 & 15 & 0.8 \\
\hline & Unit2 & Gas & 141.25 & 15 & 0.8 \\
\hline & Unit3 & Gas & 141.25 & 15 & 0.8 \\
\hline & Unit4 & Gas & 141.25 & 15 & 0.8 \\
\hline \multirow{2}{*}{ Omoku } & Unit1 & Gas & 141.25 & 15 & 0.8 \\
\hline & Unit2 & Gas & 141.25 & 15 & 0.8 \\
\hline \multirow{3}{*}{ Alaoji } & Gt4 & Gas & $126 \mathrm{MW}$ & 15 & 0.8 \\
\hline & St1 & Steam & $285 \mathrm{MW}$ & 17 & 0.85 \\
\hline & St2 & Steam & $285 \mathrm{MW}$ & 17 & 0.85 \\
\hline \multirow{3}{*}{ Geregu } & & & $148 \mathrm{MW}$ & & \\
\hline & & & $148 \mathrm{MW}$ & & \\
\hline & & & $148 \mathrm{MW}$ & & \\
\hline \multirow{4}{*}{ Omotoso } & & & $126 \mathrm{MW}$ & & \\
\hline & & & $126 \mathrm{MW}$ & & \\
\hline & & & $126 \mathrm{MW}$ & & \\
\hline & & & $126 \mathrm{MW}$ & & \\
\hline \multirow{4}{*}{ Papalanto } & & & $126 \mathrm{MW}$ & & \\
\hline & & & $126 \mathrm{MW}$ & & \\
\hline & & & $126 \mathrm{MW}$ & & \\
\hline & & & $126 \mathrm{MW}$ & & \\
\hline \multirow{5}{*}{ Afam Vi (Shell) } & & & $150 \mathrm{MW}$ & & \\
\hline & & & $150 \mathrm{MW}$ & & \\
\hline & & & $150 \mathrm{MW}$ & & \\
\hline & & & $150 \mathrm{MW}$ & & \\
\hline & & & $150 \mathrm{MW}$ & & \\
\hline \multirow{3}{*}{ Bonny (Mobil) } & & & $130 \mathrm{MW}$ & & \\
\hline & & & $130 \mathrm{MW}$ & & \\
\hline & & & $130 \mathrm{MW}$ & & \\
\hline \multirow{3}{*}{$\begin{array}{c}\text { Chevron- } \\
\text { Texaco }\end{array}$} & & & $250 \mathrm{MW}$ & & \\
\hline & & & $250 \mathrm{MW}$ & & \\
\hline & & & $250 \mathrm{MW}$ & & \\
\hline
\end{tabular}


Appendix A. A Typical Generator Data as Collected (Continuation)

\begin{tabular}{|c|c|c|c|c|c|}
\hline Station & Nomenclature & Type & $\begin{array}{l}\text { Rating } \\
\text { (MVA) }\end{array}$ & $\begin{array}{c}\text { Terminal Voltage } \\
(\mathrm{kV})\end{array}$ & $\begin{array}{l}\text { Rated PF } \\
\text { (PU) }\end{array}$ \\
\hline \multirow{4}{*}{$\begin{array}{l}\text { TotalFinaelf } \\
(1 \& 2)\end{array}$} & & & $125 \mathrm{MW}$ & & \\
\hline & & & $125 \mathrm{MW}$ & & \\
\hline & & & $125 \mathrm{MW}$ & & \\
\hline & & & $125 \mathrm{MW}$ & & \\
\hline Ethiope & & & $2800 \mathrm{MW}$ & & \\
\hline Farm Electric & & & $150 \mathrm{MW}$ & & \\
\hline ICS Power & & & $600 \mathrm{MW}$ & & \\
\hline Supertek & & & $1000 \mathrm{MW}$ & & \\
\hline \multirow{6}{*}{ Alscon } & & & $90 \mathrm{MW}$ & & \\
\hline & & & $90 \mathrm{MW}$ & & \\
\hline & & & $90 \mathrm{MW}$ & & \\
\hline & & & $90 \mathrm{MW}$ & & \\
\hline & & & $90 \mathrm{MW}$ & & \\
\hline & & & $90 \mathrm{MW}$ & & \\
\hline \multirow{3}{*}{ Ibom Power I } & & & $38 \mathrm{MW}$ & & \\
\hline & & & $38 \mathrm{MW}$ & & \\
\hline & & & $112 \mathrm{MW}$ & & \\
\hline Ibom Power Ii & & & $500 \mathrm{MW}$ & & \\
\hline $\begin{array}{c}\text { Omoku (Rivers } \\
\text { State) }\end{array}$ & & & $100 \mathrm{MW}$ & & \\
\hline
\end{tabular}


Appendix B. A Typical Generator Transformer Data as Collected

\begin{tabular}{|c|c|c|}
\hline Station & Ratings(MVA) & $V_{\text {rated }}(\mathbf{k V})$ \\
\hline \multirow{6}{*}{ Delta } & $54 / 72 / 81$ & $138 / 11.5 / 11.5 / 11.5$ \\
\hline & $45 / 81$ & $138 / 11.5 / 11.5 / 11.5$ \\
\hline & $54 / 72 / 81$ & $138 / 11.5 / 11.5 / 11.5$ \\
\hline & $54 / 72 / 81$ & $138 / 11.5 / 11.5 / 11.5$ \\
\hline & $45 / 81$ & $138 / 11.5 / 11.5 / 11.5$ \\
\hline & $54 / 72 / 81$ & $138 / 11.5 / 11.5 / 11.5$ \\
\hline \multirow{6}{*}{ Delta IV } & $72 / 96 / 120$ & $345 / 11.5$ \\
\hline & $72 / 96 / 120$ & $345 / 11.5$ \\
\hline & $72 / 96 / 120$ & $345 / 11.5$ \\
\hline & $72 / 96 / 120$ & $345 / 11.5$ \\
\hline & $72 / 96 / 120$ & $345 / 11.5$ \\
\hline & $72 / 96 / 120$ & $345 / 11.5$ \\
\hline Delta & $90 / 120 / 150$ & $330 / 132$ \\
\hline \multirow{8}{*}{ Sapele } & $90 / 140$ & $345 / 15.75$ \\
\hline & $90 / 140$ & $345 / 15.75$ \\
\hline & $90 / 140$ & $345 / 15.75$ \\
\hline & $90 / 140$ & $345 / 15.75$ \\
\hline & $105 / 140$ & $345 / 15.75$ \\
\hline & $105 / 140$ & $345 / 15.75$ \\
\hline & $126 / 168.5$ & $345 / 10.5$ \\
\hline & $126 / 168.5$ & $345 / 10.5$ \\
\hline \multirow{4}{*}{ Okpai } & $140 / 205$ & $330 / 15.75$ \\
\hline & $140 / 205$ & $330 / 15.75$ \\
\hline & $140 / 205$ & $330 / 15.75$ \\
\hline & $140 / 205$ & $330 / 15.75$ \\
\hline \multirow{9}{*}{ Afam PS } & $109 / 168$ & $10.5 / 345$ \\
\hline & $109 / 168$ & $10.5 / 345$ \\
\hline & $109 / 168$ & $10.5 / 345$ \\
\hline & $109 / 168$ & $10.5 / 345$ \\
\hline & $109 / 168$ & $10.5 / 345$ \\
\hline & $109 / 168$ & $10.5 / 345$ \\
\hline & 163 & $15.7 / 345$ \\
\hline & 163 & $15.7 / 345$ \\
\hline & 162 & $330 / 132$ \\
\hline \multirow{6}{*}{ Jebba GS } & 119 & $16 / 330$ \\
\hline & 119 & $16 / 330$ \\
\hline & 119 & $16 / 330$ \\
\hline & 119 & $16 / 330$ \\
\hline & 119 & $16 / 330$ \\
\hline & 119 & $16 / 330$ \\
\hline \multirow{6}{*}{ Kainji GS } & 145 & $16 / 330$ \\
\hline & 145 & $16 / 330$ \\
\hline & 184 & $16 / 330$ \\
\hline & 183.6 & $16 / 330$ \\
\hline & 115 & $16 / 330$ \\
\hline & 115 & $16 / 330$ \\
\hline \multirow{4}{*}{ Shiroro GS } & 200 & $15.2 / 330$ \\
\hline & 200 & $15.2 / 330$ \\
\hline & 200 & $15.2 / 330$ \\
\hline & 200 & $15.2 / 330$ \\
\hline
\end{tabular}


Appendix B. A Typical Generator Transformer Data as Collected (Continuation)

\begin{tabular}{|c|c|c|}
\hline Station & Ratings(MVA) & $V_{\text {rated }}(\mathbf{k V})$ \\
\hline \multirow{6}{*}{ Egbin GS } & 270 & $16 / 330$ \\
\hline & 270 & $16 / 330$ \\
\hline & 270 & $16 / 330$ \\
\hline & 270 & $16 / 330$ \\
\hline & 270 & $16 / 330$ \\
\hline & 270 & $16 / 330$ \\
\hline \multirow{4}{*}{ AES } & 60 & $10.5 / 132$ \\
\hline & 40 & $11.5 / 132$ \\
\hline & 40 & $11.5 / 132$ \\
\hline & 40 & $11.5 / 132$ \\
\hline Egbin GS & 150 & $330 / 132 / 33$ \\
\hline \multirow{3}{*}{ Geregu } & 168 & $345 / 15.75$ \\
\hline & 168 & $345 / 15.75$ \\
\hline & 168 & $345 / 15.75$ \\
\hline \multirow{5}{*}{ Omotosho } & 105 & $346.5 / 10.5$ \\
\hline & 105 & $346.5 / 10.5$ \\
\hline & 105 & $346.5 / 10.5$ \\
\hline & 105 & $346.5 / 10.5$ \\
\hline & 150 & $330 / 132 / 33$ \\
\hline \multirow{4}{*}{ Papalanto } & 346.5 & $10.5 / 330$ \\
\hline & 346.5 & $10.5 / 330$ \\
\hline & 346.5 & $10.5 / 330$ \\
\hline & 346.5 & $10.5 / 330$ \\
\hline Alaoji & $102 / 136 / 170$ & $15 / 330 \mathrm{kV}$ \\
\hline \multirow{2}{*}{ Gbaran NIPP } & $90 / 143$ & $139 / 15$ \\
\hline & $90 / 143$ & $139 / 15$ \\
\hline \multirow{5}{*}{ Calabar } & $90 / 143$ & $343 / 15$ \\
\hline & $90 / 143$ & $343 / 15$ \\
\hline & $90 / 143$ & $343 / 15$ \\
\hline & $90 / 143$ & $343 / 15$ \\
\hline & $90 / 143$ & $343 / 15$ \\
\hline \multirow{3}{*}{ Egbema } & $90 / 143$ & $343 / 15$ \\
\hline & $90 / 143$ & $343 / 15$ \\
\hline & $90 / 143$ & $343 / 15$ \\
\hline \multirow{4}{*}{ Ihovbor } & $90 / 143$ & $343 / 15$ \\
\hline & $90 / 143$ & $343 / 15$ \\
\hline & $90 / 143$ & $343 / 15$ \\
\hline & $90 / 143$ & $343 / 15$ \\
\hline \multirow{3}{*}{ Ikot Abasi } & $90 / 143$ & $343 / 15$ \\
\hline & $90 / 143$ & $343 / 15$ \\
\hline & $90 / 143$ & $343 / 15$ \\
\hline \multirow{4}{*}{ Sapele } & $90 / 143$ & $343 / 15$ \\
\hline & $90 / 143$ & $343 / 15$ \\
\hline & $90 / 143$ & $343 / 15$ \\
\hline & $90 / 143$ & $343 / 15$ \\
\hline \multirow{2}{*}{ Omoku } & $90 / 143$ & $343 / 15$ \\
\hline & $90 / 143$ & $343 / 15$ \\
\hline
\end{tabular}


APPENDIX C. Transmission Line Parameter Data as collected

\begin{tabular}{|c|c|c|c|c|c|c|c|c|c|c|c|}
\hline \multirow[t]{2}{*}{$\mathbf{k V}$} & \multirow[t]{2}{*}{ Name } & \multirow{2}{*}{$\begin{array}{c}\begin{array}{c}\text { Length } \\
(\mathbf{k m})\end{array}\end{array}$} & \multirow{2}{*}{$\begin{array}{c}\text { Type } \\
\text { (DC/SC) }\end{array}$} & \multirow{2}{*}{$\begin{array}{c}\text { Conductor } \\
\text { Name }\end{array}$} & \multirow{2}{*}{$\begin{array}{l}\text { Conductors } \\
\text { Per Phase }\end{array}$} & \multirow{2}{*}{ 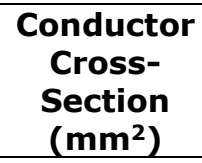 } & \multirow{2}{*}{$\begin{array}{l}\text { Zc } \\
(\Omega)\end{array}$} & \multicolumn{2}{|c|}{$\mathbf{R}_{\mathbf{1}}$} & \multicolumn{2}{|c|}{$\mathbf{X}_{1}$} \\
\hline & & & & & & & & $(\Omega / \mathbf{k m})$ & pu & $(\Omega / \mathbf{k m})$ & pu \\
\hline 330 & Afam - Alaoji & 25 & $\mathrm{DC}$ & Bison & 2 & $2 \times 350$ & 300 & 0.392 & 0.009 & 0.3049 & 0.007 \\
\hline 330 & Aja - Alagbon & 26 & DC & Bison & 2 & $2 \times 350$ & 300 & 0.0394 & & 0.303 & \\
\hline 330 & Aja - Egbin & 14 & $\mathrm{DC}$ & Bison & 2 & $2 \times 350$ & 300 & 0.17113 & 0.0022 & 1.3379 & 0.0172 \\
\hline 330 & Alagbon - Aja & 26 & DC & Bison & 2 & $2 \times 350$ & 300 & 0.0394 & & 0.303 & \\
\hline 330 & Alaoji - Ikot Ekpene & 38 & $\mathrm{DC}$ & Bison & 2 & $2 \times 350$ & 300 & 0.0394 & & 0.303 & \\
\hline 330 & Alaoji - Afam & 25 & $\mathrm{DC}$ & Bison & 2 & $2 \times 350$ & 300 & 0.392 & 0.009 & 0.303 & 0.007 \\
\hline 330 & Makurdi -Ugwuaji & 150 & $\mathrm{DC}$ & Bison & 2 & $2 \times 350$ & 300 & 0.0394 & & 0.303 & \\
\hline 330 & Benin - Sapele & 50 & $\mathrm{DC}$ & Bison & 2 & $2 \times 350$ & 300 & 0.0392 & 0.0018 & 0.3027 & 0.0139 \\
\hline 330 & Gwagwalada - Lokoja & 140 & $\mathrm{DC}$ & Bison & 2 & $2 \times 350$ & 300 & 0.0394 & & 0.303 & \\
\hline 330 & Gwagwalada - Shiroro & 114 & $\mathrm{SC}$ & Bison & 2 & $2 \times 350$ & 300 & 0.0394 & & 0.303 & \\
\hline 330 & Ikeja West - Egbin & 62 & $\mathrm{DC}$ & Bison & 2 & $2 \times 350$ & 300 & 0.03864 & 0.0022 & 0.3021 & 0.0172 \\
\hline 330 & Ikot Ekpene -Ugwuaji & 143 & $\mathrm{DC}$ & Bison & 2 & $2 \times 350$ & 300 & 0.0394 & & 0.303 & \\
\hline 330 & Ikot Ekpene -Ugwuaji & 143 & $\mathrm{DC}$ & Bison & 2 & $2 \times 350$ & 300 & 0.0394 & & 0.303 & \\
\hline 330 & Jebba - Kainji & 81 & $\mathrm{DC}$ & Bison & 2 & $2 \times 350$ & 300 & 0.03899 & 0.0029 & 0.3307 & 0.0246 \\
\hline 330 & Jebba Ts - Jebba Gs & 8 & $\mathrm{DC}$ & Bison & 2 & $2 \times 350$ & 300 & 0.04084 & 0.0003 & 0.2995 & 0.0022 \\
\hline 330 & Jos - Makurdi & 230 & $\mathrm{DC}$ & Bison & 2 & $2 \times 350$ & 300 & 0.0394 & & 0.303 & \\
\hline
\end{tabular}


APPENDIX C. Transmission Line Parameter Data as collected (Continuation)

\begin{tabular}{|c|c|c|c|c|c|c|c|c|c|c|c|}
\hline \multirow[t]{2}{*}{$\mathbf{k V}$} & \multirow[t]{2}{*}{ Name } & \multirow{2}{*}{$\begin{array}{c}\text { Length } \\
(\mathrm{km})\end{array}$} & \multirow{2}{*}{$\begin{array}{c}\text { Type } \\
\text { (DC/SC) }\end{array}$} & \multirow{2}{*}{$\begin{array}{c}\text { Conductor } \\
\text { Name }\end{array}$} & \multirow{2}{*}{$\begin{array}{l}\text { Conductors } \\
\text { Per Phase }\end{array}$} & \multirow{2}{*}{$\begin{array}{c}\text { Conductor } \\
\text { Cross- } \\
\text { Section } \\
\left(\mathbf{m m}^{2}\right) \\
\end{array}$} & \multirow{2}{*}{$\begin{array}{l}\mathrm{Zc} \\
(\Omega)\end{array}$} & \multicolumn{2}{|c|}{$\mathbf{R}_{\mathbf{1}}$} & \multicolumn{2}{|c|}{$\mathbf{X}_{1}$} \\
\hline & & & & & & & & $(\Omega / \mathbf{k m})$ & pu & $(\Omega / \mathbf{k m})$ & pu \\
\hline 330 & Kainji - Jebba & 81 & DC & Bison & 2 & $2 \times 350$ & 300 & 0.03899 & 0.0029 & 0.3307 & 0.0246 \\
\hline 330 & Katampe - Gwagwalada & 30 & DC & Bison & 2 & $2 \times 350$ & 300 & 0.0394 & & 0.303 & \\
\hline 330 & Katampe - Shiroro* & 144 & DC & Bison & 2 & $2 \times 350$ & 300 & 0.0394 & & 0.303 & \\
\hline 330 & Lokoja - Ajaokuta & 38 & DC & Bison & 2 & $2 \times 350$ & 300 & 0.0394 & & 0.303 & \\
\hline 330 & Lokoja - Gwagwalada & 140 & DC & Bison & 2 & $2 \times 350$ & 300 & 0.0394 & & 0.303 & \\
\hline 330 & Makurdi - Aliade & 50 & DC & Bison & 2 & $2 \times 350$ & 300 & 0.0394 & & 0.303 & \\
\hline 330 & Makurdi - Jos & 230 & DC & Bison & 2 & $2 \times 350$ & 300 & 0.0394 & & 0.303 & \\
\hline 330 & New Haven - Ugwuaji & 5 & DC & Bison & 2 & $2 \times 350$ & 300 & 0.0394 & & 0.303 & \\
\hline 330 & Ugwuaji - Aliade & 150 & DC & Bison & 2 & $2 \times 350$ & 300 & 0.0394 & & 0.303 & \\
\hline 330 & Ugwuaji - Ikot Ekpene & 143 & DC & Bison & 2 & $2 \times 350$ & 300 & 0.0394 & & 0.303 & \\
\hline 330 & Ugwuaji - Ikot Ekpene & 143 & DC & Bison & 2 & $2 \times 350$ & 300 & 0.0394 & & 0.303 & \\
\hline 330 & Okpai - Onitsha & 80 & DC & Bison & 2 & $2 \times 350$ & 300 & 0.12251 & 0.009 & 0.0953 & 0.007 \\
\hline 330 & Sapele - Benin & 50 & DC & Bison & 2 & $2 \times 350$ & 300 & 0.0392 & 0.0018 & 0.3027 & 0.0139 \\
\hline 330 & Shiroro - Gwagwalada & 114 & DC & Bison & 2 & $2 \times 350$ & 300 & 0.0394 & & 0.303 & \\
\hline 330 & Shiroro - Katampe* & 144 & DC & Bison & 2 & $2 \times 350$ & 300 & 0.0394 & & 0.303 & \\
\hline 330 & Ajaokuta - Benin North & 195 & SC & Bison & 2 & $2 \times 350$ & 300 & 0.039 & & 0.331 & \\
\hline 330 & Ajaokuta - Benin North & 195 & SC & Bison & 2 & $2 \times 350$ & 300 & 0.039 & & 0.331 & \\
\hline 330 & Shiroro - Jebba & 244 & SC & Bison & 2 & $2 \times 350$ & 300 & 0.0299 & 0.0067 & 0.3133 & 0.0702 \\
\hline 330 & Shiroro - Jebba & 244 & $\mathrm{SC}$ & Bison & 2 & $2 \times 350$ & 300 & 0.0299 & 0.0067 & 0.3133 & 0.0702 \\
\hline 330 & Ajaokuta - Benin & 195 & $\mathrm{SC}$ & Bison & 2 & $2 \times 350$ & 300 & 0.03909 & 0.007 & 0.3127 & 0.056 \\
\hline 330 & Ajaookuta - Benin & 195 & SC & Bison & 2 & $2 \times 350$ & 300 & 0.03909 & 0.007 & 0.3127 & 0.056 \\
\hline 330 & Akangba - Ikeja West & 18 & SC & Bison & 2 & $2 \times 350$ & 300 & 0.1331 & 0.0022 & 1.0406 & 0.0172 \\
\hline
\end{tabular}


APPENDIX C. Transmission Line Parameter Data as collected (Continuation)

\begin{tabular}{|c|c|c|c|c|c|c|c|c|c|c|c|}
\hline \multirow[t]{2}{*}{$\mathbf{k V}$} & \multirow[t]{2}{*}{ Name } & \multirow{2}{*}{$\begin{array}{l}\text { Length } \\
(\mathbf{k m})\end{array}$} & \multirow{2}{*}{$\begin{array}{c}\text { Type } \\
\text { (DC/SC) }\end{array}$} & \multirow{2}{*}{$\begin{array}{c}\text { Conductor } \\
\text { Name }\end{array}$} & \multirow{2}{*}{$\begin{array}{l}\text { Conductors } \\
\text { Per Phase }\end{array}$} & \multirow{2}{*}{$\begin{array}{c}\text { Conductor } \\
\text { Cross- } \\
\text { Section } \\
\left(\mathbf{m m}^{2}\right) \\
\end{array}$} & \multirow{2}{*}{$\begin{array}{l}\mathrm{Zc} \\
(\Omega)\end{array}$} & \multicolumn{2}{|c|}{$\mathbf{R}_{\mathbf{1}}$} & \multicolumn{2}{|c|}{$\mathbf{X}_{1}$} \\
\hline & & & & & & & & $(\Omega / \mathbf{k m})$ & pu & $(\Omega / \mathbf{k m})$ & pu \\
\hline 330 & Akangba - Ikeja West & 18 & SC & Bison & 2 & $2 \times 350$ & 300 & 0.1331 & 0.0022 & 1.0406 & 0.0172 \\
\hline 330 & Aladja - Sapele & 63 & SC & Bison & 2 & $2 \times 350$ & 300 & 0.03976 & 0.0023 & 0.3384 & 0.019 \\
\hline 330 & Alaoji - Onitsha & 138 & SC & Bison & 2 & $2 \times 350$ & 300 & 0.3867 & 0.049 & 0.3306 & 0.0419 \\
\hline 330 & Benin - Ajaokuta & 195 & SC & Bison & 2 & $2 \times 350$ & 300 & 0.03909 & 0.007 & 0.3127 & 0.056 \\
\hline 330 & Benin - Ajaokuta & 195 & SC & Bison & 2 & $2 \times 350$ & 300 & 0.03909 & 0.007 & 0.3127 & 0.056 \\
\hline 330 & Benin - Delta & 107 & SC & Bison & 2 & $2 \times 350$ & 300 & 0.02341 & 0.0023 & 0.1934 & 0.019 \\
\hline 330 & Benin - Egbin & 218 & SC & Bison & 2 & $2 \times 350$ & 300 & 0.039 & & 0.331 & \\
\hline 330 & Benin - Omotoso & 120 & SC & Bison & 2 & $2 \times 350$ & 300 & 0.039 & & 0.331 & \\
\hline 330 & Ihovbor - Benin & 20 & SC & Bison & 2 & $2 \times 350$ & 300 & 0.039 & & 0.331 & \\
\hline 330 & Birnin Kebbi - Kainji & 310 & SC & Bison & 2 & $2 \times 350$ & 300 & 0.03899 & 0.0111 & & 0.0942 \\
\hline 330 & Delta - Aladja & 32 & $\mathrm{SC}$ & Bison & 2 & $2 \times 350$ & 300 & 0.07827 & 0.0023 & & 0.019 \\
\hline 330 & Delta - Benin & 107 & $\mathrm{SC}$ & Bison & 2 & $2 \times 350$ & 300 & 0.02341 & 0.0023 & & 0.019 \\
\hline 330 & Egbin - Benin & 218 & SC & Bison & 2 & $2 \times 350$ & 300 & 0.039 & & 0.331 & \\
\hline 330 & Egbin - Erunkan & 30 & SC & Bison & 2 & $2 \times 350$ & 300 & 0.039 & & 0.331 & \\
\hline 330 & Egbin - Ikeja West & 62 & SC & Bison & 2 & $2 \times 350$ & 300 & 0.039 & & 0.331 & \\
\hline 330 & Gombe - Damaturu & 160 & SC & Bison & 2 & $2 \times 350$ & 300 & 0.039 & & 0.331 & \\
\hline
\end{tabular}


APPENDIX C. Transmission Line Parameter Data as collected (Continuation)

\begin{tabular}{|c|c|c|c|c|c|c|c|c|c|c|c|}
\hline \multirow[t]{2}{*}{$\mathbf{k V}$} & \multirow[t]{2}{*}{ Name } & \multirow{2}{*}{$\begin{array}{l}\text { Length } \\
(\mathbf{k m})\end{array}$} & \multirow{2}{*}{$\begin{array}{c}\text { Type } \\
\text { (DC/SC) }\end{array}$} & \multirow{2}{*}{$\begin{array}{c}\text { Conductor } \\
\text { Name }\end{array}$} & \multirow{2}{*}{$\begin{array}{l}\text { Conductors } \\
\text { Per Phase }\end{array}$} & \multirow{2}{*}{$\begin{array}{c}\text { Conductor } \\
\text { Cross- } \\
\text { Section } \\
\left(\mathbf{m m}^{2}\right) \\
\end{array}$} & \multirow{2}{*}{$\begin{array}{c}\mathrm{Zc} \\
(\Omega)\end{array}$} & \multicolumn{2}{|c|}{$\mathbf{R}_{\mathbf{1}}$} & \multicolumn{2}{|c|}{$\mathbf{X}_{1}$} \\
\hline & & & & & & & & $(\Omega / \mathbf{k m})$ & pu & $(\Omega / \mathbf{k m})$ & pu \\
\hline 330 & Gombe - Jos & 265 & SC & Bison & 2 & $2 \times 350$ & 300 & 0.03904 & 0.0095 & 0.3329 & 0.081 \\
\hline 330 & Gombe - Yola & 240 & $\mathrm{SC}$ & Bison & 2 & $2 \times 350$ & 300 & 0.039 & & 0.331 & \\
\hline 330 & Ikeja West - Akangba & 18 & SC & Bison & 2 & $2 \times 350$ & 300 & & 0.0022 & 1.0406 & 0.0172 \\
\hline 330 & Ikeja West - Akangba & 18 & SC & Bison & 2 & $2 \times 350$ & 300 & & 0.0022 & 1.0406 & 0.0172 \\
\hline 330 & Ikeja West - Egbin & 62 & SC & Bison & 2 & $2 \times 350$ & 300 & 0.039 & & 0.331 & \\
\hline 330 & Ikeja West - Omotoso & 160 & $\mathrm{SC}$ & Bison & 2 & $2 \times 350$ & 300 & 0.039 & & 0.331 & \\
\hline 330 & Ikeja West - Osogbo & 252 & SC & Bison & 2 & $2 \times 350$ & 300 & 0.02118 & 0.0049 & 0.1798 & 0.0416 \\
\hline 330 & Jebba - Shiroro & 244 & $\mathrm{SC}$ & Bison & 2 & $2 \times 350$ & 300 & 0.0299 & 0.0067 & 0.3133 & 0.0702 \\
\hline 330 & Jebba - Shiroro & 244 & $\mathrm{SC}$ & Bison & 2 & $2 \times 350$ & 300 & 0.0299 & 0.0067 & 0.3133 & 0.0702 \\
\hline 330 & Jos - Gombe & 265 & $\mathrm{SC}$ & Bison & 2 & $2 \times 350$ & 300 & 0.03904 & 0.0095 & 0.3329 & 0.081 \\
\hline 330 & Kaduna - Jos & 197 & SC & Bison & 2 & $2 \times 350$ & 300 & 0.0387 & 0.007 & 0.3311 & 0.0599 \\
\hline 330 & Kaduna - Kano & 230 & SC & Bison & 2 & $2 \times 350$ & 300 & 0.03883 & 0.0082 & 0.331 & 0.0699 \\
\hline 330 & Kaduna - Shiroro & 96 & $\mathrm{SC}$ & Bison & 2 & $2 \times 350$ & 300 & 0.03857 & 0.0034 & 0.3312 & 0.0292 \\
\hline 330 & Kaduna - Shiroro & 96 & $\mathrm{SC}$ & Bison & 2 & $2 \times 350$ & 300 & 0.03857 & 0.0034 & 0.3312 & 0.0292 \\
\hline 330 & Kainji - Birnin Kebbi & 310 & $\mathrm{SC}$ & Bison & 2 & $2 \times 350$ & 300 & 0.03899 & 0.0111 & 0.3309 & 0.0942 \\
\hline 330 & Kano - Kaduna & 230 & $\mathrm{SC}$ & Bison & 2 & $2 \times 350$ & 300 & 0.03883 & 0.0082 & 0.331 & 0.0699 \\
\hline 330 & Maiduguri - Damaturu & 260 & SC & Bison & 2 & $2 \times 350$ & 300 & 0.039 & & 0.331 & \\
\hline 330 & New Haven - Onitsha & 96 & $\mathrm{SC}$ & Bison & 2 & $2 \times 350$ & 300 & & 0.003 & 0.3312 & 0.0292 \\
\hline 330 & Omotosho - Benin & 120 & $\mathrm{SC}$ & Bison & 2 & $2 \times 350$ & 300 & 0.039 & & 0.331 & \\
\hline 330 & Omotoso - Ikeja West & 160 & $\mathrm{SC}$ & Bison & 2 & $2 \times 350$ & 300 & 0.039 & & 0.331 & \\
\hline 330 & Onitsha - Alaoji & 138 & SC & Bison & 2 & $2 \times 350$ & 300 & 0.3867 & 0.049 & 0.3306 & 0.0419 \\
\hline 330 & Onitsha - Benin & 137 & $\mathrm{SC}$ & Bison & 2 & $2 \times 350$ & 300 & 0.03895 & 0.0049 & 0.3307 & 0.0416 \\
\hline
\end{tabular}


APPENDIX C. Transmission Line Parameter Data as collected (Continuation)

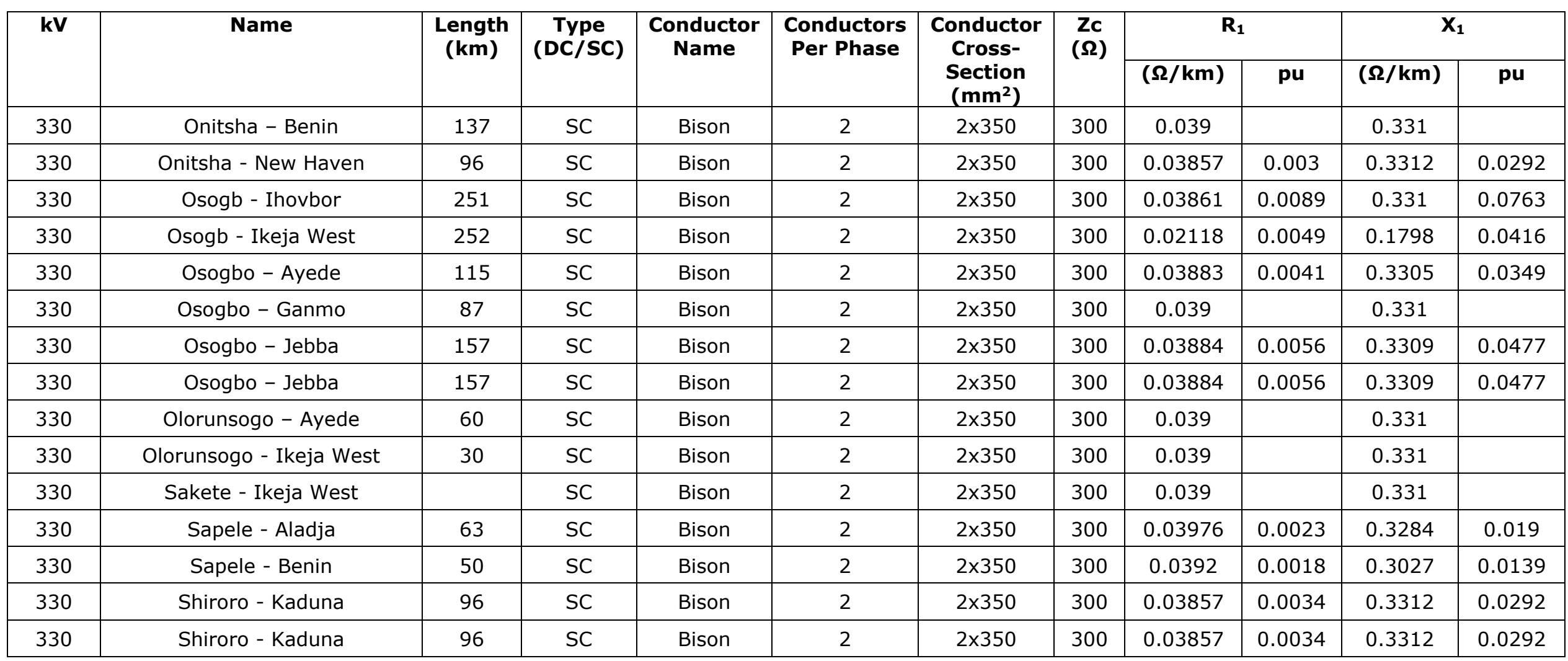


Appendix D. A Typical Load Data as Collected for a Period of 4 Months (January - April, 2017)

Appendix D1. January 2017 Load Flow Data

\begin{tabular}{|c|c|c|c|c|c|c|c|c|c|c|c|c|c|c|}
\hline \multirow{2}{*}{$\frac{\text { Name of Bus }}{\text { Lagos }}$} & \multicolumn{3}{|c|}{$1^{\text {st }}$ Week (MW) } & \multicolumn{3}{|c|}{$2^{\text {nd }}$ Week (MW) } & \multicolumn{3}{|c|}{$3^{\text {rd }}$ Week(MW) } & \multicolumn{3}{|c|}{$4^{\text {th }}$ Week (MW) } & \multirow{2}{*}{\begin{tabular}{|c|}
$\begin{array}{c}\text { Total } \\
\text { (MW) }\end{array}$ \\
7809 \\
\end{tabular}} & \multirow{2}{*}{$\begin{array}{c}\begin{array}{c}\text { Arg } \\
(\mathbf{M W})\end{array} \\
650.75\end{array}$} \\
\hline & 804 & 785 & 644 & 755 & 800 & 807 & 336 & 711 & 452 & 623 & 441 & 651 & & \\
\hline Kaduna & 112 & 135 & 196 & 125 & 91 & 133 & 72 & 87 & 113 & 138 & 100 & 158 & 1460 & 121.67 \\
\hline Kano & 151 & 132 & 110 & 144 & 154 & 145 & 179 & 130 & 102 & 108 & 87 & 83 & 1525 & 127.08 \\
\hline Yola & 14 & 25 & 32 & 16 & 18 & 15 & 4 & 22 & 9 & 12 & 11 & 7 & 185 & 15.417 \\
\hline Jos & 57 & 86 & 75 & 30 & 37 & 27 & 25 & 37 & 24 & 28 & 38 & 30 & 494 & 41.167 \\
\hline Gombe & 68 & 58 & 90 & 97 & 66 & 101 & 19 & 91 & 22 & 32 & 30 & 53 & 727 & 60.583 \\
\hline Shiroro & 33.5 & 20 & 32.8 & 35.7 & 72 & 51.9 & 12 & 47 & 5 & 30 & 27.4 & 49 & 416.3 & 34.692 \\
\hline Aiyede & 140 & 134 & 145 & 88 & 90 & 94 & 58 & 110 & 90 & 80 & 100 & 110 & 1239 & 103.25 \\
\hline Osogbo & 141.7 & 95.6 & 130.1 & 149 & 136.9 & 141.8 & 128.2 & 111.2 & 119 & 163 & 92 & 116 & 1524 & 127 \\
\hline Ganmo & 33 & 33 & 39.5 & 41 & 50.5 & 33 & 47 & 29 & 38 & 15 & 29.5 & 21 & 409.5 & 34.125 \\
\hline Benin & 164.4 & 111.3 & 127.5 & 141 & 135.1 & 124.9 & 85.3 & 125.7 & 106 & 139 & 99.7 & 158.5 & 1519.3 & 126.61 \\
\hline Effurun & 9.5 & 42.4 & 47.1 & 68.7 & 59.9 & 67.5 & 66.6 & 55.6 & 26.8 & 45.3 & 32.4 & 32.9 & 554.7 & 46.225 \\
\hline Onitsha & 115 & 118 & 100 & 142 & 116 & 133 & 37 & 73 & 46 & 54 & 69 & 98 & 1101 & 91.75 \\
\hline Alaoji & 259.6 & 273.2 & 281.2 & 340 & 267.5 & 323.6 & & 312 & 42.3 & 205 & 109.3 & 245.6 & 2659.5 & 241.77 \\
\hline New Haven & 70 & 60 & 78 & 106 & 88 & 114 & 26 & 72 & 46 & 42 & 56 & 84 & 842 & 70.167 \\
\hline Jebba & 6.7 & 12 & 17 & 18.7 & 2.3 & 14.2 & 8.1 & 7 & 15.9 & 9.8 & 16.2 & 9.2 & 137.1 & 11.425 \\
\hline Birnin Kebbi & 102 & 118 & 93 & 119 & 102 & 131 & 110 & 126 & 74 & 88 & 93 & 99 & 1255 & 104.58 \\
\hline Sakate & 152 & 156 & 146 & 80 & 146 & 79 & & 104 & 35.5 & 100 & 100 & 112 & 1210.5 & 110.05 \\
\hline Katampe & 218.9 & 261.8 & 260.2 & 173 & 151.5 & 248.7 & 53.9 & 228.7 & 138 & 176 & 215.9 & 161.8 & 2289.1 & 190.76 \\
\hline
\end{tabular}


Appendix D2. February 2017 Load Flow Data

\begin{tabular}{|c|c|c|c|c|c|c|c|c|c|c|c|c|c|c|}
\hline \multirow{2}{*}{$\begin{array}{c}\text { Name of Bus } \\
\text { Lagos }\end{array}$} & \multicolumn{3}{|c|}{$1^{\text {st }}$ Week (MW) } & \multicolumn{3}{|c|}{$2^{\text {nd }}$ Week (MW) } & \multicolumn{3}{|c|}{$3^{\text {rd }}$ Week(MW) } & \multicolumn{3}{|c|}{$4^{\text {th }}$ Week (MW) } & \multirow{2}{*}{$\begin{array}{l}\text { Total } \\
\text { (MW) } \\
11311\end{array}$} & \multirow{2}{*}{$\begin{array}{c}\begin{array}{c}\text { Arg } \\
\text { (MW) }\end{array} \\
942.58\end{array}$} \\
\hline & 803 & 1007 & 987 & 910 & 1075 & 1014 & 1024 & 884 & 1081 & 988 & 940 & 598 & & \\
\hline Kaduna & 188 & 225 & 138 & 278 & 277 & 212 & 269 & 170 & 271 & 190 & 185 & 278 & 2681 & 223.42 \\
\hline Kano & 264 & 278 & 255 & 208 & 258 & 243 & 263 & 196 & 303 & 143 & 256 & 292 & 2959 & 246.58 \\
\hline Yola & 49 & 47 & 38 & 58 & 47 & 36 & 62 & 35 & 45 & 31 & 52 & 47 & 547 & 45.583 \\
\hline Jos & 80 & 77 & 86 & 95 & 110 & 76 & 124 & 78 & 84 & 112 & 87 & 114 & 1123 & 93.583 \\
\hline Gombe & 105 & 138 & 110 & 124 & 124 & 90 & 122 & 103 & 128 & 71 & 120 & 127 & 1362 & 113.5 \\
\hline Shiroro & 84 & 81 & 66 & 92 & 72 & 60 & 92 & 84 & 56 & 84 & 101 & 31 & 903 & 75.25 \\
\hline Aiyede & 194 & 197 & 190 & 182 & 164 & 140 & 160 & 130 & 180 & 154 & 174 & 168 & 2033 & 169.42 \\
\hline Osogbo & 75.2 & 194.2 & 156.3 & 191 & 153.4 & 145.6 & 196.1 & 112.6 & 183 & 136 & 185.9 & 127.2 & 1856.7 & 154.73 \\
\hline Ganmo & 43 & 53 & 43 & 29 & 57 & 39 & 43 & 51 & 54 & 35 & 57 & 32 & 536 & 44.667 \\
\hline Benin & 139.1 & 145.5 & 123.4 & 184 & 149.2 & 136.6 & 168.3 & 131.1 & 129 & 154 & 165.5 & 125.7 & 1750.4 & 145.87 \\
\hline Effurun & 77.4 & 71.6 & 68.2 & 54.2 & 53.8 & 63.9 & 99.5 & 84.2 & 83.7 & 43.9 & 67.7 & 60.4 & 828.5 & 69.042 \\
\hline Onitsha & 119 & 140 & 123 & 184 & 153 & 112 & 124 & 128 & 136 & 105 & 140 & 103 & 1567 & 130.58 \\
\hline Alaoji & 412 & 403.3 & 384.2 & 164 & 391.7 & 283.5 & 317.9 & 288.4 & 272 & 288 & 357.6 & 264.2 & 3827.1 & 318.93 \\
\hline New Haven & 94 & 170 & 146 & 164 & 128 & 118 & 152 & 140 & 146 & 96 & 132 & 126 & 1612 & 134.33 \\
\hline Jebba & 12 & 6.5 & 11.9 & 13.4 & 10 & 16.8 & 9.2 & 14.2 & 15.9 & 15 & 3.8 & 14.4 & 143.1 & 11.925 \\
\hline Birnin Kebbi & 146 & 180 & 150 & 185 & 163 & 163 & 183 & 174 & 175 & 163 & 180 & 169 & 2031 & 169.25 \\
\hline Sakate & 188 & 177 & 198 & 202 & 194 & 188 & 194 & 189 & 177 & 193 & 203 & 196 & 2299 & 191.58 \\
\hline Katampe & 309 & 336.5 & 291.2 & 354 & 324.4 & 316.5 & 387.2 & 364.1 & 335 & 290 & 323.9 & 284.7 & 3916.4 & 326.37 \\
\hline
\end{tabular}


Appendix D3. March 2017 Load Flow Data

\begin{tabular}{|c|c|c|c|c|c|c|c|c|c|c|c|c|c|c|}
\hline \multirow{2}{*}{$\begin{array}{c}\text { Name of Bus } \\
\text { Lagos }\end{array}$} & \multicolumn{3}{|c|}{$1^{\text {st }}$ Week (MW) } & \multicolumn{3}{|c|}{$2^{\text {nd }}$ Week (MW) } & \multicolumn{3}{|c|}{$3^{\text {rd }}$ Week(MW) } & \multicolumn{3}{|c|}{$4^{\text {th }}$ Week (MW) } & \multirow{2}{*}{$\begin{array}{r}\begin{array}{r}\text { Total } \\
\text { (MW) }\end{array} \\
9060\end{array}$} & \multirow{2}{*}{$\begin{array}{r}\begin{array}{c}\text { Arg } \\
(\mathbf{M W})\end{array} \\
755\end{array}$} \\
\hline & 343 & 942 & 762 & 886 & 670 & 874 & 716 & 973 & 725 & 694 & 624 & 851 & & \\
\hline Kaduna & 194 & 235 & 175 & 220 & 173 & 262 & 274 & 266 & 244 & 236 & 179 & 250 & 2708 & 225.7 \\
\hline Kano & 257 & 250 & 260 & 280 & 303 & 306 & 290 & 303 & 300 & 274 & 239 & 256 & 3318 & 276.5 \\
\hline Yola & 24 & 49 & 61 & 57 & 46 & 67 & 58 & 64 & 58 & 65 & 63 & 51 & 663 & 55.25 \\
\hline Jos & 71 & 100 & 97 & 64 & 80 & 92 & 65 & 97 & 72 & 128 & 98 & 79 & 1043 & 86.92 \\
\hline Gombe & 91 & 150 & 113 & 103 & 105 & 130 & 97 & 115 & 66 & 90 & 147 & 131 & 1338 & 111.5 \\
\hline Shiroro & 80 & 105 & 62 & 82 & 73 & 89 & 27 & 58 & 49 & 108 & 98 & 100 & 931.2 & 77.6 \\
\hline Aiyede & 130 & 16 & 60 & 139 & 50 & 166 & 120 & 174 & 144 & 62 & 90 & 136 & 1287 & 107.3 \\
\hline Osogbo & 148.5 & 129 & 96.6 & 192 & 103.9 & 225 & 138 & 175 & 156 & 143 & 91.4 & 139 & 1738.2 & 144.9 \\
\hline Ganmo & 71 & 49.5 & 39.5 & 57 & 28.3 & 59 & 2.4 & 51.5 & 29.4 & 24 & 28 & 34 & 473.6 & 39.47 \\
\hline Benin & 120.4 & 157 & 116 & 161 & 85.4 & 117 & 115 & 118 & 98.8 & 174 & 186 & 178 & 1626.8 & 135.6 \\
\hline Effurun & 62.3 & 102 & 39.9 & 84.4 & 29.7 & 83.1 & 41.1 & 46 & 60 & 83 & 74.9 & 29.8 & 736.4 & 61.37 \\
\hline Onitsha & 76 & 145 & 130 & 111 & 51 & 133 & 76 & 162 & 72 & 133 & 124 & 94 & 1307 & 108.9 \\
\hline Alaoji & 287.8 & 397 & 240 & 331 & 134.5 & 335 & 239 & 279 & 79.5 & 401 & 348 & 350 & 3422.2 & 285.2 \\
\hline New Haven & 98 & 176 & 104 & 182 & 104 & 144 & 112 & 140 & 76 & 140 & 140 & 108 & 1524 & 127 \\
\hline Jebba & 9.9 & 2.8 & 5.8 & 20.5 & 12.1 & 8.1 & 12.6 & 12.8 & 11.5 & 13 & 13.9 & 6.2 & 129.6 & 10.8 \\
\hline Birnin Kebbi & 170 & 163 & 171 & 181 & 162 & 187 & 170 & 169 & 164 & 184 & 195 & 191 & 2107 & 175.6 \\
\hline Sakate & 185 & 220 & 155 & 220 & 155 & 208 & 185 & 209 & 172 & 214 & 215 & 201 & 2339 & 194.9 \\
\hline Katampe & 376 & 337 & 322 & 325 & 295.9 & 335 & 185 & 375 & 265 & 358 & 360 & 345 & 3877.7 & 323.1 \\
\hline
\end{tabular}


Appendix D4. April 2017 Load Flow Data

\begin{tabular}{|c|c|c|c|c|c|c|c|c|c|c|c|c|c|c|}
\hline \multirow{2}{*}{$\begin{array}{c}\text { Name of Bus } \\
\text { Lagos }\end{array}$} & \multicolumn{3}{|c|}{$1^{\text {st }}$ Week (MW) } & \multicolumn{3}{|c|}{$2^{\text {nd }}$ Week (MW) } & \multicolumn{3}{|c|}{$3^{\text {rd }}$ Week(MW) } & \multicolumn{3}{|c|}{$4^{\text {th }}$ Week (MW) } & \multirow{2}{*}{$\begin{array}{c}\begin{array}{c}\text { Total } \\
\text { (MW) }\end{array} \\
9325\end{array}$} & \multirow{2}{*}{$\begin{array}{c}\begin{array}{c}\text { Arg } \\
(\mathbf{M W})\end{array} \\
777.1\end{array}$} \\
\hline & 821 & 847 & 848 & 805 & 738 & 709 & 794 & 925 & 623 & 675 & 664 & 876 & & \\
\hline Kaduna & 258 & 259 & 219 & 207 & 221 & 232 & 232 & 236 & 170 & 189 & 235 & 280 & 2738 & 228.2 \\
\hline Kano & & 280 & 256 & 232 & 220 & 235 & 160 & 266 & 234 & 1875 & 226 & 264 & 2560 & 232.7 \\
\hline Yola & 46 & 58 & 34 & 44 & 42 & 42 & 36 & 36 & 40 & 43 & & 67 & 488 & 44.36 \\
\hline Jos & 132 & 80 & 114 & 66 & 64 & 49 & 73 & 65 & 45 & 65 & 63 & 106 & 922 & 76.83 \\
\hline Gombe & 133 & 131 & 102 & 100 & 100 & 86 & 77 & 94 & 85 & 85 & & 128 & 1121 & 101.9 \\
\hline Shiroro & 79.4 & 85 & 82 & 68.8 & 57 & 60.2 & 89.3 & 66.1 & 58 & 90 & 49.6 & 62 & 846.9 & 70.58 \\
\hline Aiyede & 148 & 90 & 110 & 130 & 140 & 120 & 80 & 140 & 80 & 140 & 90 & 146 & 1414 & 117.8 \\
\hline Osogbo & 81.6 & 134 & 93.2 & 82.5 & 87.3 & 148 & 154 & 144 & 151 & 186 & 129 & 105 & 1493.6 & 124.5 \\
\hline Ganmo & 26.5 & 26 & 52.5 & 36 & 64.3 & 37.5 & 31 & 38.5 & 47.5 & 69 & 43.1 & 48 & 519.4 & 43.28 \\
\hline Benin & 141.1 & 131 & 140 & 182 & 165.7 & 179 & 126 & 153 & 130 & 179 & 144 & 74 & 1744 & 145.3 \\
\hline Effurun & 30.4 & 39.1 & 17.1 & 89.8 & 57.9 & 57 & 69.6 & 51.9 & 72.4 & 49 & 52.2 & 88.3 & 674.8 & 56.23 \\
\hline Onitsha & 111 & 132 & 32 & 32 & 43 & 83 & 103 & 69 & 75 & 97 & 104 & 116 & 997 & 83.08 \\
\hline Alaoji & 230.6 & 277 & 282 & 302 & 265.4 & 341 & 167 & 216 & 243 & 218 & 300 & 270 & 3111 & 259.3 \\
\hline New Haven & 88 & 114 & 88 & 100 & 78 & 92 & 68 & 72 & 72 & 100 & 84 & 92 & 1048 & 87.33 \\
\hline Jebba & 7.7 & 11.5 & 4.8 & 14.5 & 13 & 10.9 & 11.8 & 6.1 & 11.2 & 17 & 14.4 & 5.4 & 128.6 & 10.72 \\
\hline Birnin Kebbi & 175 & 131 & 169 & & 140 & 171 & 140 & 154 & 157 & 148 & 150 & 176 & 1711 & 155.5 \\
\hline Sakate & 200 & 211 & 184 & 204 & 222 & 236 & 216 & 217 & 230 & 193 & 228 & 243 & 2584 & 215.3 \\
\hline Katampe & 287.4 & 317 & 269 & 392 & 320.3 & 293 & 302 & 323 & 322 & 301 & 202 & 189 & 3519.3 & 293.3 \\
\hline
\end{tabular}


Appendix D5. Summary of Load Flow Data from January to April, 2017

\begin{tabular}{|c|c|c|c|c|c|c|c|}
\hline Name of Bus & Jan & Feb & Mar & Apr & $\begin{array}{l}\text { Total } \\
\text { (MW) }\end{array}$ & $\begin{array}{c}\text { Arg } \\
(M W)\end{array}$ & $\begin{array}{c}\text { Arg } \\
\text { (MVA) }\end{array}$ \\
\hline Lagos & 650.75 & 942.583 & 755 & 777.08 & 3125.42 & 781.35 & 976.69 \\
\hline Kaduna & 121.67 & 223.417 & 225.667 & 228.17 & 798.917 & 199.73 & 249.66 \\
\hline Kano & 127.08 & 246.583 & 276.5 & 232.73 & 882.894 & 220.72 & 275.9 \\
\hline Yola & 15.417 & 45.5833 & 55.25 & 44.364 & 160.614 & 40.153 & 50.192 \\
\hline Jos & 41.167 & 93.5833 & 86.9167 & 76.833 & 298.5 & 74.625 & 93.281 \\
\hline Gombe & 60.583 & 113.5 & 111.5 & 101.91 & 387.492 & 96.873 & 121.09 \\
\hline Shiroro & 34.692 & 75.25 & 77.6 & 70.575 & 258.117 & 64.529 & 80.661 \\
\hline Aiyede & 103.25 & 169.417 & 107.25 & 117.83 & 497.75 & 124.44 & 155.55 \\
\hline Osogbo & 127 & 154.725 & 144.85 & 124.47 & 551.042 & 137.76 & 172.2 \\
\hline Ganmo & 34.125 & 44.6667 & 39.4667 & 43.283 & 161.542 & 40.385 & 50.482 \\
\hline Benin & 126.61 & 145.867 & 135.567 & 145.33 & 553.375 & 138.34 & 172.93 \\
\hline Effurun & 46.225 & 69.0417 & 61.3667 & 56.233 & 232.867 & 58.217 & 72.771 \\
\hline Onitsha & 91.75 & 130.583 & 108.917 & 83.083 & 414.333 & 103.58 & 129.48 \\
\hline Alaoji & 241.77 & 318.925 & 285.183 & 259.25 & 1105.13 & 276.28 & 345.35 \\
\hline New Haven & 70.167 & 134.333 & 127 & 87.333 & 418.833 & 104.71 & 130.89 \\
\hline Jebba & 11.425 & 11.925 & 10.8 & 10.717 & 44.8667 & 11.217 & 14.021 \\
\hline Birnin Kebbi & 104.58 & 169.25 & 175.583 & 155.55 & 604.962 & 151.24 & 189.05 \\
\hline Sakate & 110.05 & 191.583 & 194.917 & 215.33 & 711.879 & 177.97 & 222.46 \\
\hline Katampe & 190.76 & 326.367 & 323.142 & 293.28 & 1133.54 & 283.39 & 354.23 \\
\hline
\end{tabular}


Appendix E. Data for Generating Stations from January to April, 2017

\begin{tabular}{|c|c|c|c|c|c|c|c|c|c|c|c|c|c|c|}
\hline \multirow{3}{*}{$\begin{array}{c}\text { Generating Station } \\
\text { Kainji }\end{array}$} & & & & & & & & & & & & & & \\
\hline & \multicolumn{3}{|c|}{$1^{\text {st }}$ Week (MW) } & \multicolumn{3}{|c|}{$2^{\text {nd }}$ Week (MW) } & \multicolumn{3}{|c|}{$3^{\text {rd }}$ Week (MW) } & \multicolumn{3}{|c|}{$4^{\text {th }}$ Week (MW) } & \multirow{2}{*}{$\begin{array}{c}\text { Total (MW) } \\
3755\end{array}$} & \multirow{2}{*}{$\frac{\operatorname{Arg}(\mathbf{M W})}{312.92}$} \\
\hline & 61 & 210 & 406 & 290 & 406 & 285 & 295 & 289 & 294 & 408 & 404 & 407 & & \\
\hline Jebba & 365 & 439 & 437 & 353 & 438 & 356 & 252 & 348 & 280 & 285 & 192 & 287 & 4032 & 336 \\
\hline Shiroro & 300 & 300 & 300 & 300 & 300 & 300 & 300 & 300 & 300 & 300 & 300 & 300 & 3600 & 300 \\
\hline Egbin & $\mathrm{N} / \mathrm{G}$ & 360 & 360 & 328 & 359 & 361 & 336 & 384 & 317 & $\mathrm{~N} / \mathrm{G}$ & $\mathrm{N} / \mathrm{G}$ & 106 & 2911 & 323.44 \\
\hline Sapele & 64 & 65 & 64 & 65 & 65 & 67 & 42 & 40 & 40 & 67 & 65 & 65 & 709 & 59.083 \\
\hline Delta & 240 & 240 & 240 & 180 & 240 & $\mathrm{~N} / \mathrm{G}$ & 140 & 140 & 140 & 140 & 140 & 160 & 2000 & 181.82 \\
\hline Afam IV-V & $\mathrm{N} / \mathrm{G}$ & $\mathrm{N} / \mathrm{G}$ & $\mathrm{N} / \mathrm{G}$ & $\mathrm{N} / \mathrm{G}$ & $\mathrm{N} / \mathrm{G}$ & N/G & $\mathrm{N} / \mathrm{G}$ & N/G & $\mathrm{N} / \mathrm{G}$ & $\mathrm{N} / \mathrm{G}$ & $\mathrm{N} / \mathrm{G}$ & $\mathrm{N} / \mathrm{G}$ & & \\
\hline Geregu & 60 & 100 & 100 & 94 & 94 & 120 & 273 & 302 & 259 & 245 & 202 & 200 & 2049 & 170.75 \\
\hline Omotosho & 67 & 113 & 109 & 99.5 & 112 & 104 & 33.8 & 109 & 109 & 109 & 101 & 111 & 1177.6 & 98.133 \\
\hline Olorunsogo Gas & $\mathrm{N} / \mathrm{G}$ & 28.4 & 30 & 32.7 & 32.5 & 63.4 & 126.3 & 129 & 132 & 102 & 118 & 126 & 920.1 & 83.645 \\
\hline Geregu NIPP & 70 & $\mathrm{~N} / \mathrm{G}$ & $\mathrm{N} / \mathrm{G}$ & $\mathrm{N} / \mathrm{G}$ & $\mathrm{N} / \mathrm{G}$ & $\mathrm{N} / \mathrm{G}$ & $\mathrm{N} / \mathrm{G}$ & N/G & $\mathrm{N} / \mathrm{G}$ & $\mathrm{N} / \mathrm{G}$ & $\mathrm{N} / \mathrm{G}$ & $\mathrm{N} / \mathrm{G}$ & 70 & 70 \\
\hline Sapele NIPP & 109.6 & $\mathrm{~N} / \mathrm{G}$ & N/G & $\mathrm{N} / \mathrm{G}$ & N/G & N/G & 113.6 & 115 & 115 & $\mathrm{~N} / \mathrm{G}$ & $\mathrm{N} / \mathrm{G}$ & $\mathrm{N} / \mathrm{G}$ & 453.7 & 113.43 \\
\hline Alaoji NIPP & $\mathrm{N} / \mathrm{G}$ & $\mathrm{N} / \mathrm{G}$ & 116 & 63.8 & 117 & 111 & $\mathrm{~N} / \mathrm{G}$ & 100 & $\mathrm{~N} / \mathrm{G}$ & $\mathrm{N} / \mathrm{G}$ & $\mathrm{N} / \mathrm{G}$ & 112 & 620.3 & 103.38 \\
\hline Olorunsogo NIPP & $\mathrm{N} / \mathrm{G}$ & $\mathrm{N} / \mathrm{G}$ & $\mathrm{N} / \mathrm{G}$ & $\mathrm{N} / \mathrm{G}$ & $\mathrm{N} / \mathrm{G}$ & $\mathrm{N} / \mathrm{G}$ & $\mathrm{N} / \mathrm{G}$ & N/G & $\mathrm{N} / \mathrm{G}$ & 154 & 78.6 & $\mathrm{~N} / \mathrm{G}$ & 232.5 & 116.25 \\
\hline Omotosho II NIPP & 108.3 & 95.9 & 106 & 101 & 102 & 110 & 99.4 & 111 & 109 & 112 & 103 & 105 & 1262.6 & 105.22 \\
\hline Ihovbor & $\mathrm{N} / \mathrm{G}$ & $\mathrm{N} / \mathrm{G}$ & $\mathrm{N} / \mathrm{G}$ & $\mathrm{N} / \mathrm{G}$ & $\mathrm{N} / \mathrm{G}$ & $\mathrm{N} / \mathrm{G}$ & $\mathrm{N} / \mathrm{G}$ & $\mathrm{N} / \mathrm{G}$ & 88 & 89.3 & 93.1 & 89 & 359.4 & 89.85 \\
\hline Okpai & $\mathrm{N} / \mathrm{G}$ & 143 & 148 & 142 & 150 & 419 & 209 & 211 & 213 & 210 & 205 & 210 & 2260 & 205.45 \\
\hline Afam VI & 573 & 559 & 578 & 562 & 581 & 410 & 413 & 421 & 424 & $\mathrm{~N} / \mathrm{G}$ & $\mathrm{N} / \mathrm{G}$ & 170 & 4691 & 469.1 \\
\hline Ibom & $\mathrm{N} / \mathrm{G}$ & $\mathrm{N} / \mathrm{G}$ & $\mathrm{N} / \mathrm{G}$ & $\mathrm{N} / \mathrm{G}$ & $\mathrm{N} / \mathrm{G}$ & $\mathrm{N} / \mathrm{G}$ & $\mathrm{N} / \mathrm{G}$ & N/G & $\mathrm{N} / \mathrm{G}$ & $\mathrm{N} / \mathrm{G}$ & $\mathrm{N} / \mathrm{G}$ & $\mathrm{N} / \mathrm{G}$ & & \\
\hline Omoku & 85.2 & 5.4 & 71 & 27.3 & 75.3 & N/G & 58.1 & 55.5 & 56 & 55 & 53.3 & 56 & 597.7 & 54.336 \\
\hline A.E.S. & $\mathrm{N} / \mathrm{G}$ & $\mathrm{N} / \mathrm{G}$ & $\mathrm{N} / \mathrm{G}$ & $\mathrm{N} / \mathrm{G}$ & $\mathrm{N} / \mathrm{G}$ & $\mathrm{N} / \mathrm{G}$ & $\mathrm{N} / \mathrm{G}$ & N/G & $\mathrm{N} / \mathrm{G}$ & $\mathrm{N} / \mathrm{G}$ & $\mathrm{N} / \mathrm{G}$ & $\mathrm{N} / \mathrm{G}$ & & \\
\hline Trans Amadi & $\mathrm{N} / \mathrm{G}$ & $\mathrm{N} / \mathrm{G}$ & $\mathrm{N} / \mathrm{G}$ & $\mathrm{N} / \mathrm{G}$ & $\mathrm{N} / \mathrm{G}$ & $\mathrm{N} / \mathrm{G}$ & $\mathrm{N} / \mathrm{G}$ & N/G & $\mathrm{N} / \mathrm{G}$ & $\mathrm{N} / \mathrm{G}$ & $\mathrm{N} / \mathrm{G}$ & $\mathrm{N} / \mathrm{G}$ & & \\
\hline Rivers IPP & $\mathrm{N} / \mathrm{G}$ & $\mathrm{N} / \mathrm{G}$ & $\mathrm{N} / \mathrm{G}$ & $\mathrm{N} / \mathrm{G}$ & N/G & N/G & $\mathrm{N} / \mathrm{G}$ & N/G & $\mathrm{N} / \mathrm{G}$ & $\mathrm{N} / \mathrm{G}$ & $\mathrm{N} / \mathrm{G}$ & $\mathrm{N} / \mathrm{G}$ & & \\
\hline ASCO & $\mathrm{N} / \mathrm{G}$ & $\mathrm{N} / \mathrm{G}$ & $\mathrm{N} / \mathrm{G}$ & $\mathrm{N} / \mathrm{G}$ & $\mathrm{N} / \mathrm{G}$ & $\mathrm{N} / \mathrm{G}$ & $\mathrm{N} / \mathrm{G}$ & N/G & $\mathrm{N} / \mathrm{G}$ & $\mathrm{N} / \mathrm{G}$ & $\mathrm{N} / \mathrm{G}$ & $\mathrm{N} / \mathrm{G}$ & & \\
\hline Odukpani NIPP & 114.3 & 114 & 117 & 113 & 119 & 114 & 113.9 & 117 & 102 & 115 & 109 & 117 & 1365.1 & 113.76 \\
\hline Gbarain & $\mathrm{N} / \mathrm{G}$ & $\mathrm{N} / \mathrm{G}$ & $\mathrm{N} / \mathrm{G}$ & $\mathrm{N} / \mathrm{G}$ & $\mathrm{N} / \mathrm{G}$ & $\mathrm{N} / \mathrm{G}$ & $\mathrm{N} / \mathrm{G}$ & $\mathrm{N} / \mathrm{G}$ & $\mathrm{N} / \mathrm{G}$ & $\mathrm{N} / \mathrm{G}$ & $\mathrm{N} / \mathrm{G}$ & $\mathrm{N} / \mathrm{G}$ & & \\
\hline Paras Energy & & & & & & & & No & eading & & & & & \\
\hline
\end{tabular}

72 | Page ISS N: 2636-607X 
Appendix E2. February 2017 Generating Stations Data

\begin{tabular}{|c|c|c|c|c|c|c|c|c|c|c|c|c|c|c|}
\hline \multirow{2}{*}{$\begin{array}{c}\text { Generating Station } \\
\text { Kainji }\end{array}$} & \multicolumn{3}{|c|}{$1^{\text {st }}$ Week (MW) } & \multicolumn{3}{|c|}{$2^{\text {nd }}$ Week (MW) } & \multicolumn{3}{|c|}{$3^{\text {rd }}$ Week (MW) } & \multicolumn{3}{|c|}{$4^{\text {th }}$ Week (MW) } & \multirow{2}{*}{$\begin{array}{c}\text { Total (MW) } \\
4294 \\
\end{array}$} & \multirow{2}{*}{$\begin{array}{c}\text { Arg (MW) } \\
357.83\end{array}$} \\
\hline & 316 & 315 & 315 & 315 & 317 & 249 & 412 & 422 & 417 & 407 & 405 & 404 & & \\
\hline Jebba & 276 & 370 & 286 & 370 & 360 & 375 & 371 & 368 & 288 & 325 & 369 & 282 & 4040 & 336.67 \\
\hline Shiroro & 300 & 300 & 100 & 300 & 300 & 300 & 300 & 300 & 210 & 200 & 300 & 300 & 3210 & 291.82 \\
\hline Egbin & 310 & 328 & 320 & 320 & 341 & 325 & 355 & 327 & 324 & 545 & 362 & 350 & 4207 & 350.58 \\
\hline Sapele & $\mathrm{N} / \mathrm{G}$ & $\mathrm{N} / \mathrm{G}$ & 38 & 45 & 46 & 40 & 47 & $\mathrm{~N} / \mathrm{G}$ & 68 & 67 & 67 & 67 & 485 & 53.889 \\
\hline Delta & 450 & 450 & 330 & 460 & 460 & 540 & 540 & 480 & 490 & 450 & 500 & 390 & 5540 & 461.67 \\
\hline Afam IV-V & $\mathrm{N} / \mathrm{G}$ & $\mathrm{N} / \mathrm{G}$ & N/G & $\mathrm{N} / \mathrm{G}$ & N/G & N/G & $\mathrm{N} / \mathrm{G}$ & $\mathrm{N} / \mathrm{G}$ & N/G & $\mathrm{N} / \mathrm{G}$ & N/G & $\mathrm{N} / \mathrm{G}$ & & \\
\hline Geregu & 161 & 252 & 200 & 175 & 240 & N/G & 254 & 224 & 249 & 168 & 225 & N/G & 2148 & 214.8 \\
\hline Omotosho & 142.3 & 202 & 242 & 193 & 222 & 207 & 171.4 & 172 & 173 & 167 & 168 & 140 & 2198.9 & 183.24 \\
\hline Olorunsogo Gas & 227.6 & 212 & 209 & 141 & 145 & $\mathrm{~N} / \mathrm{G}$ & 117.6 & 98.1 & 115 & 94.5 & 97.7 & 98 & 1554.9 & 141.35 \\
\hline Geregu NIPP & 67 & 68 & 85 & 111 & 144 & 197 & 140 & 81 & 93 & 65 & 136 & $\mathrm{~N} / \mathrm{G}$ & 1186.9 & 107.9 \\
\hline Sapele NIPP & 106.6 & 111 & 110 & 110 & 110 & 106 & 108.2 & 104 & 111 & 106 & 108 & 108 & 1299.9 & 108.33 \\
\hline Alaoji NIPP & 111.2 & 115 & 114 & 115 & 115 & $\mathrm{~N} / \mathrm{G}$ & $\mathrm{N} / \mathrm{G}$ & $\mathrm{N} / \mathrm{G}$ & $\mathrm{N} / \mathrm{G}$ & $\mathrm{N} / \mathrm{G}$ & N/G & $\mathrm{N} / \mathrm{G}$ & 570.7 & 114.14 \\
\hline Olorunsogo NIPP & $\mathrm{N} / \mathrm{G}$ & $\mathrm{N} / \mathrm{G}$ & $\mathrm{N} / \mathrm{G}$ & $\mathrm{N} / \mathrm{G}$ & $\mathrm{N} / \mathrm{G}$ & $\mathrm{N} / \mathrm{G}$ & $\mathrm{N} / \mathrm{G}$ & $\mathrm{N} / \mathrm{G}$ & $\mathrm{N} / \mathrm{G}$ & $\mathrm{N} / \mathrm{G}$ & $\mathrm{N} / \mathrm{G}$ & $\mathrm{N} / \mathrm{G}$ & & \\
\hline Omotosho II NIPP & 174.4 & 188 & 107 & 159 & $\mathrm{~N} / \mathrm{G}$ & 197 & 202.9 & 136 & 193 & 154 & 203 & 186 & 1901.5 & 172.86 \\
\hline Ihovbor & $\mathrm{N} / \mathrm{G}$ & 221 & 224 & 218 & 110 & 220 & 215.6 & 209 & 222 & 199 & 213 & 214 & 2264.2 & 205.84 \\
\hline Okpai & 427 & 453 & 403 & 394 & 397 & 259 & 428 & 218 & 433 & 208 & 210 & 368 & 4198 & 349.83 \\
\hline Afam VI & 403 & 561 & 524 & 563 & 6033 & 413 & 537 & 186 & 621 & 274 & 613 & 568 & 11296 & 941.33 \\
\hline Ibom & 83.7 & 102 & 106 & 91.6 & 91.5 & 101 & 102.9 & 83.2 & 92 & 83.3 & 82.1 & 82 & 1102.2 & 91.85 \\
\hline Omoku & 47.6 & 48 & 50 & 49.1 & 49.4 & 51.3 & 49.1 & 50.6 & 48 & 49.8 & 48.7 & 49 & 590.9 & 49.242 \\
\hline A.E.S. & $\mathrm{N} / \mathrm{G}$ & $\mathrm{N} / \mathrm{G}$ & N/G & $\mathrm{N} / \mathrm{G}$ & $\mathrm{N} / \mathrm{G}$ & $\mathrm{N} / \mathrm{G}$ & $\mathrm{N} / \mathrm{G}$ & $\mathrm{N} / \mathrm{G}$ & $\mathrm{N} / \mathrm{G}$ & $\mathrm{N} / \mathrm{G}$ & N/G & $\mathrm{N} / \mathrm{G}$ & & \\
\hline Trans Amadi & $\mathrm{N} / \mathrm{G}$ & $\mathrm{N} / \mathrm{G}$ & $\mathrm{N} / \mathrm{G}$ & $\mathrm{N} / \mathrm{G}$ & $\mathrm{N} / \mathrm{G}$ & $\mathrm{N} / \mathrm{G}$ & $\mathrm{N} / \mathrm{G}$ & $\mathrm{N} / \mathrm{G}$ & $\mathrm{N} / \mathrm{G}$ & $\mathrm{N} / \mathrm{G}$ & $\mathrm{N} / \mathrm{G}$ & $\mathrm{N} / \mathrm{G}$ & & \\
\hline Rivers IPP & $\mathrm{N} / \mathrm{G}$ & $\mathrm{N} / \mathrm{G}$ & $\mathrm{N} / \mathrm{G}$ & $\mathrm{N} / \mathrm{G}$ & $\mathrm{N} / \mathrm{G}$ & N/G & $\mathrm{N} / \mathrm{G}$ & $\mathrm{N} / \mathrm{G}$ & $\mathrm{N} / \mathrm{G}$ & $\mathrm{N} / \mathrm{G}$ & N/G & $\mathrm{N} / \mathrm{G}$ & & \\
\hline ASCO & $\mathrm{N} / \mathrm{G}$ & $\mathrm{N} / \mathrm{G}$ & N/G & $\mathrm{N} / \mathrm{G}$ & $\mathrm{N} / \mathrm{G}$ & N/G & $\mathrm{N} / \mathrm{G}$ & $\mathrm{N} / \mathrm{G}$ & $\mathrm{N} / \mathrm{G}$ & $\mathrm{N} / \mathrm{G}$ & N/G & $\mathrm{N} / \mathrm{G}$ & & \\
\hline Odukpani NIPP & 112.4 & 118 & 118 & 334 & 357 & 229 & 229.5 & 221 & 237 & 225 & 229 & 222 & 2630.9 & 219.24 \\
\hline Gbarain & 107.3 & 112 & 113 & 113 & 112 & 107 & 109.4 & $\mathrm{~N} / \mathrm{G}$ & 112 & 107 & 108 & 105 & 1205.8 & 109.62 \\
\hline Paras Energy & 65.1 & 65.1 & 65 & 65.1 & 65.1 & 65.5 & 65.1 & 63 & 66 & 35.2 & 65.8 & 65 & 750.7 & 62.558 \\
\hline
\end{tabular}


Appendix E3. March 2017 Generating Stations Data

\begin{tabular}{|c|c|c|c|c|c|c|c|c|c|c|c|c|c|c|}
\hline \multirow{2}{*}{$\begin{array}{c}\text { Generating Station } \\
\text { Kainji } \\
\end{array}$} & \multicolumn{3}{|c|}{$1^{\text {st }}$ Week (MW) } & \multicolumn{3}{|c|}{$2^{\text {nd }}$ Week (MW) } & \multicolumn{3}{|c|}{$3^{\text {rd }}$ Week (MW) } & \multicolumn{3}{|c|}{$4^{\text {th }}$ Week (MW) } & \multirow{2}{*}{$\frac{\text { Total (MW) }}{3832}$} & \multirow{2}{*}{$\frac{\operatorname{Arg}(\mathbf{M W})}{319.33}$} \\
\hline & 395 & 393 & 126 & 399 & 148 & 398 & 264 & 398 & 147 & 393 & 380 & 391 & & \\
\hline Jebba & 363 & 356 & 355 & 341 & 340 & 339 & 340 & 367 & 358 & 357 & 328 & 338 & 4182 & 348.5 \\
\hline Shiroro & 279 & 276 & 201 & 280 & 196 & 270 & 198 & 271 & 270 & 271 & 198 & 267 & 2977 & 248.08 \\
\hline Egbin & 60 & 431 & 402 & 564 & 537 & 559 & 434 & 535 & 444 & 380 & 370 & 388 & 5104 & 425.33 \\
\hline Sapele & $\mathrm{N} / \mathrm{G}$ & $\mathrm{N} / \mathrm{G}$ & $\mathrm{N} / \mathrm{G}$ & $\mathrm{N} / \mathrm{G}$ & $\mathrm{N} / \mathrm{G}$ & $\mathrm{N} / \mathrm{G}$ & $\mathrm{N} / \mathrm{G}$ & $\mathrm{N} / \mathrm{G}$ & $\mathrm{N} / \mathrm{G}$ & $\mathrm{N} / \mathrm{G}$ & $\mathrm{N} / \mathrm{G}$ & $\mathrm{N} / \mathrm{G}$ & & \\
\hline Delta & 325 & 325 & 240 & 260 & 260 & 345 & 250 & 345 & 300 & 320 & 320 & 320 & 3610 & 300.83 \\
\hline Afam IV-V & $\mathrm{N} / \mathrm{G}$ & $\mathrm{N} / \mathrm{G}$ & $\mathrm{N} / \mathrm{G}$ & $\mathrm{N} / \mathrm{G}$ & $\mathrm{N} / \mathrm{G}$ & $\mathrm{N} / \mathrm{G}$ & $\mathrm{N} / \mathrm{G}$ & $\mathrm{N} / \mathrm{G}$ & $\mathrm{N} / \mathrm{G}$ & $\mathrm{N} / \mathrm{G}$ & $\mathrm{N} / \mathrm{G}$ & $\mathrm{N} / \mathrm{G}$ & & \\
\hline Geregu & 180 & 257 & $\mathrm{~N} / \mathrm{G}$ & 292 & $\mathrm{~N} / \mathrm{G}$ & 138 & $\mathrm{~N} / \mathrm{G}$ & 250 & 40 & 300 & $\mathrm{~N} / \mathrm{G}$ & 260 & 1717 & 214.63 \\
\hline Omotosho & 86.2 & 221 & 224 & 215 & 153 & 213 & 211 & 222 & 220 & 216 & 168 & 182 & 2330.6 & 194.22 \\
\hline Olorunsogo Gas & $\mathrm{N} / \mathrm{G}$ & 60.4 & 140 & 136 & 137 & 145 & 173 & 186 & 177 & 173 & 163 & 168 & 1657.1 & 150.65 \\
\hline Geregu NIPP & $\mathrm{N} / \mathrm{G}$ & 83 & $\mathrm{~N} / \mathrm{G}$ & 142 & $\mathrm{~N} / \mathrm{G}$ & 135 & $\mathrm{~N} / \mathrm{G}$ & 117 & $\mathrm{~N} / \mathrm{G}$ & 119 & 2 & 115 & 713 & 101.86 \\
\hline Sapele NIPP & 212 & 222 & 188 & 223 & 180 & 197 & 105 & 212 & 222 & 220 & 204 & 222 & 2405.5 & 200.46 \\
\hline Alaoji NIPP & 109 & 113 & 115 & 114 & 83.8 & 106 & 112 & 117 & 116 & 115 & 105 & 113 & 1319.6 & 109.97 \\
\hline Olorunsogo NIPP & $\mathrm{N} / \mathrm{G}$ & 105 & 110 & 111 & 84.3 & 100 & $\mathrm{~N} / \mathrm{G}$ & $\mathrm{N} / \mathrm{G}$ & $\mathrm{N} / \mathrm{G}$ & $\mathrm{N} / \mathrm{G}$ & $\mathrm{N} / \mathrm{G}$ & $\mathrm{N} / \mathrm{G}$ & 510.2 & 102.04 \\
\hline Omotosho II NIPP & 77.5 & 153 & 175 & 183 & 105 & 307 & 327 & 288 & 226 & 202 & 103 & 80 & 2226.1 & 185.51 \\
\hline Ihovbor & 103 & 111 & 112 & 109 & 84.7 & 109 & 106 & 114 & 112 & 110 & 103 & 111 & 1284.7 & 107.06 \\
\hline Okpai & 414 & 421 & 375 & 317 & 317 & 366 & 278 & 328 & 279 & 361 & 342 & 343 & 4141 & 345.08 \\
\hline Afam VI & 108 & 108 & 108 & 108 & 108 & 108 & 108 & 108 & 108 & 140 & 137 & 210 & 1459 & 121.58 \\
\hline Ibom & 108 & 102 & 83 & 110 & 72.5 & 102 & 107 & 82.2 & 68 & 108 & 82.6 & 107 & 1131.1 & 94.258 \\
\hline Omoku & 58.9 & 58.6 & 60 & 52.2 & 19.2 & 40 & 50.6 & 43 & 60 & 69.9 & 69.2 & 72 & 653.7 & 54.475 \\
\hline A.E.S. & $\mathrm{N} / \mathrm{G}$ & $\mathrm{N} / \mathrm{G}$ & $\mathrm{N} / \mathrm{G}$ & $\mathrm{N} / \mathrm{G}$ & $\mathrm{N} / \mathrm{G}$ & $\mathrm{N} / \mathrm{G}$ & $\mathrm{N} / \mathrm{G}$ & $\mathrm{N} / \mathrm{G}$ & $\mathrm{N} / \mathrm{G}$ & $\mathrm{N} / \mathrm{G}$ & $\mathrm{N} / \mathrm{G}$ & $\mathrm{N} / \mathrm{G}$ & & \\
\hline Trans Amadi & $\mathrm{N} / \mathrm{G}$ & $\mathrm{N} / \mathrm{G}$ & $\mathrm{N} / \mathrm{G}$ & $\mathrm{N} / \mathrm{G}$ & $\mathrm{N} / \mathrm{G}$ & $\mathrm{N} / \mathrm{G}$ & $\mathrm{N} / \mathrm{G}$ & $\mathrm{N} / \mathrm{G}$ & $\mathrm{N} / \mathrm{G}$ & $\mathrm{N} / \mathrm{G}$ & $\mathrm{N} / \mathrm{G}$ & $\mathrm{N} / \mathrm{G}$ & & \\
\hline Rivers IPP & $\mathrm{N} / \mathrm{G}$ & $\mathrm{N} / \mathrm{G}$ & $\mathrm{N} / \mathrm{G}$ & $\mathrm{N} / \mathrm{G}$ & $\mathrm{N} / \mathrm{G}$ & $\mathrm{N} / \mathrm{G}$ & $\mathrm{N} / \mathrm{G}$ & $\mathrm{N} / \mathrm{G}$ & $\mathrm{N} / \mathrm{G}$ & $\mathrm{N} / \mathrm{G}$ & $\mathrm{N} / \mathrm{G}$ & $\mathrm{N} / \mathrm{G}$ & & \\
\hline ASCO & $\mathrm{N} / \mathrm{G}$ & $\mathrm{N} / \mathrm{G}$ & $\mathrm{N} / \mathrm{G}$ & $\mathrm{N} / \mathrm{G}$ & $\mathrm{N} / \mathrm{G}$ & $\mathrm{N} / \mathrm{G}$ & $\mathrm{N} / \mathrm{G}$ & $\mathrm{N} / \mathrm{G}$ & $\mathrm{N} / \mathrm{G}$ & $\mathrm{N} / \mathrm{G}$ & $\mathrm{N} / \mathrm{G}$ & $\mathrm{N} / \mathrm{G}$ & & \\
\hline Odukpani NIPP & 204 & 224 & 225 & 227 & 201 & 216 & 226 & 80.5 & 190 & 216 & 211 & 232 & 2453 & 204.42 \\
\hline Gbarain & 106 & 112 & 105 & 112 & 91.7 & 111 & 96.7 & 115 & $\mathrm{~N} / \mathrm{G}$ & $\mathrm{N} / \mathrm{G}$ & $\mathrm{N} / \mathrm{G}$ & 112 & 961.5 & 106.83 \\
\hline Paras Energy & 60 & 60 & 68 & 67.5 & 56 & 56 & 62 & 63.2 & 64 & 66.3 & 68.5 & 64 & 755 & 62.917 \\
\hline
\end{tabular}


Appendix E4. April 2017 Generating Stations Data

\begin{tabular}{|c|c|c|c|c|c|c|c|c|c|c|c|c|c|c|}
\hline \multirow{2}{*}{$\frac{\text { Generating Station }}{\text { Kainji }}$} & \multicolumn{3}{|c|}{$1^{\text {st }}$ Week (MW) } & \multicolumn{3}{|c|}{$2^{\text {nd }}$ Week (MW) } & \multicolumn{3}{|c|}{$3^{\text {rd }}$ Week (MW) } & \multicolumn{3}{|c|}{$4^{\text {th }}$ Week (MW) } & \multirow{2}{*}{$\frac{\text { Total (MW) }}{4321}$} & \multirow{2}{*}{$\frac{\operatorname{Arg}(\mathbf{M W})}{360.08}$} \\
\hline & 285 & 392 & 389 & 392 & 390 & 389 & 284 & 389 & 349 & 390 & 283 & 389 & & \\
\hline Jebba & 349 & 347 & 349 & 361 & 264 & 351 & 347 & 357 & 356 & 340 & 262 & 340 & 4023 & 335.25 \\
\hline Shiroro & 194 & 266 & 270 & 269 & 270 & 269 & 269 & 270 & $\mathrm{~N} / \mathrm{G}$ & 267 & 268 & 265 & 2877 & 261.55 \\
\hline Egbin & 349 & 343 & 338 & 330 & 341 & 341 & 329 & 343 & 322 & 353 & 354 & 350 & 4093 & 341.08 \\
\hline Sapele & $\mathrm{N} / \mathrm{G}$ & 45 & 46 & 50 & 51 & 55 & 54 & 55 & 53 & 54 & 52 & 50 & 565 & 51.364 \\
\hline Delta & 250 & 250 & 250 & 250 & 250 & 250 & 189 & 250 & 250 & 250 & 260 & 260 & 2959 & 246.58 \\
\hline Afam IV-V & $\mathrm{N} / \mathrm{G}$ & $\mathrm{N} / \mathrm{G}$ & $\mathrm{N} / \mathrm{G}$ & $\mathrm{N} / \mathrm{G}$ & $\mathrm{N} / \mathrm{G}$ & $\mathrm{N} / \mathrm{G}$ & $\mathrm{N} / \mathrm{G}$ & $\mathrm{N} / \mathrm{G}$ & $\mathrm{N} / \mathrm{G}$ & $\mathrm{N} / \mathrm{G}$ & $\mathrm{N} / \mathrm{G}$ & $\mathrm{N} / \mathrm{G}$ & & \\
\hline Geregu & 160 & 297 & 120 & 241 & 180 & 229 & 200 & 200 & 130 & 190 & 130 & 240 & 2317 & 193.08 \\
\hline Omotosho & 139.7 & 148 & 81 & 145 & 140 & 146 & 139 & 148 & 144 & 141 & 140 & 143 & 1654.7 & 137.89 \\
\hline Olorunsogo Gas & 139.6 & 145 & 141 & 144 & 159 & 171 & 162 & 181 & 141 & 135 & 136 & 133 & 1786.7 & 148.89 \\
\hline Geregu NIPP & 78 & 91 & 76 & 114 & 65 & 109 & 20 & 90 & 79 & 129 & 70 & 130 & 1051 & 87.583 \\
\hline Sapele NIPP & 110.4 & 215 & 217 & 217 & 139 & 140 & 119 & 147 & 171 & 198 & 173 & 175 & 2021.3 & 168.44 \\
\hline Alaoji NIPP & 111.2 & 115 & 113 & 114 & 117 & 113 & 48.3 & 113 & $\mathrm{~N} / \mathrm{G}$ & $\mathrm{N} / \mathrm{G}$ & $\mathrm{N} / \mathrm{G}$ & $\mathrm{N} / \mathrm{G}$ & 843.8 & 105.48 \\
\hline Olorunsogo NIPP & $\mathrm{N} / \mathrm{G}$ & $\mathrm{N} / \mathrm{G}$ & $\mathrm{N} / \mathrm{G}$ & $\mathrm{N} / \mathrm{G}$ & $\mathrm{N} / \mathrm{G}$ & $\mathrm{N} / \mathrm{G}$ & $\mathrm{N} / \mathrm{G}$ & $\mathrm{N} / \mathrm{G}$ & $\mathrm{N} / \mathrm{G}$ & $\mathrm{N} / \mathrm{G}$ & $\mathrm{N} / \mathrm{G}$ & $\mathrm{N} / \mathrm{G}$ & & \\
\hline Omotosho II NIPP & 112.5 & 118 & 114 & 115 & 105 & 109 & 103 & 106 & 110 & 110 & 95 & 110 & 1307.3 & 108.94 \\
\hline Ihovbor & 108.5 & 111 & 110 & 110 & 108 & 111 & 101 & 110 & 111 & 105 & 107 & 109 & 1299.9 & 108.33 \\
\hline Okpai & 419 & 428 & 312 & 360 & 362 & 360 & 344 & 363 & 363 & 354 & 222 & 359 & 4246 & 353.83 \\
\hline Afam VI & 142 & 143 & 143 & 144 & 144 & 144 & 139 & 143 & 143 & 140 & 143 & 142 & 1710 & 142.5 \\
\hline Ibom & 92.7 & 108 & 108 & 109 & 108 & 108 & 76.5 & 91.4 & 46 & 101 & 102 & 103 & 1154 & 96.167 \\
\hline Omoku & 59.1 & 61.6 & 62 & 60.2 & 58.1 & 60.5 & 1.1 & 60.1 & 60 & 87 & 83.3 & 85 & 738.5 & 61.542 \\
\hline A.E.S. & $\mathrm{N} / \mathrm{G}$ & $\mathrm{N} / \mathrm{G}$ & $\mathrm{N} / \mathrm{G}$ & $\mathrm{N} / \mathrm{G}$ & $\mathrm{N} / \mathrm{G}$ & $\mathrm{N} / \mathrm{G}$ & $\mathrm{N} / \mathrm{G}$ & $\mathrm{N} / \mathrm{G}$ & $\mathrm{N} / \mathrm{G}$ & $\mathrm{N} / \mathrm{G}$ & $\mathrm{N} / \mathrm{G}$ & $\mathrm{N} / \mathrm{G}$ & & \\
\hline Trans Amadi & $\mathrm{N} / \mathrm{G}$ & $\mathrm{N} / \mathrm{G}$ & $\mathrm{N} / \mathrm{G}$ & $\mathrm{N} / \mathrm{G}$ & $\mathrm{N} / \mathrm{G}$ & $\mathrm{N} / \mathrm{G}$ & $\mathrm{N} / \mathrm{G}$ & $\mathrm{N} / \mathrm{G}$ & $\mathrm{N} / \mathrm{G}$ & $\mathrm{N} / \mathrm{G}$ & $\mathrm{N} / \mathrm{G}$ & $\mathrm{N} / \mathrm{G}$ & & \\
\hline Rivers IPP & $\mathrm{N} / \mathrm{G}$ & $\mathrm{N} / \mathrm{G}$ & $\mathrm{N} / \mathrm{G}$ & $\mathrm{N} / \mathrm{G}$ & $\mathrm{N} / \mathrm{G}$ & $\mathrm{N} / \mathrm{G}$ & $\mathrm{N} / \mathrm{G}$ & $\mathrm{N} / \mathrm{G}$ & $\mathrm{N} / \mathrm{G}$ & $\mathrm{N} / \mathrm{G}$ & $\mathrm{N} / \mathrm{G}$ & $\mathrm{N} / \mathrm{G}$ & & \\
\hline ASCO & $\mathrm{N} / \mathrm{G}$ & $\mathrm{N} / \mathrm{G}$ & $\mathrm{N} / \mathrm{G}$ & $\mathrm{N} / \mathrm{G}$ & $\mathrm{N} / \mathrm{G}$ & $\mathrm{N} / \mathrm{G}$ & $\mathrm{N} / \mathrm{G}$ & $\mathrm{N} / \mathrm{G}$ & $\mathrm{N} / \mathrm{G}$ & $\mathrm{N} / \mathrm{G}$ & $\mathrm{N} / \mathrm{G}$ & $\mathrm{N} / \mathrm{G}$ & & \\
\hline Odukpani Nipp & 220 & 191 & 223 & 224 & 111 & 335 & 314 & 344 & 196 & 220 & 235 & 335 & 2947.5 & 245.63 \\
\hline Gbarain & 107.7 & 114 & 111 & 111 & 110 & 111 & $\mathrm{~N} / \mathrm{G}$ & 110 & 112 & 111 & 112 & 110 & 1219.6 & 110.87 \\
\hline Paras Energy & 64 & 67.8 & 68 & 64.4 & 61.6 & 61.6 & 61.6 & 63 & 63 & 63 & 63 & 60 & 760.9 & 63.408 \\
\hline
\end{tabular}




\section{Appendix F. Script For Matlab Plot}

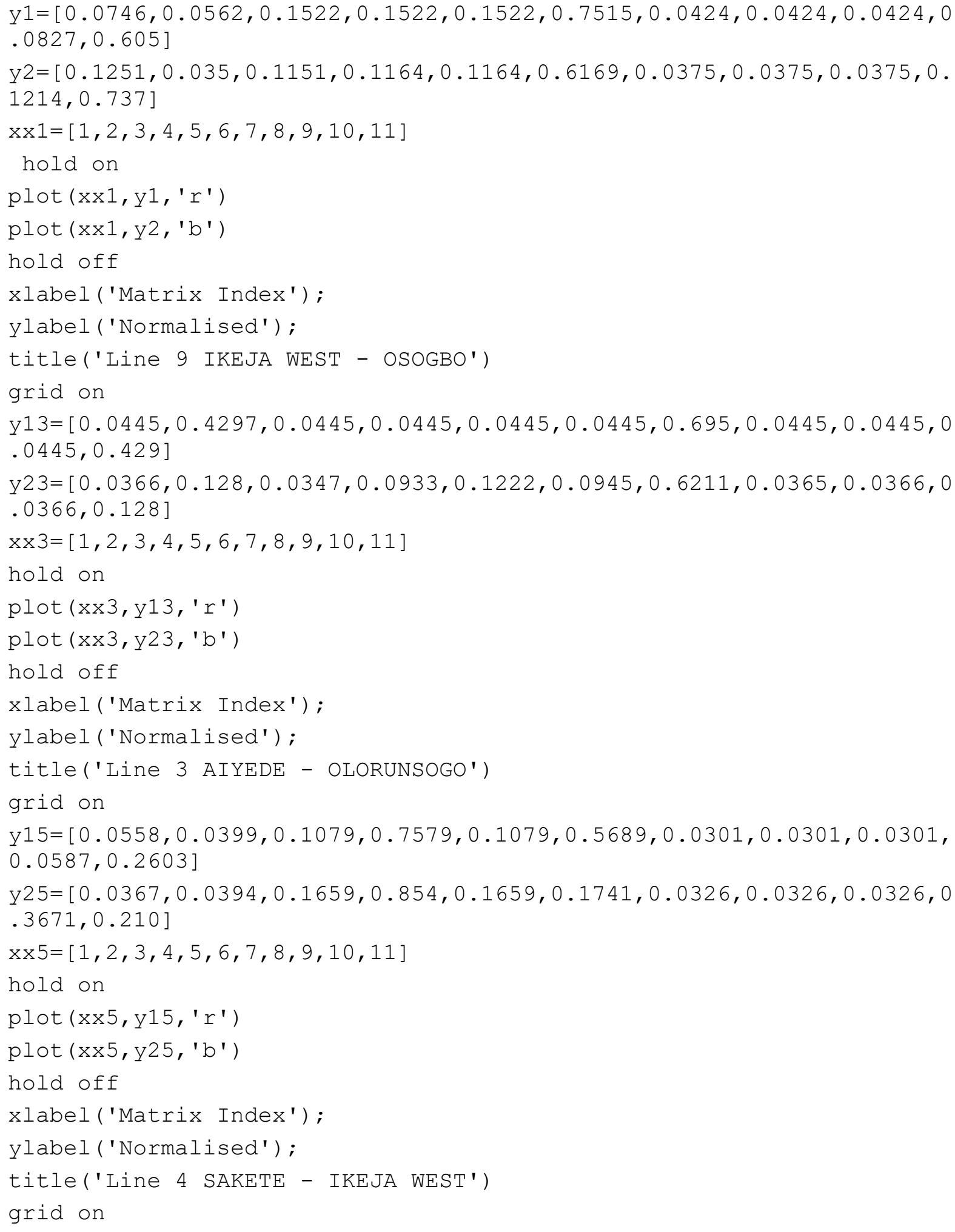


Appendix G. Load Flow Result when the System was Stable

\begin{tabular}{|c|c|c|c|c|c|c|}
\hline From Bus & To Bus & Line & $\begin{array}{l}\text { P Flow } \\
(\mathrm{MW})\end{array}$ & $\begin{array}{l}\text { Q Flow } \\
\text { (MVar) }\end{array}$ & $\begin{array}{l}\text { P Loss } \\
(\mathrm{MW})\end{array}$ & $\begin{array}{l}\text { Q Loss } \\
\text { (MVar) }\end{array}$ \\
\hline Ikeja W. TS & Egbin Bus & 1 & -21.38575512 & -61.6889582 & 0.232292547 & 1.68927168 \\
\hline Ajah TS & Egbin Bus & 2 & $-1.29337 \mathrm{E}-07$ & 0.100006155 & $4.95032 \mathrm{E}-07$ & -0.09999871 \\
\hline Ikeja W. TS & Akangba TS & 3 & $5.21416 \mathrm{E}-08$ & -0.09480167 & $5.21416 \mathrm{E}-08$ & -0.094801672 \\
\hline Ikeja W. TS & Sakete TS & 4 & 21.85388473 & 22.09116469 & 0.052804731 & 0.312330687 \\
\hline Omotosho NIPP / Sec & Ikeja W. TS & 5 & 71.44236746 & 23.32227776 & 0.300375509 & 2.214276731 \\
\hline Ikeja W. TS & Olorunsogo Sec & 6 & -25.75158564 & -39.0093316 & 0.119019769 & 0.818934359 \\
\hline Aiyede TS & Olorunsogo Sec & 7 & -31.3925109 & -18.4653041 & 0.694049192 & 0.497617124 \\
\hline Osogbo TS & Aiyede TS & 8 & -15.85716567 & -3.03059035 & 0.011455233 & 0.004153713 \\
\hline Ikeja W. TS & Osogbo TS & 9 & 5.776257462 & 18.78979753 & 0.02006519 & 0.076356444 \\
\hline Ajah TS & Lekki TS & 10 & $1.29337 \mathrm{E}-07$ & -0.10000616 & $1.29337 \mathrm{E}-07$ & -0.100006155 \\
\hline Ajah TS & Alagbon TS & 11 & $1.29337 \mathrm{E}-07$ & -0.10000616 & $1.29337 \mathrm{E}-07$ & -0.100006155 \\
\hline Ajah TS & Egbin Bus & 12 & $-1.29337 \mathrm{E}-07$ & 0.100006155 & $4.95032 \mathrm{E}-07$ & -0.09999871 \\
\hline Osogbo TS & Ganmo TS & 13 & 4.651657937 & 4.696231432 & 0.002449937 & -0.074128568 \\
\hline Okearo TS & Egbin Bus & 14 & -2.805499495 & -7.8884222 & 0.003609361 & -0.071911724 \\
\hline Okearo TS & Egbin Bus & 15 & -2.805499495 & -7.8884222 & 0.003609361 & -0.071911724 \\
\hline Ikeja W. TS & Okearo TS & 16 & -2.777387294 & -7.78868905 & 0.028112201 & 0.099733143 \\
\hline Ikeja W. TS & Okearo TS & 17 & -2.777387294 & -7.78868905 & 0.028112201 & 0.099733143 \\
\hline Ikeja W. TS & Akangba TS & 18 & $5.21416 \mathrm{E}-08$ & -0.09480167 & $5.21416 \mathrm{E}-08$ & -0.094801672 \\
\hline $\begin{array}{c}\text { Omotosho NIPP } \\
\text { Phase Pri }\end{array}$ & Omotosho NIPP / Sec & 19 & 71.5805643 & 26.08621448 & 0.138196836 & 2.763936718 \\
\hline Egbin GS Pri & Egbin Bus & 20 & 0 & 0 & 0 & 0 \\
\hline Olorunsogo GS Pri & Olorunsogo Sec & 21 & 58.00723764 & 59.79262985 & 0.050072138 & 1.001442754 \\
\hline
\end{tabular}


Appendix G. Load Flow Result when the System was Stable (Continuation)

\begin{tabular}{|c|c|c|c|c|c|c|}
\hline From Bus & To Bus & Line & $\begin{array}{l}\text { P Flow } \\
(\mathrm{MW})\end{array}$ & $\begin{array}{l}\text { Q Flow } \\
\text { (MVar) }\end{array}$ & $\begin{array}{l}\text { P Loss } \\
(\mathrm{MW})\end{array}$ & $\begin{array}{l}\text { Q Loss } \\
\text { (MVar) }\end{array}$ \\
\hline \multicolumn{7}{|l|}{ Line Flows } \\
\hline Egbin Bus & Ikeja West TS & 1 & 21.61804766 & 63.37822986 & 0.232292547 & 1.68927168 \\
\hline Egbin Bus & Ajah TS & 2 & $6.24369 E-07$ & -0.20000486 & $4.95032 \mathrm{E}-07$ & -0.09999871 \\
\hline Akangba TS & Ikeja West TS & 3 & $3.78106 \mathrm{E}-15$ & $6.91822 \mathrm{E}-13$ & $5.21416 \mathrm{E}-08$ & -0.094801672 \\
\hline Sakete TS & Ikeja West TS & 4 & -21.80108 & -21.778834 & 0.052804731 & 0.312330687 \\
\hline Ikeja West TS & Omotosho NIPP / Sec & 5 & -71.14199195 & -21.108001 & 0.300375509 & 2.214276731 \\
\hline Olorunsogo Sec & Ikeja West TS & 6 & 25.87060541 & 39.82826592 & 0.119019769 & 0.818934359 \\
\hline Olorunsogo Sec & Aiyede TS & 7 & 32.08656009 & 18.96292118 & 0.694049192 & 0.497617124 \\
\hline Aiyede TS & Osogbo TS & 8 & 15.8686209 & 3.034744059 & 0.011455233 & 0.004153713 \\
\hline Osogbo TS & Ikeja West TS & 9 & -5.756192271 & -18.7134411 & 0.02006519 & 0.076356444 \\
\hline Lekki TS & Ajah TS & 10 & 0 & 0 & $1.29337 \mathrm{E}-07$ & -0.100006155 \\
\hline Alagbon TS & Ajah TS & 11 & 0 & 0 & $1.29337 \mathrm{E}-07$ & -0.100006155 \\
\hline Egbin Bus & Ajah TS & 12 & $6.24369 E-07$ & -0.20000486 & $4.95032 \mathrm{E}-07$ & -0.09999871 \\
\hline Ganmo TS & Osogbo TS & 13 & -4.649208 & -4.77036 & 0.002449937 & -0.074128568 \\
\hline Egbin Bus & Okearo TS & 14 & 2.809108856 & 7.816510473 & 0.003609361 & -0.071911724 \\
\hline Egbin Bus & Okearo TS & 15 & 2.809108856 & 7.816510473 & 0.003609361 & -0.071911724 \\
\hline Okearo TS & Ikeja West TS & 16 & 2.805499495 & 7.888422197 & 0.028112201 & 0.099733143 \\
\hline Okearo TS & Ikeja West TS & 17 & 2.805499495 & 7.888422197 & 0.028112201 & 0.099733143 \\
\hline Akangba TS & Ikeja West TS & 18 & $3.78106 \mathrm{E}-15$ & $6.91822 \mathrm{E}-13$ & $5.21416 \mathrm{E}-08$ & -0.094801672 \\
\hline Omotosho NIPP / Sec & Omotosho NIPP Phase Pri & 19 & -71.44236746 & -23.3222778 & 0.138196836 & 2.763936718 \\
\hline Egbin Bus & Egbin G.S Pri & 20 & 0 & 0 & 0 & 0 \\
\hline Olorunsogo Sec & Olorunsogo G.S Pri & 21 & -57.9571655 & -58.7911871 & 0.050072138 & 1.001442754 \\
\hline
\end{tabular}


Appendix G. Load Flow Result when the System was Stable (Continuation)

\begin{tabular}{|c|c|c|c|c|c|c|}
\hline From Bus & To Bus & Line & $\begin{array}{l}\text { P Flow } \\
(\mathrm{MW})\end{array}$ & $\begin{array}{l}\text { Q Flow } \\
\text { (MVar) }\end{array}$ & $\begin{array}{c}\text { P Loss } \\
(\mathrm{MW})\end{array}$ & $\begin{array}{l}\text { Q Loss } \\
\text { (MVar) }\end{array}$ \\
\hline \multicolumn{7}{|l|}{$\begin{array}{c}\text { Global Summary } \\
\text { Report }\end{array}$} \\
\hline \multicolumn{7}{|l|}{ Total Generation } \\
\hline Real Power (MW) & & & 156.8240686 & & & \\
\hline $\begin{array}{l}\text { Reactive Power } \\
\text { (Mvar) }\end{array}$ & & & 164.4900854 & & & \\
\hline \multicolumn{7}{|l|}{ Total Generation } \\
\hline Real Power (MW) & & & 155.139843 & & & \\
\hline $\begin{array}{l}\text { Reactive Power } \\
\text { (Mvar) }\end{array}$ & & & 155.719864 & & & \\
\hline \multicolumn{7}{|l|}{ Total Generation } \\
\hline Real Power (MW) & & & 1.68422556 & & & \\
\hline $\begin{array}{l}\text { Reactive Power } \\
\text { (Mvar) }\end{array}$ & & & 8.770221396 & & & \\
\hline
\end{tabular}


Appendix H. Voltage and Power Profiles for a Stable System

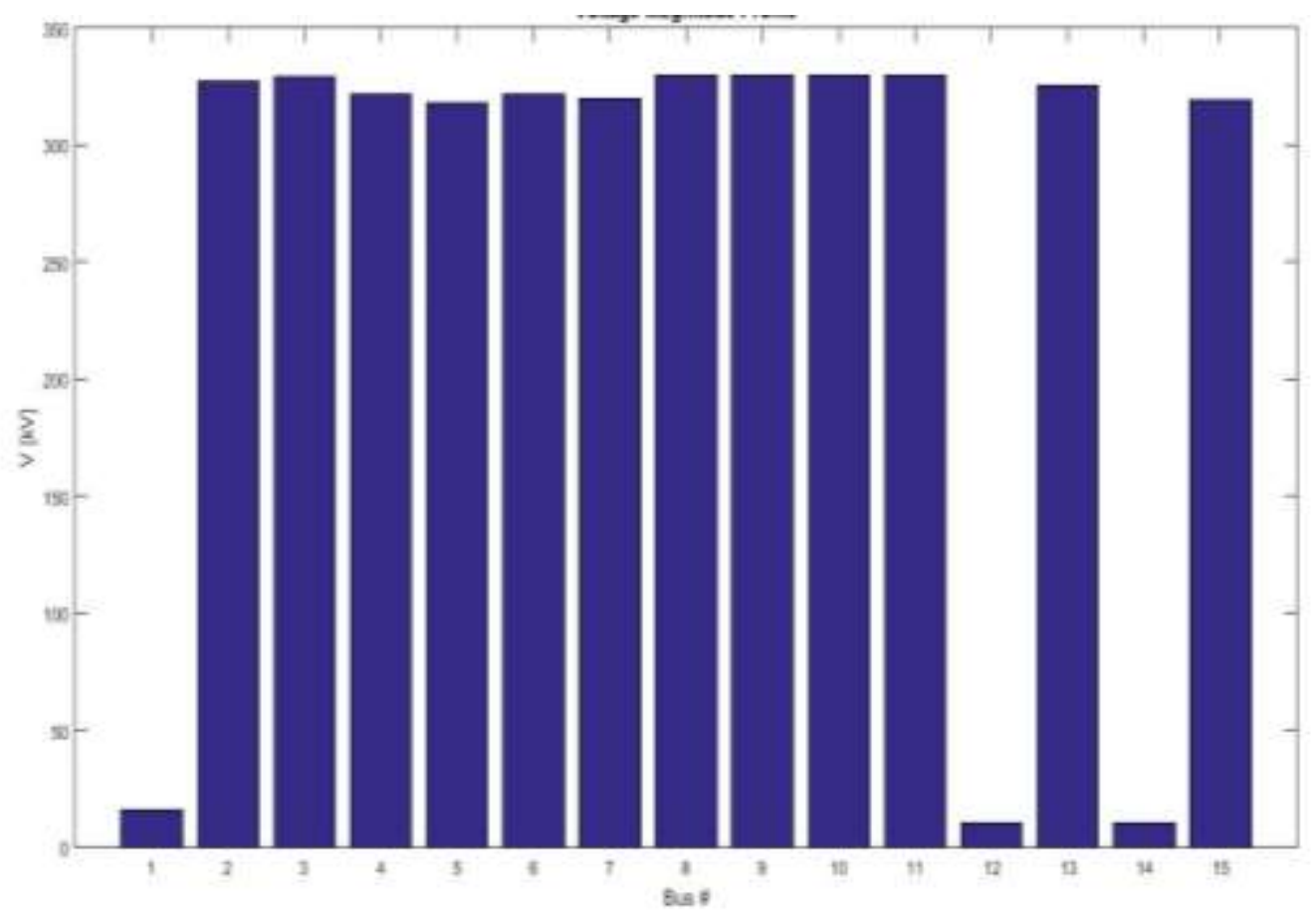

Figure H1. Voltage Magnitude Profile for a stable system

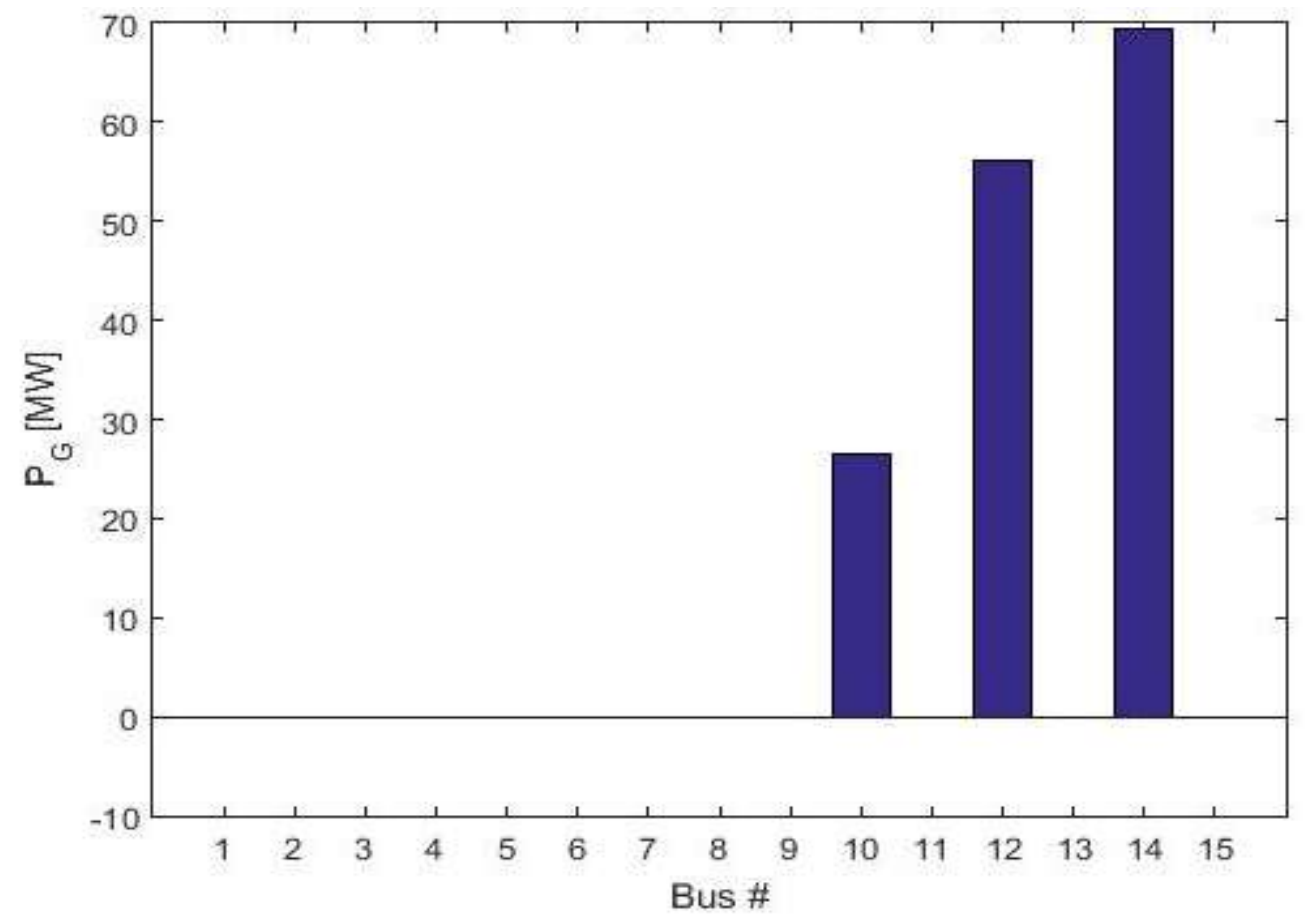

Figure H2. Real Power Profile for a Stable System 
Appendix I. Network Considered For Optimal Placement of PMU

Graph Representation of "LoadflowSWest(mdl)" Network

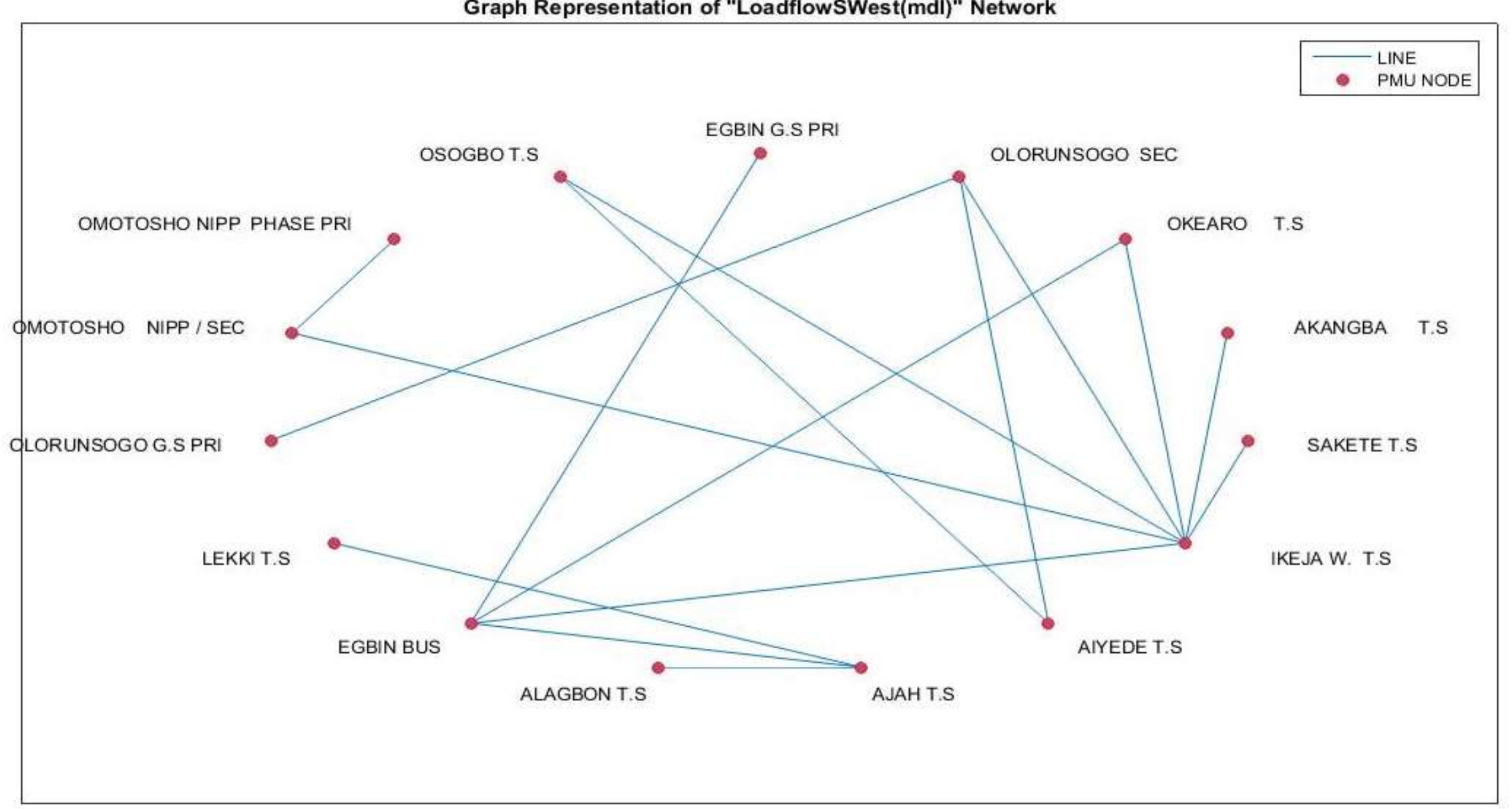

Figure I. Graphical Representation of the Network Considered for Optimal Placement of PMU 